Programa de Pós Graduação em Fisioterapia

“ESTUDO DAS RESPOSTAS BIOQUÍMICA E MUSCULAR DA ADMINISTRAÇÃO DE ESTATINA E SUA DESCONTINUIDADE ASSOCIADAS À ATIVIDADE FÍSICA EM RATOS”

Mariana Rotta Bonfim

Presidente Prudente

2010 
Mariana Rotta Bonfim

\title{
ESTUDO DAS RESPOSTAS BIOQUÍMICA E MUSCULAR DA ADMINISTRAÇÃO DE ESTATINA E SUA DESCONTINUIDADE ASSOCIADAS À ATIVIDADE FÍSICA EM RATOS
}

\author{
Dissertação apresentada à Faculdade de \\ Ciências e Tecnologia - FCT/Unesp, Campus de \\ Presidente Prudente, para obtenção do título de \\ mestre no programa de pós-graduação em \\ fisioterapia.
}

Orientador: Prof. Dr. José Carlos Silva Camargo Filho

Presidente Prudente 2010 


\section{Bonfim, Mariana Rotta.}

B683v Estudo das respostas bioquímica e muscular da administração de estatina e sua descontinuidade associadas à atividade física em ratos / Mariana Rotta Bonfim. - Presidente Prudente : [s.n], 2010 120 f. : il.

Dissertação (mestrado) - Universidade Estadual Paulista, Faculdade de Ciências e Tecnologia

Orientador: José Carlos Silva Camargo Filho

Banca: Luiz Carlos Marques Vanderlei, Willian Dias Belangero Inclui bibliografia

1. Inibidores de Hidroximetilglutaril CoA-redutases. 2. Atividade Motora. 3. Músculo Esquelético. I. Autor. II. Universidade Estadual Paulista. Faculdade de Ciências e Tecnologia. III. Título.

$\operatorname{CDD}(18 . e d)$.

Ficha catalográfica elaborada pela Seção Técnica de Aquisição e Tratamento da Informação - Serviço Técnico de Biblioteca e Documentação - UNESP, Câmpus de Presidente Prudente. claudia@fct.unesp.br 


\section{BANCA EXAMINADORA}
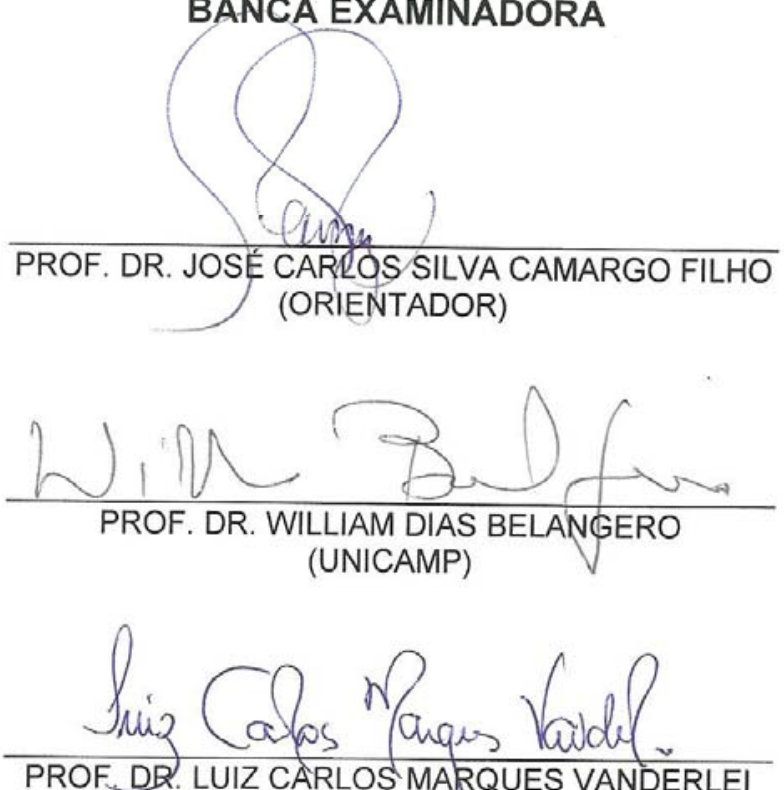
(FCT/UNESP)

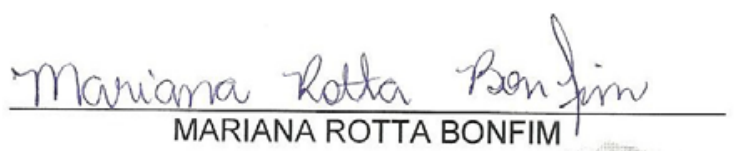

PRESIDENTE PRUDENTE (SP), 05 DE FEVEREIRO DE 2010.

RESULTADO

Faculdade de Ciências e Tecnologia Seção de Pós-Graduação

Rua Roberto Simonsen, 305 CEP 19060-900 Presidente Prudente SP

Tel 18 3229-5352 fax $183223-4519$ posgrad@fct.unesp.br 


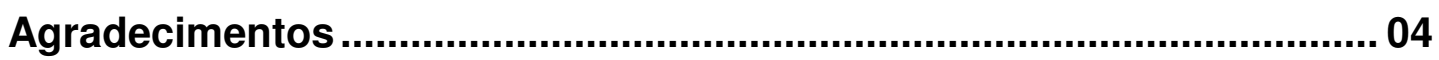

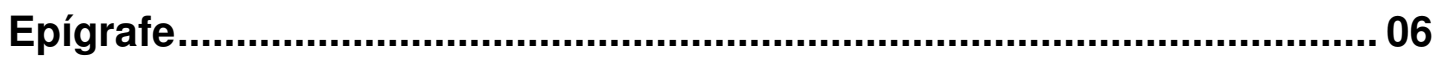

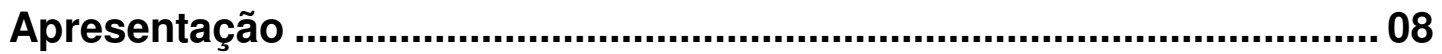

INTRODUÇÃO

ARTIGO I: Respostas bioquímicas da administração de atorvastatina e sua descontinuidade associadas à atividade física em ratos.................................. 16

ARTIGO II: Efeitos da administração de atorvastatina e sua descontinuidade associadas à atividade física na musculatura esquelética de ratos 38

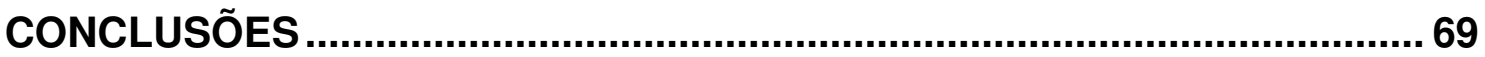

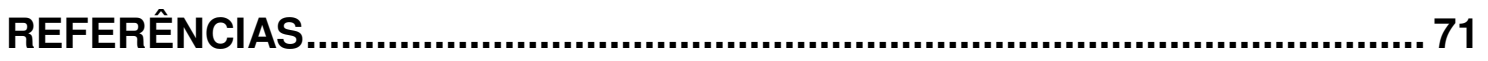

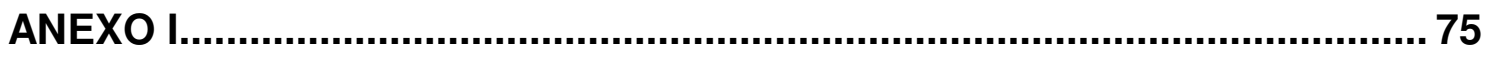

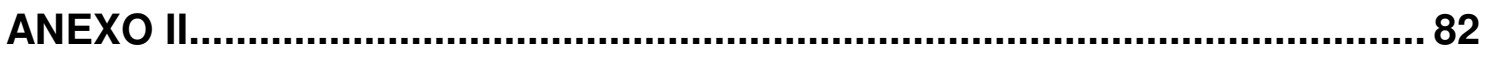

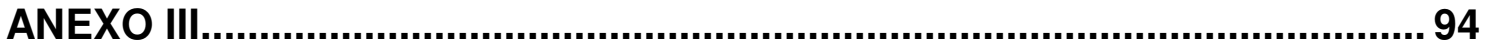


Agradecimentos 
Agradeço a todos que, direta ou indiretamente, fizeram parte desta etapa da minha vida acadêmica:

Aos meus pais, pela paciência nos momentos de crise, pelas palavras nos momentos de tristeza, pela vibração nos momentos de alegria, pelo apoio nos momentos de decisão, e pela amizade e amor em todos os momentos! Amo vocês.

Aos demais familiares, pela compreensão quando necessária, pela união, pela amizade e pela torcida por minhas conquistas.

Ao meu grande amor, que mesmo no alto do morro não deixou de estar presente, e que com certeza fez a diferença no meu caminho até aqui.

Ao meu orientador, por todo o tempo dedicado ao meu trabalho e por todos os ensinamentos acadêmicos e de vida, mas principalmente pela confiança em mim depositada.

A todos os integrantes do LAPMUS, em especial aos amigos Sidney, Bruna e Fábio. Sem vocês eu não conseguiria! Obrigada pela colaboração e, acima de tudo, pela amizade.

Aos amigos antigos e aos amigos adquiridos, pelos momentos de descontração, estudos e conversas sobre a vida.

"Estou adquirindo um título e posso não saber até onde chegarei com ele, mas independente de onde estiver, sei muito bem aquilo que não quero ser!"

Mariana Rotta Bonfim 
Epígrafe 
$\mathcal{N} a ̃ o$ desças os degraus do sonho Para não despertar os monstros. Não subas aos sótãos - onde Os deuses, por trás das suas máscaras, Ocultam o próprio enigma. Não desças, não subas, fica. O mistério está é na tua vida! Eé um sonho louco este nosso mundo...

(Mário Quintana) 


\section{Apresentação}


Esta dissertação é composta de uma introdução e de dois artigos científicos, originados de pesquisas realizadas no Laboratório de Histologia do departamento de Fisioterapia da FCT/UNESP - Presidente Prudente.

Em consonância com as regras do Programa de Pós-Graduação em Fisioterapia, os artigos foram redigidos de acordo com as normas dos periódicos Revista de Nutrição (Anexo I) e Brazilian Journal of Medical and Biological Research (Anexo II), sendo que para este último o manuscrito foi submetido na língua inglesa (Anexo III).

\section{- Artigo $\mathrm{l}$.}

Bonfim MR, Garcia BC, Kodama FY, Santos ACA, Padulla SAT, Pedroso DG, Porto VS, Haidamus LL, Camargo Filho JCS. Respostas bioquímicas da administração de atorvastatina e sua descontinuidade associadas à atividade física em ratos. Submetido à apreciação visando publicação no periódico "Revista de Nutrição". Página 16.

\section{- Artigo II.}

Bonfim MR, Garcia BC, Kodama FY, Padulla SAT, Camargo Filho JCS. Efeitos da administração de atorvastatina e sua descontinuidade associadas à atividade física na musculatura esquelética de ratos. Submetido à apreciação visando publicação no periódico "Brazilian Journal of Medical and Biological Research". Página 35. 


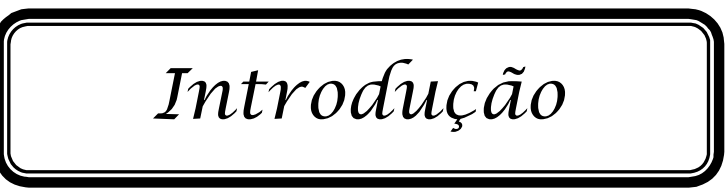


Atualmente, muita atenção tem se dado às alterações lipídicas, uma vez que se tem bem definida a relação entre seus altos níveis e a ocorrência de doenças cardíacas. As primeiras pesquisas sobre os fatores associados ao desenvolvimento da doença cardiovascular começaram a ser desenvolvidas por volta do ano de 1948, na cidade de Framinghan, pelas quais se reconheceu que a hipertensão arterial e a hipercolesterolemia exerciam influência no quadro das doenças coronarianas, observando-se associação positiva entre hipercolesterolemia e doença isquêmica coronariana, bem como risco progressivo para doenças coronarianas em função de níveis séricos de colesterol mais elevados ${ }^{(1)}$.

Assim, durante as décadas de 1950 a 1970 muitos agentes redutores de colesterol foram formulados e introduzidos no uso clínico, e foram muito utilizados por demonstrarem eficácia em reduzir os lipídios sanguíneos. Entretanto, o foco das atenções foi os agentes inibidores da enzima 3-Hidroxi3-Metilglutaril coenzima A (HMG-CoA) redutase, as estatinas, consideradas hoje os medicamentos de primeira escolha no tratamento dos distúrbios lipídicos ${ }^{(2,3)}$.

As estatinas foram descobertas no ano de 1971, e seu desenvolvimento se deu a partir da evidência de que a produção hepática de colesterol excedia sua quantidade absorvida pela dieta e, portanto, um inibidor de sua síntese endógena poderia ser um efetivo agente redutor de colesterol ${ }^{(4)}$. Desenvolveuse, assim, a estatina, um agente inibidor competitivo da enzima HMG-CoA redutase, que age controlando a formação de mevalonato que, por sua vez, é uma reação irreversível durante o processo de biossíntese de colesterol ${ }^{(2,4)}$. 
A estatina, portanto, age reduzindo a síntese hepática do colesterol, o que acarreta no aumento da síntese dos receptores de lipoproteína de baixa densidade (LDL-C) nos hepatócitos; há, portanto, aumento da captação de lipoproteínas de muito baixa e de intermediária densidade (VLDL e IDL, respectivamente) e de LDL da circulação para repor o colesterol intracelular, resultando na diminuição do colesterol total (CT), do LDL-colesterol e dos triglicerídeos (TG), bem como no aumento da lipoproteína de alta densidade (HDL-C) circulantes ${ }^{(5,6)}$. Na prática, estes medicamentos reduzem o LDL-C de $15 \%$ a $55 \%$, os TG de $7 \%$ a $28 \%$, e elevam o HDL-C de $2 \%$ a $10 \%{ }^{(3,7)}$, permitindo ainda a redução da mortalidade cardiovascular, da incidência de eventos isquêmicos coronários agudos, da necessidade de revascularização do miocárdio e da ocorrência de acidente vascular cerebral (AVC) ${ }^{(8)}$.

As estatinas são geralmente bem toleradas pela maioria dos pacientes, entretanto, seu uso está relacionado à ocorrência de efeitos tóxicos que acometem principalmente a musculatura esquelética ${ }^{(9)}$. As lesões musculares decorrentes do uso das estatinas podem ser de grau leve a grave, variando de mialgia a rabdomiólise, e atingindo cerca de 5 a $10 \%$ dos pacientes ${ }^{(10)}$. 0 método preconizado para seu diagnóstico e para o acompanhamento de sua evolução é a análise laboratorial dos níveis séricos da enzima creatina quinase, os quais guiarão a conduta a ser tomada para cada paciente $e^{(7,11)}$.

Porém, vale ressaltar que em muitos casos não há uma relação estabelecida entre as manifestações clínicas e os valores de CK encontrados nos pacientes, podendo haver manifestações sem seu aumento, ou seu aumento sem manifestações ${ }^{(12)}$. Além disso, os critérios utilizados para inclusão dos sujeitos nos estudos geralmente limitam a participação de 
pessoas com histórico de intolerância à estatina ou com alterações nos parâmetros bioquímicos, tornando difícil uma estimativa precisa da incidência das alterações musculares ${ }^{(10)}$, podendo inclusive subestimá-la ${ }^{(13)}$.

Apesar das evidências, as formas de indução de lesão muscular por estatina não são bem definidas, havendo teorias sobre as alterações na excitabilidade da membrana celular, devido à redução da quantidade de colesterol de membrana; alterações na respiração celular, devido à redução de intermediários da cadeia respiratória (Ubiquinona - Coenzima Q10); e ocorrência de apoptose, devido ao aumento de cálcio citosólico e, consequentemente, ativação de sua sinalização via mitocondrial ${ }^{(14,15)}$. Todavia, as pesquisas indicam que provavelmente o mecanismo de lesão estaria relacionado ao prejuízo mitocondrial que, por sua vez, poderia interferir na regulação do cálcio citosólico, acarretando na ocorrência de processos apoptóticos e degenerativos que explicariam as lesões musculares pelas estatinas $^{(14,16)}$.

Na prática, os usuários de estatina relatam que as câimbras e a rigidez muscular estão entre os desconfortos musculares mais frequentes, que acabam por limitar a execução das atividades diárias, sendo que após a descontinuidade do medicamento todos os sintomas desaparecem ${ }^{(17,18)}$. Além disso, estudos apontam que indivíduos em tratamento com medicamentos hipolipemiantes apresentam exacerbação das dores musculares quando submetidos à prática de atividade física, estando sua incidência diretamente relacionada à intensidade do esforço praticado ${ }^{(17)}$. Verificou-se ainda que a terapia por estatinas em atletas hipercolesterolêmicos acarreta, em alguns 
casos, na intolerância à prática da sua modalidade esportiva, havendo a necessidade da troca da medicação ou até mesmo a cessação de seu uso ${ }^{(19)}$.

Pode-se supor que a alteração no fluxo sanguíneo provocada pela prática de atividade física, direcionando-o para os locais em maior atividade e, portanto, com maiores necessidades, como a musculatura esquelética, poderia estar levando a uma modificação na farmacocinética do medicamento, supostamente elevando sua concentração na musculatura e, portanto, exacerbando as lesões por estatinas ${ }^{(20)}$. Todavia, verificou-se que a atividade física não acarreta em diferenças na concentração de estatina no plasma e na musculatura esquelética ${ }^{(20)}$, sugerindo que outros fatores estariam associados a esta exacerbação, como o uso prejudicado de substratos energéticos e a depleção energética ${ }^{(20)}$.

De maneira geral, apesar da interação de estatina e atividade física estar relacionada à exacerbação da lesão muscular, ela representa uma interessante estratégia terapêutica. Em situações nas quais o exercício físico foi adicionado à terapêutica por estatinas verificou-se que a alteração nos níveis lipídicos séricos foi mais significante que 0 uso somente da terapêutica medicamentosa ${ }^{(21,22)}$. Todavia, não se pode descartar a existência dos danos musculares, fazendo-se necessário o estudo de novas estratégias terapêuticas visando à manutenção das alterações lipídicas associada ao menor comprometimento da musculatura.

$\mathrm{Na}$ prática clínica, frente à ocorrência dos sintomas musculares associados ou não ao aumento dos níveis de creatina quinase (CK), as condutas indicadas são a interrupção da atividade física ou do uso da estatina $^{(10,11)}$. Apesar de se saber que tais atitudes acarretam na melhora dos 
sintomas musculares ${ }^{(11,17)}$, não existem estudos in situ da resposta muscular à descontinuidade de medicamento ou da atividade física, bem como não se sabe o comportamento das variáveis bioquímicas.

Sendo assim, visamos com esse trabalho analisar as respostas bioquímicas e musculares da administração de atorvastatina e sua descontinuidade associadas ao exercício físico em ratos. Temos como hipótese a possível sustentação das alterações lipídicas e a redução e reparação das lesões musculares provocadas pela terapêutica conjunta de estatina e atividade física, uma vez que se está mantendo um agente atuante nas alterações lipídicas e se retirando o componente nocivo à musculatura esquelética.

Para testar essas hipóteses elaboramos dois trabalhos que são apresentados em seguida. O primeiro deles, intitulado "Respostas bioquímicas da administração de atorvastatina e sua descontinuidade associadas ao exercício físico em ratos", teve por objetivos avaliar as alterações bioquímicas, tanto do perfil lipídico quanto dos biomarcadores de lesão hepática e muscular, decorrentes da descontinuidade da estatina com continuidade da atividade física; o segundo, intitulado "Efeitos da administração de atorvastatina e sua descontinuidade associadas ao exercício físico na musculatura esquelética de ratos", analisou os efeitos da intervenção acima citada na musculatura, a partir de análises histológicas e histoquímicas do tecido muscular esquelético. 


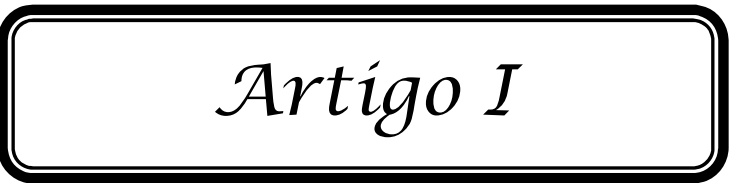




\section{RESPOSTAS BIOQUÍMICAS DA ADMINISTRAÇÃO DE ATORVASTATINA E SUA DESCONTINUIDADE ASSOCIADAS À ATIVIDADE FÍSICA EM RATOS}

BIOCHEMICAL RESPONSES TO ATORVASTATIN ADMINISTRATION AND ITS DISCONTINUITY ASSOCIATED TO PHYSICAL EXERCISE IN RATS

\section{Estatinas e atividade física. Statins and physical activity.}

Mariana Rotta Bonfim ${ }^{1}$, Bruna Corral Garcia ${ }^{1}$, Fábio Yoshikazu Kodama ${ }^{1}$,Alice Cristina Antonio dos Santos ${ }^{1}$, Susimary Aparecida Trevizan Padulla², Danilo Gibin Pedroso ${ }^{3}$, Viviane da Silva Porto ${ }^{3}$; Leandro Lopes Haidamus ${ }^{4}$; José Carlos Silva Camargo Filho ${ }^{2}$

${ }^{1}$ Mestrandos do Curso de Pós-Graduação em Fisioterapia - Faculdade de Ciências e Tecnologia da Universidade Estadual Paulista, Presidente Prudente (SP), Brasil.

${ }^{2}$ Doutores Docentes do Departamento de Fisioterapia - Faculdade de Ciências e Tecnologia da Universidade Estadual Paulista, Presidente Prudente (SP), Brasil.

${ }^{3}$ Graduandos do Curso de Farmácia Bioquímica da Universidade do Oeste Paulista, Presidente Prudente (SP) , Brasil.

${ }^{4}$ Doutor Docente do Curso de Farmácia Bioquímica da Universidade do Oeste Paulista, Presidente Prudente (SP), Brasil.

Trabalho baseado na dissertação de mestrado de Mariana Rotta Bonfim, intitulada "Estudo das respostas bioquímica e muscular da administração de estatina e sua descontinuidade associadas à atividade física em ratos", defendida aos 05 dias de Fevereiro de 2010, pelo Programa de Pós Graduação em Fisioterapia da Faculdade de Ciências e Tecnologia - UNESP (120 f).

\section{- Faculdade de Ciências e Tecnologia - Unesp}

Rua Roberto Simonsen, 305. Vila Santa Helena. CEP: 19060-900

- Universidade do Oeste Paulista (UNOESTE) - Campus I:

Rua José Bongiovani, 700. Vila Liberdade. CEP: 19050-680

\section{Endereço para Correspondência:}

José Carlos Silva Camargo Filho

FCT/Unesp - Departamento de Fisioterapia

Rua Roberto Simonsen, 305; CEP 19060-900 - Presidente Prudente/SP

Tel: (18) 3229-5388 - Ramal: 5466 / Fax: (18) 3229-5353

E-mail: camargo@fct.unesp.br 


\section{RESUMO}

Objetivo: Investigar o efeito do uso e da descontinuidade da atorvastatina associadas a um programa de atividade física nos parâmetros bioquímicos de ratos. Métodos: 56 ratos machos Wistar, divididos em 4 grupos: sedentário, exercitado, sedentário com estatina e exercitado com estatina, foram submetidos ao uso da Atorvastatina (10 $\mathrm{mg} / \mathrm{Kg} / \mathrm{dia}$ ) ou placebo sete dias na semana por 4 semanas, e a um programa de atividade física em esteira de 60 minutos diários, 5 dias na semana por 4 semanas. Após este período, 8 animais de cada grupo foram sacrificados; os demais animais foram submetidos à descontinuidade da estatina ou placebo, permanecendo a atividade física por 2 semanas. Nos três momentos distintos das intervenções, foram realizadas coletas de sangue para verificação dos parâmetros bioquímicos lipídicos e de biomarcadores de lesão hepática e muscular. Resultados: O uso da atorvastatina por 4 semanas reduziu efetivamente os níveis de colesterol total, fração não HDL-c e triacilgliceróis sem alteração dos biomarcadores de lesão muscular e hepática; a descontinuidade de seu uso acarretou em aumento dos níveis lipídicos. A adição da atividade física reduziu significantemente os níveis de triacilgliceróies e elevou os de HDL-c, permitindo que não houvesse aumento dos níveis lipídicos após a descontinuidade do uso da estatina. Conclusão: Conclui-se que o uso da estatina em conjunto com a prática de atividade física promove efeitos benéficos no perfil lipídico, que são sustentados até mesmo após a descontinuidade do fármaco.

Descritores: Inibidores de Hidroximetilglutaril-CoA redutases, Atividade motora, Lipídeos, Músculo esquelético, Fígado. 


\section{ABSTRACT}

Objective: Investigate the effect of atorvastatin use and its discontinuity associated to a physical activity program in the biochemical profiles of rats. Methods: 56 male wistar rats, divided into 4 groups: sedentary, exercised, sedentary with statin, and exercised with statin, were submitted to Atorvastatin use or placebo seven days per week for four weeks, and a physical activity program in treadmill consisted of 60 minutes daily of activity, 5 days per week for four weeks. After this period, eight animals of each group were sacrificed and the others were submitted to the discontinuance of statin or placebo, maintaining the physical activity for 2 weeks. In the three different intervention moments, the blood was collected to verify the lipid and muscle and liver lesion biomarkers parameters. Results: The use of Atorvastatin for 4 weeks effectively reduced total cholesterol levels, non HDL-c fraction and triglyceride levels with no alteration on muscle and liver biomarkers; the discontinuance of its use led to the rise of lipids levels. Adding the physical activity in the statin treatment significantly reduced triglyceride levels and raised HDL-c levels, and allowed the maintenance of the lipids levels after the discontinuance of the statin. Conclusion: The results of this study suggest that statin use together with physical activity practice promote beneficial effects in the lipid profile, that are sustained even after the discontinuance of the drug.

Keywords: Hydroxymethylglutaryl-CoA reductase inhibitors, Motor activity, Lipids, Skeletal muscle, Liver. 


\section{INTRODUÇÃO}

As estatinas, inibidores competitivos da enzima 3-hidroxi-3-metilglutaril coenzima-A redutase (HMG-CoA Redutase), são os fármacos mais efetivos no tratamento da hipercolesterolemia, atuando tanto na adequação dos níveis lipídicos sanguíneos como na redução da morbidade e mortalidade cardiovascular ${ }^{(1,2)}$.

Estes fármacos atuam na via limitante da síntese do colesterol, inibindo a ação da HMG-CoA redutase e, consequentmente, a conversão de HMG-CoA em Mevalonato. Dessa forma, a reação em cascata da síntese do colesterol é inibida, reduzindo assim seus níveis séricos e acarretando no aumento da expressão hepática dos receptores de lipoproteínas de baixa densidade (LDL-C), contribuindo para a depuração do colesterol sérico ${ }^{(3)}$.

São inquestionáveis os efeitos satisfatórios da estatina na adequação dos níveis lipídicos; entretanto, a utilização destes fármacos é associada à ocorrência de efeitos colaterais indesejáveis, como hepatotoxicidade, que é dose-dependente e ocorre em 0,5 a $2,0 \%$ dos pacientes ${ }^{(2)}$, e miopatia ${ }^{(4,5)}$. Estudos ${ }^{(6,7)}$ apontam que os desconfortos musculares ocasionados pelo uso das estatinas interferem na realização das atividades diárias, justificados pelas dores, câimbras e/ou rigidez muscular, sendo que praticamente todos os sintomas musculares desaparecem após descontinuidade no uso do fármaco ${ }^{(8)}$.

Além disso, a prática de atividade física está relacionada à exacerbação das dores musculares relatadas pelos usuários de estatina, estando sua incidência diretamente relacionada ao nível de atividade física dos praticantes ${ }^{(6)}$, sendo inclusive considerada fator de risco para lesões musculares ${ }^{(9)}$. Entretanto, em situações nas quais o exercício físico foi adicionado à terapêutica por estatinas verificou-se que a alteração nos níveis lipídicos séricos foi mais significante que o uso somente da terapêutica medicamentosa ${ }^{(10,11)}$, o que caracteriza a prática de atividade física uma interessante ferramenta terapêutica.

De maneira geral, em situações nas quais haja o comprometimento da musculatura esquelética durante a terapêutica por estatinas e atividade física, as condutas que poderão ser tomadas incluem a descontinuidade do uso do medicamento ou a interrupção da prática de atividade física ${ }^{(1,8)}$. Apesar dessas recomendações, não há na literatura estudos que relatem os efeitos tanto bioquímicos séricos quanto musculares destas medidas terapêuticas, o que torna necessário o desenvolvimento de estudos visando identificar as melhores estratégias para a manutenção das alterações lipídicas associada ao menor comprometimento da musculatura quando do tratamento conjunto de estatinas e atividade física. 
Nesse sentido, o objetivo deste estudo foi investigar os efeitos do uso e da descontinuidade da atorvastatina associadas à continuidade do programa de atividade física nos parâmetros lipídicos sanguíneos e nos biomarcadores de lesão hepática e muscular de ratos wistar. A opção pela interrupção do uso do medicamento em detrimento da prática de atividade física se deu pela nossa hipótese de que tal estratégia poderia levar à manutenção dos benefícios lipídicos com concomitante redução dos efeitos maléficos hepáticos e musculares, uma vez que está sendo mantido um agente atuante no perfil lipídico e retirado o componente mais nocivo à musculatura esquelética.

\section{MÉTODOS}

Os procedimentos adotados nesse estudo foram aprovados pelo Comitê de Ética em Pesquisa da Faculdade de Ciências e Tecnologia - UNESP de Presidente Prudente - SP, sob protocolo nํ64/2009, e estão de acordo com os "Princípios Éticos na Experimentação Animal" adotados pela Sociedade Brasileira de Ciência em Animais de Laboratório (SBCAL).

Para a realização dos experimentos foram utilizados 56 ratos machos da linhagem Wistar (Rattus novergicus), com cinco meses de idade, os quais foram acondicionados em gaiolas de polipropileno com quatro animais, em ambiente com temperatura $(22 \pm 2 \circ \mathrm{C})$ e umidade $(50 \pm 10 \%)$ controladas, e ciclo claro/escuro de 12 horas (7-19h). Os ratos foram alimentados com ração comercial padrão para roedores (Primor® - Moinho Primos S.A.) e água ad libitum.

Os animais foram divididos em quatro grupos de 14 animais, sendo os grupos: placebo sedentário (G1); placebo atividade física (G2); medicamento sedentário (G3) e medicamento atividade física (G4). A formação dos grupos foi determinada pelos resultados da fase de seleção de corredores do programa de atividade física, na qual os animais que apresentaram resposta positiva ao estímulo de corrida em esteira foram alocados nos grupos de atividade física. Este critério foi baseado em estudos prévios $^{(12,13)}$ e tem por objetivo evitar viés nos resultados, assegurando que as alterações nos parâmetros bioquímicos do animal sejam em resposta à atividade realizada e não a outros fatores. Além disso, tomou-se o cuidado de obter o equilíbrio de peso corporal entre os grupos no início do experimento, o que foi verificado pela ausência de diferenças estatísticas no valor inicial desta variável $(p=0,625)$.

Dentro de cada grupo, oito animais foram sacrificados após um mês de intervenção, sendo que os seis restantes foram submetidos a um período de descontinuidade do uso do fármaco ou placebo, permanecendo o protocolo de 
atividade física por duas semanas (G2 e G4). Nessa fase, a escolha dos animais foi aleatória, e realizada por um pesquisador não integrante da pesquisa.

\section{INSEIR FIGURA 1}

O tempo das intervenções foi estipulado a partir dos efeitos do medicamento na musculatura esquelética. De acordo com estudos prévios, após 15 dias de uso das estatinas já há ocorrência de lesões musculares em ratos ${ }^{(14,15)}$, sendo que a maior parte das queixas de sintomas musculares pelos pacientes ocorre no primeiro mês de uso $^{(6)}$, o que justifica a escolha de 4 semanas de intervenção. Quanto ao período de descontinuidade, não há um consenso sobre o tempo necessário para a recuperação da musculatura e, portanto, optamos verificar a resposta muscular após 2 semanas sem o uso do medicamento.

Os animais dos grupos medicados (G3 e G4) receberam Atorvastatina Cálcica (Lipitor®, Pfizer) via oral, pela técnica de gavagem, sete dias na semana, durante quatro semanas. A dose utilizada foi de $10 \mathrm{mg} / \mathrm{Kg} / \mathrm{dia}^{(16,17)}$, calculada a partir da média de peso corporal do grupo de estudo, tendo sido feito o reajuste semanal conforme a mudança de peso dos animais.O fármaco foi preparado a partir da maceração dos comprimidos e sua posterior dissolução em veículo de Hidroxipropil Metilcelulose (HPMC) a $0,5 \%{ }^{(14,15,18)}$, sendo administrado um volume de $2 \mathrm{~mL}$ por animal.

Os animais dos grupos placebo (G1 e G2) receberam solução de Hidroxipropil Metilcelulose (HPMC - 0,5\%) via gavagem, 7 dias na semana por 4 semanas, tendo sido administrado o volume de $2 \mathrm{~mL}$ por animal. Ambos, fármaco e placebo, foram administrados no período da manhã, trinta minutos antes do programa de atividade física ${ }^{(18)}$.

A atividade física consistiu na caminhada em esteira rolante para animais de pequeno porte, com velocidade fixada em 9,75 metros por minuto sem adição de inclinação. O protocolo utilizado foi adaptado de um trabalho anterior ${ }^{(19)}$, e compreendeu três fases:

I) Fase de Seleção dos Corredores: consistiu em 3 dias consecutivos de 5 minutos de caminhada em esteira, com a finalidade de identificar os animais mais aptos a realizar o esforço, os quais foram distribuídos nos grupos dos animais que realizaram o programa de atividade física.

II) Fase de Adaptação: consistiu em sessões diárias de caminhada com duração de 5, $15,30,45$ e 60 minutos durante os cinco primeiros dias de experimento, com a finalidade de adaptação dos animais ao programa de atividade física. 
III) Programa de Atividade física: consistiu em sessões diárias de 60 minutos de exercício em esteira, cinco dias por semana, durante quatro semanas. Os animais da fase de descontinuidade permaneceram neste programa por mais duas semanas, totalizando seis semanas de atividade física.

O desempenho dos animais foi monitorado todos os dias durante a sessão, observando-se a presença de recusa ao exercício ou o instinto de fuga, uma vez que tais comportamentos poderiam indicar a presença de desconforto ou fraqueza no membro afetado. Foram relatados a quantidade de animais que apresentaram tal característica no decorrer do programa e a frequência de ocorrência desses comportamentos $^{(13)}$.

Durante o protocolo experimental foi feita a coleta de sangue para verificação dos parâmetros bioquímicos séricos, tendo sido utilizada a técnica da punção cardíaca esternal a céu fechado, obtendo-se $2 \mathrm{~mL}$ de sangue para cada amostra. As coletas foram realizadas sempre no período da manhã, entre 07:30 e 10:00 horas, no período que antecedeu as intervenções (T0), após 4 semanas de intervenção (T1) e após 2 semanas de descontinuidade (T2). Para todas as análises adotou-se 72 horas de repouso e 12 horas de jejum, a fim de se obter os resultados do estado basal do animal. As amostras foram centrifugadas a $3000 \mathrm{rpm}$, durante 10 minutos até a obtenção do soro, sendo conservados a $-18^{\circ} \mathrm{C}$ até o momento das dosagens.

O sangue coletado foi utilizado para as seguintes dosagens séricas:

- Perfil Lipídico: colesterol total (CT); lipoproteína de alta densidade (HDL-C); triacilglicerol (TAG) e fração não HDL-c (NHDL) (obtida por meio da equação NHDL = CT - HDL-C) $)^{(1)}$;

- Marcador de lesão muscular: creatina fosfoquinase (CK-nac);

- Marcadores de lesão hepática: alanina aminotransferase (ALT) e aspartato aminotransferase (AST).

As análises de perfil lipídico foram feitas pelo método colorimétrico enzimático, sendo o HDL-c determinado pelo método direto; as análises das enzimas CK, ALT e AST foram feitas pelo método cinético (UV-IFCC). Todas as análises foram realizadas no analisador bioquímico Opera (Bayer $\left.{ }^{\circledR}\right)$, utilizando-se kits da Labtest ${ }^{\circledR}$.

Os dados obtidos foram analisados pelo programa estatístico SPSS 13.0 for Windows, e são apresentados como média e desvio padrão. Para verificação da presença de diferenças significantes entre os períodos de intervenção utilizou-se o teste de Wilcoxon; as diferenças entre os grupos foram mensuradas pelo teste de Kruskal-Wallis seguido do pós-teste de Dunn. Para todas as análises utilizou-se nível de significância de $p<0,05$. 


\section{RESULTADOS}

Durante o protocolo experimental foram a óbito três animais do grupo medicado e exercitado (G4); um deles apresentou inquietude na prática do exercício na parte da manhã, caracterizada pelo instinto de fuga, indo a óbito no período da tarde. Dentre os demais animais, um ocorreu sem causa aparente, e o outro com suspeita de pneumonia. Estes animais foram repostos. Já no grupo placebo sedentário (G1), dois animais não resistiram ao procedimento da punção cardíaca no T1, porém não foram repostos; assim, este grupo ficou com apenas 12 animais, tendo sido prejudicada a fase de descontinuidade, uma vez que contou com apenas 4 animais.

Com relação ao peso corporal dos animais, verificou-se que os grupos iniciaram o experimento com o mesmo padrão, sendo que após 4 semanas de intervenção o grupo placebo sedentário (G1) foi o que apresentou os maiores valores (Figura 2). Ao final do experimento, verificou-se que apenas o grupo medicamento atividade física (G4) apresentou redução do peso e se distinguiu dos demais grupos, todavia em nenhum momento a diferença entre os grupos foi significante.

\section{INSERIR FIGURA 2}

De acordo com os resultados de perfil lipídico, verificou-se que no período inicial do experimento (TO) não houve diferença significante entre os grupos de estudo, o mesmo ocorrendo após período de 4 semanas de intervenção (T1). Nesse momento, em cada grupo, houve a eutanásia de oito animais e a interrupção do uso de placebo ou medicamento nos demais, sendo que a ausência de diferença significante nos parâmetros lipídicos entre esses animais em todos os grupos foi um indicativo de que eles estavam no mesmo padrão. Assim, quando foi feita a análise do T1 apenas com os animais da descontinuidade, verificou-se a ausência de diferença significante entre os grupos, o mesmo ocorrendo no T2. Os mesmos comportamentos acima foram observados para as variáveis biomarcadoras de lesão hepática e muscular.

Com relação às diferenças entre os períodos de estudo, verificou-se que entre T0 e T1, os animais do grupo placebo sedentário (G1) apresentaram reduções significantes no colesterol total (CT), na fração NHDL-c e nos triacilgliceróis (TAG), sendo que os animais placebo atividade física (G2) apresentaram redução significante nos valores da fração NHDL-c (Tabela 1). A descontinuidade do uso do placebo (T2) não alterou os valores de perfil lipídico, uma vez que não foram encontradas diferenças significantes entre T1 e T2 (tabela 2). 


\section{INSERIR TABELA 1}

Nos animais que fizeram uso somente do fármaco verificou-se redução significante nos níveis de CT, da fração NHDL-c e de TAG (tabela 1), sendo que a descontinuidade de seu uso não sustentou estas alterações, levando ao aumento significante do CT e da fração NHDL-c (Tabela 2). A associação do fármaco com o atividade física acarretou em alterações diferenciadas, tendo sido verificada a redução significante dos TAG, destacando o aumento significante da fração HDL-c (tabela 1); a descontinuidade do fármaco com a continuidade do exercício não alterou os parâmetros lipídicos dos animais, visto que não foram encontradas alterações significantes nas variáveis entre T1 e T2 (Tabela 2).

\section{INSERIR TABELA 2}

Com relação aos biomarcadores de lesão hepática e muscular, verificou-se pouca ou nenhuma alteração decorrente das intervenções. Entre os períodos T0 e T1 apenas a variável hepática ALT apresentou alterações, sendo seu aumento significante nos grupos G1, G2 e G4 (tabela 3); nenhuma alteração significante foi verificada após período de descontinuidade de fármaco ou placebo, não havendo também alterações na variável AST (Tabela 4).

\section{INSERIR TABELA 3}

Apesar de se esperar o aumento nos níveis de creatina quinase (CK) decorrente das intervenções, neste trabalho não foi verificado alterações significantes desta variável, indicando que talvez elas não tenham interferido na integridade muscular. De maneira semelhante, a observação dos sinais clínicos associados ao atividade física em esteira indicou a presença de comportamentos de fuga ou recusa ao esforço pelos animais, porém tanto o número de ocorrências quanto o número de animais acometidos por esse comportamento foram reduzidos em todos os grupos estudados, não se podendo afirmar que as intervenções interferiram na prática do atividade física.

\section{DISCUSSÃO}

O presente estudo buscou verificar os efeitos do uso da estatina e sua descontinuidade associadas ao atividade física nos parâmetros bioquímicos 
sanguíneos de ratos. No que diz respeito à utilização apenas da atorvastatina $(10 \mathrm{mg} / \mathrm{Kg} / \mathrm{dia})$, verificou-se que tal intervenção acarretou na redução significante dos níveis de Colesterol Total (CT), da fração NHDL-c e dos triacilgliceróis (TAG) séricos dos animais.

De fato, o uso das estatinas está relacionado a modificações nos parâmetros lipídicos, apresentando redução dos níveis de CT, LDL-c e TAG, bem como no aumento de HDL-c ${ }^{(1,2,5)}$. Tais modificações estão associadas à ação deste fármaco no organismo, o qual age impedindo a ocorrência de uma passagem precoce e limitante da síntese do colesterol via inibição da ação da enzima HMG-CoA redutase. Dessa forma, há redução da síntese do colesterol endógeno o que, conseqüentemente, aumenta a síntese de receptores hepáticos de LDL-colesterol e, portanto, a sua captação sérica ${ }^{(5,20)}$, permitindo assim as alterações anteriormente apontadas.

Entretanto, verificou-se neste estudo que os animais sedentários no tratamento com placebo também apresentaram uma redução significante das concentrações séricas das frações lipídicas CT, NHDL-c e do TAG, o que não era esperado. De maneira geral, a escolha das substâncias placebo/veículo utilizadas na pesquisa possui grande importância, uma vez que estas não podem interferir na farmacocinética do medicamento. As substâncias utilizadas nesta pesquisa foram escolhidas baseadas em estudos prévios ${ }^{(16-18)}$ que tiveram como objetivo verificar o efeito in vivo do uso de estatina em animais.

Estes estudos utilizam como placebo e veículo a substância de metilcelulose $(0,5 \%)^{(18)}$, tanto no formato Carboxi ${ }^{(16,17)}$ quanto Hidroxipropil ${ }^{(16,17)}$, visto que tal substância é um composto de celulose que não é absorvido pelo organismo e, portanto, não interfere na farmacocinética do medicamento. No presente estudo, optou-se pelo uso da Hidroxipropil Metilcelulose (HPMC - 0,05\%) visto sua facilidade de acesso por nossa equipe. Todavia, por ser um composto de celulose e, portanto, uma fibra solúvel, o HPMC acaba interferindo na absorção e reabsorção de outros compostos, inclusive o colesterol, o que pode causar a redução dos níveis séricos lipídicos ${ }^{(21)}$.

Estudos que avaliaram o efeito da suplementação de HPMC por indivíduos hipercolesterolêmicos verificaram a presença de alteração no perfil lipídico, caracterizada pela redução de CT e da fração LDL-c; não foi encontrada alteração de TAG, a qual foi atribuída ao uso conjunto de HPMC a uma fonte de carboidrato, no caso suco de limão(21,22). Em estudo recente ${ }^{(23)}$, verificou-se que o uso conjunto de HPMC e estatina propiciou uma maior redução dos níveis lipídicos séricos dos pacientes, considerando o HPMC um coadjuvante no tratamento com estatinas. 
Nesse sentido, pode-se considerar que as alterações encontradas nos animais controle são resultado da ação da HPMC; já a sua associação à estatina (G3) poderia ter contribuído para as reduções encontradas nesse grupo, porém não se configuraram como primordial, visto que apenas nesse grupo houve aumento significante das variáveis após a descontinuidade do uso do medicamento e veículo.

Além da utilização de agentes hipolipemiantes, a prática de atividade física também está relacionada à redução de CT, fração LDL-c e TAG, bem como aumento da HDL-c ${ }^{(24)}$. Sendo assim, a hipótese da pesquisa foi a otimização das alterações do perfil lipídico dos animais pela adição do atividade física ao tratamento com estatina. Todavia, verificou-se nesse estudo que a prática de atividade física isolado alterou somente os valores da fração NHDL-c, sendo que sua associação com a estatina alterou significantemente apenas TAG e fração HDL-c.

De acordo com estudos prévios ${ }^{(25,26)}$ que avaliaram o efeito do exercício aeróbio moderado e contínuo no perfil lipídico e na adiposidade de ratos, verificou-se que os maiores benefícios decorrentes do exercício físico tendem a ocorrer nos animais que geralmente recebem dieta com alto valor lipídico, sendo que os animais normolipidêmicos, como no presente estudo, apresentaram pouca ou nenhuma alteração, o que poderia explicar os resultados encontrados.

Além disso, esses estudos ${ }^{(25,26)}$ geralmente utilizam oito semanas de programa de treinamento, obtendo resultados positivos. No presente estudo, utilizou-se 4 semanas de intervenção tendo como referência o uso do medicamento, sendo que um programa de atividade física mais extenso poderia ter trazido benefícios adicionais ao perfil lipídico dos animais.

Outro fator a ser considerado é a ingestão alimentar dos animais. Uma vez que o exercício acarreta no aumento da taxa metabólica, existe a possibilidade dos animais exercitados aumentarem seu consumo alimentar, impedindo alterações mais significantes no perfil lipídico. Apesar da possível influência deste fator nos resultados obtidos, a variável ingestão alimentar não foi avaliada neste trabalho, sendo esta uma das limitações do estudo.

Ademais, visto que o uso do placebo nesse trabalho foi considerado responsável pelas alterações lipídicas nos animais sedentários, tornou-se expectativa que os animais exercitados em uso de placebo apresentassem reduções mais significantes, o que não ocorreu. Tal fato pode estar relacionado ao momento de administração do HPMC; de acordo com o estudo de Maki et al (2000) ${ }^{(21)}$, o efeito redutor de colesterol exercido por essa substância é mais consistente quando ela é administrada junto, e não entre as alimentações. 
Essa informação se torna relevante se considerarmos que após a administração do placebo ou medicamento os animais sedentários retornavam para suas gaiolas e tinham acesso irrestrito ao alimento, ao passo que os animais exercitados ficavam o período anterior e durante a prática do atividade física sem acesso ao alimento, o que somava certa de 100 a 120 minutos após administração do HPMC. Uma forma de controlar essa variável seria restringir o acesso ao alimento dos animais sedentários pelo mesmo período a que os animais exercitados são expostos, sendo essa outra limitação deste estudo, bem como uma sugestão para trabalhos futuros.

A hipótese central do trabalho era de que a adição da atividade física ao uso da estatina acarretaria em redução adicional das variáveis lipídicas, o que não ocorreu. De acordo com estudos previamente publicados, o efeito lipídico adicional desta associação é controverso. No estudo de Wittke $(1999)^{(10)}$, verificou-se presença de alterações marcantes nos níveis lipídicos de indivíduos dislipidêmicos decorrentes do uso conjunto de estatina e atividade física; em contrapartida, no estudo de Coen et al. $(2009)^{(9)}$ esta associação ocasionou efeito adicional apenas na fração LDL-oxidada, o que foi atribuído ao nível sérico lipídico inicial dos participantes que, no caso, foi superior no primeiro estudo comparado ao último. No presente estudo foram utilizados animais normolipidêmicos e, portanto, tal fato associado demais fatores acima relatados podem estar contribuindo para as pequenas alterações encontradas.

Apesar desses achados, a adição da estatina ao exercício ocasionou um efeito muito benéfico do ponto de vista da saúde cardiovascular, que foi o aumento significante de HDL-c. Esta fração lipídica é muito conhecida pelo seu papel antiaterogênico via sua ação no transporte reverso do colesterol, estando inversamente associada às doenças coronarianas e outros distúrbios vasculares ${ }^{(27)}$, sendo seus altos níveis preconizados pelas recomendações mundiais.

No que diz respeito aos valores do biomarcador de lesão muscular (CK), verificou-se que não houve diferenças entre os diferentes momentos analisados em todos os grupos estudados, levando a concluir que não houve danos musculares em decorrência das intervenções administradas. Além disso, a observação dos sinais clínicos associados à atividade física em esteira indicou que o comportamento dos animais não foi influenciado pela prática da atividade física.

Porém, apesar de se recomendar o uso da CK como marcador de danos musculares decorrentes da estatina, muita controvérsia ainda existe no meio clínico e científico acerca deste tema. Isto porque muitos pacientes que apresentam CK aumentada podem não ter as manifestações clínicas de dor ou desconfortos musculares ${ }^{(28)}$, enquanto outros que as tenham, podem apresentar valores normais de 
$\mathrm{CK}^{(8)}$. Assim, a detecção das alterações musculares decorrentes do uso de estatinas deve ser bem cautelosa, tendo primariamente em vista os sinais clínicos apresentados pelo seu usuário; além disso, a realização da análise histológica do tecido seria a ferramenta mais fidedigna para se afirmar que as intervenções utilizadas neste trabalho não acarretaram lesão muscular, sendo esta uma variável de estudo bastante interessante para trabalhos futuros.

Com relação aos marcadores de lesão hepática, verificou-se que não houve alteração de AST decorrente de nenhuma das intervenções, inclusive no período de descontinuidade do fármaco ou placebo; em contrapartida, observaram-se aumento significante de $A L T$, apenas durante o primeiro período de intervenção para os grupos G1, G2 e G4. Apesar de tanto o exercício físico ${ }^{(29)}$ quanto a estatina ${ }^{(4)}$ estarem relacionados ao aumento dos níveis de $A L T$, o comportamento desta variável neste estudo não permite uma conclusão consistente acerca do fator desencadeante destas alterações, levando-nos a concluir que esta elevação foi decorrente de fatores externos não associados às intervenções.

Vale ressaltar que apesar destes achados, em muitos casos a terapêutica medicamentosa não pode ser interrompida e, portanto, faz-se necessário também identificar os efeitos da descontinuidade do exercício com a continuidade do uso da estatina nos parâmetros estudados. Ademais, visto as limitações no uso da CK como ferramenta de detecção de lesão muscular por estatinas, a análise tecidual do músculo esquelético acabaria por confirmar os resultados obtidos neste trabalho, sendo esses dois pontos extremamente relevantes para a continuidade dos estudos acerca do tema proposto.

Em síntese, o uso da atorvastatina por quatro semanas reduziu efetivamente os níveis lipídicos séricos, sem alteração dos níveis de biomarcadores muscular e hepático, sendo que a descontinuidade de seu uso acarretou em aumento dos níveis lipídicos séricos. Em contrapartida, a adição atividade física reduziu significantemente os níveis de triacilgliceróis e elevou os níveis de HDL-c, permitindo que não houvesse aumento das concentrações séricas dos lipídios após a descontinuidade do uso da estatina. Assim, os resultados deste estudo sugerem que o uso da estatina em conjunto com o atividade física promove efeitos benéficos no perfil lipídico que são sustentados até mesmo após a descontinuidade do fármaco.

\section{AGRADECIMENTOS}

Agradecemos os responsáveis pelo Laboratório de Análises Clínicas da Universidade do Oeste Paulista (Unoeste) pela realização das análises deste trabalho; o técnico do laboratório de histologia da FCT/UNESP, Sidney Siqueira Leirião pela colaboração no 
desenvolvimento da pesquisa; e a Coordenação do Curso de Mestrado em Fisioterapia da Universidade Estadual Paulista (Unesp) campus de Presidente Prudente pelo apoio durante a realização deste trabalho.

\section{REFERÊNCIAS}

1. Sociedade Brasileira de Cardiologia. IV Diretrizes brasileira sobre dislipidemias e prevenção da aterosclerose. Arquivos Brasileiros de Cardiologia. 2007; 88(1):2-19.

2. Third report of the national cholesterol education program (NCEP) expert panel on detection, evaluation, and treatment of high blood cholesterol in adults (Adult Treatment Panel III) final report. Circulation. 2002;106:3143-3421.

3. Veillard NR, Mach F. Statins: the new aspirin?. Cellular and Molecular Life Sciences. 2002; 59:1771-1786.

4. Brown WV. Safety of statins. Current Opinion in Lipidology. 2008; 19:558-562.

5. Josan K, Majumdar SR, McAlister FA. The efficacy and safety of intensive statin therapy: a meta-analysis of randomized trials. Canadian Medical Association Journal. 2008; 178(5):576-84.

6. Bruckert E, Hayem G, Dejager S, Yau C, B'egaud B. Mild to moderate muscular symptoms with high-dosage statin therapy in hyperlipidemic patients - the primo study. Cardiovascular Drugs and Therapy. 2005; 19:403-414.

7. Franc S, Dejager S, Bruckert E, Chauvenet M, Giral P, Turpin G. A Comprehensive description of muscle symptoms associated with lipid-lowering drugs. Cardiovascular Drugs and Therapy. 2003;17:459-465.

8. Thompson PD, Clarkson PM, Rosenson RS. An assessment of statin safety by muscle experts. The American Journal of Cardiology. 2006; 97(8A).

9. Joy TR, Hegele RA. Narrative review: statin-related myopathy. Annals of Internal Medicine. 2009;150:858-868.

10. Coen PM, Flynna MG, Markofskia MM, Pencea BD, Hannemannb RE. Adding exercise training to rosuvastatin treatment: influence on serum lipids and biomarkers of muscle and liver damage. Metabolism Clinical and Experimental. 2009; 58:1030-1038.

11. Wittke R. Effect of fluvastatin in combination with moderate endurance training on parameters of lipid metabolism. Sports Medicine Institute. 1999; 27(5):329-335.

12. Manchado FB, Gobatto CA, Contarteze RVL, Papoti M, Mello MAR. Máxima fase estável de lactato é ergômetr-dependente em modelo experimental utilizando ratos. Rev Bras Med Esporte. 2006;12(5):259-262. 
13. Manchado FB, Gobatto CA, Contarteze RVL, Papoti M, Mello MAR. Maximal lactate steady state in running rats. Journal of Exercise Physiology Online. 2005;5(4): 29-35.

14. Westwood FR, Bigley A, Randall K, Marsden AM, Scott RC. Statin-induced muscle necrosis in the rat: distribution, development, and fibre selectivity. Toxicologic Pathology. 2005; 33:246-257.

15. Westwood FR, Scott RC, Marsden AM, Bigley A, Randall K. Rosuvastatin: characterization of induced myopathy in the rat. Toxicologic Pathology. 2008; 36:345.

16. Pierno S, Didonna MP, Cippone V, De Luca A, Pisoni M, Frigeri A, Nicchia GP, Svelto M, Chiesa G, Sirtori C, Scanziani E, Rizzo C, De Vito D, Camerino DC. Effects of chronic treatment with statins and fenofibrate on rat skeletal muscle: a biochemical, histological and electrophysiological study. British Journal of Pharmacology. 2006;149:909-919.

17. Liantonio A, Giannuzzi V, Cippone V, Camerino GM, Pierno S, Camerino DC. Fluvastatin and atorvastatin affect calcium homeostasis of rat skeletal muscle fibers in vivo and in vitro by impairing the sarcoplasmic reticulum/mitochondria $\mathrm{Ca}^{2}+$-release system. The American Society for Pharmacology and Experimental Therapeutics. 2007; 321:626-634.

18. Seachrist JL, Loi C, Evans MG, Criswell KA, Rothwell CE. Roles of exercise and pharmacokinetics in cerivastatin-induced skeletal muscle toxicity. Toxicological Sciences. 2005; 88(2):551-561.

19. Padulla AST, Azoubel R, Bonfim MR, Accioly MF, Camargo Filho JCS, Padovani JA, Souza DRS. Effects of statin and aerobic physical exercise association in the cardiomyocites of the rat: morphometric study. Int J Morphol. 2009;27(1):83-88.

20. Hou R, Goldberg AC. Lowering Low-Density Lipoprotein Cholesterol: Statins, Ezetimibe, Bi le Acid Sequestrants, and Combinations: Comparative Efficacy and Safety. Endocrinol Metab Clin. 2009; 38:79-97.

21. Maki KC, Davidson MH, Torri S, Ingram KA, O’Mullane J, Daggy BP, Albrecht HH. High-molecular-weight hydroxypropylmethylcellulose taken with or between meals is hypocholesterolemic in adult men. American Society for Nutritional Sciences. 2000; 130: 1705-1710.

22. Reppas C, Swidan SZ, Tobey SW, Turowski M, Dressman JB. Hydroxypropylmethylcellulose significantly lowers blood cholesterol in mildly hypercholesterolemic human subjects. European Journal of Clinical Nutrition. 2009; 63:71-77. 
23. Maki KC, Carson ML, Miller MP, Anderson WHK, Turowski M, Reeves MS, Kaden V, Dicklin MR. Hydroxypropylmethylcellulose lowers cholesterol in statin treated men and women with primary hypercholesterolemia. European Journal of Clinical Nutrition. 2009; 63:1001-1007.

24. Mark C. Houston, Fazio S, Chilton FH, Wise DE, Jones KB, Barringer TA, Bramlet DA. Nonpharmacologic treatment of dyslipidemia. Progress in Cardiovascular Diseases. 2009; 52:61-94.

25. Cheik NC, Guerra RLF, VIANA FP, Rossi EA, Carlos IZ, Vendramini R, Duarte ACGO, Damaso AR. Efeito de diferentes freqüências de exercício físico na prevenção da dislipidemia e da obesidade em ratos normo e hipercolesterolêmicos. Revista Brasileira de Educação Física e Esporte. 2006; 20(2):121-29.

26. Sene-Fiorese M, Duarte FO, Scarmagnani FRR, Cheik NC, Manzoni MSJ, Nonaka KO, Rossi EA, Duarte ACGO, Damaso AR. Efficiency of intermittent exercise on adiposity and fatty liver in rats fed with high-fat diet. Obesity. 2008; 16:2217-2222.

27. Florentin M, Liberopoulosa EN, Wierzbickib AS, Mikhailidis DP. Multiple actions of high-density lipoprotein. Current Opinion in Cardiology. 2008; 23:370-378.

28. Glueck CJ, Rawal B, Khan NA, Yeramaneni S, Goldenberg N, Wang P. Should high creatine kinase discourage the initiation or continuance of statins for the treatment of hypercholesterolemia? Metabolism Clinical and Experimental. 2009; 58:233-238.

29. Pettersson J, Hindorf U, Persson P, Bengtsson T, Malmqvist U, Werkström V, Ekelund M. Muscular exercise can cause highly pathological liver function tests in healthy men. British Journal of Clinical Pharmacology. 2007; 65(2):253-259. 
FIGURA 1.

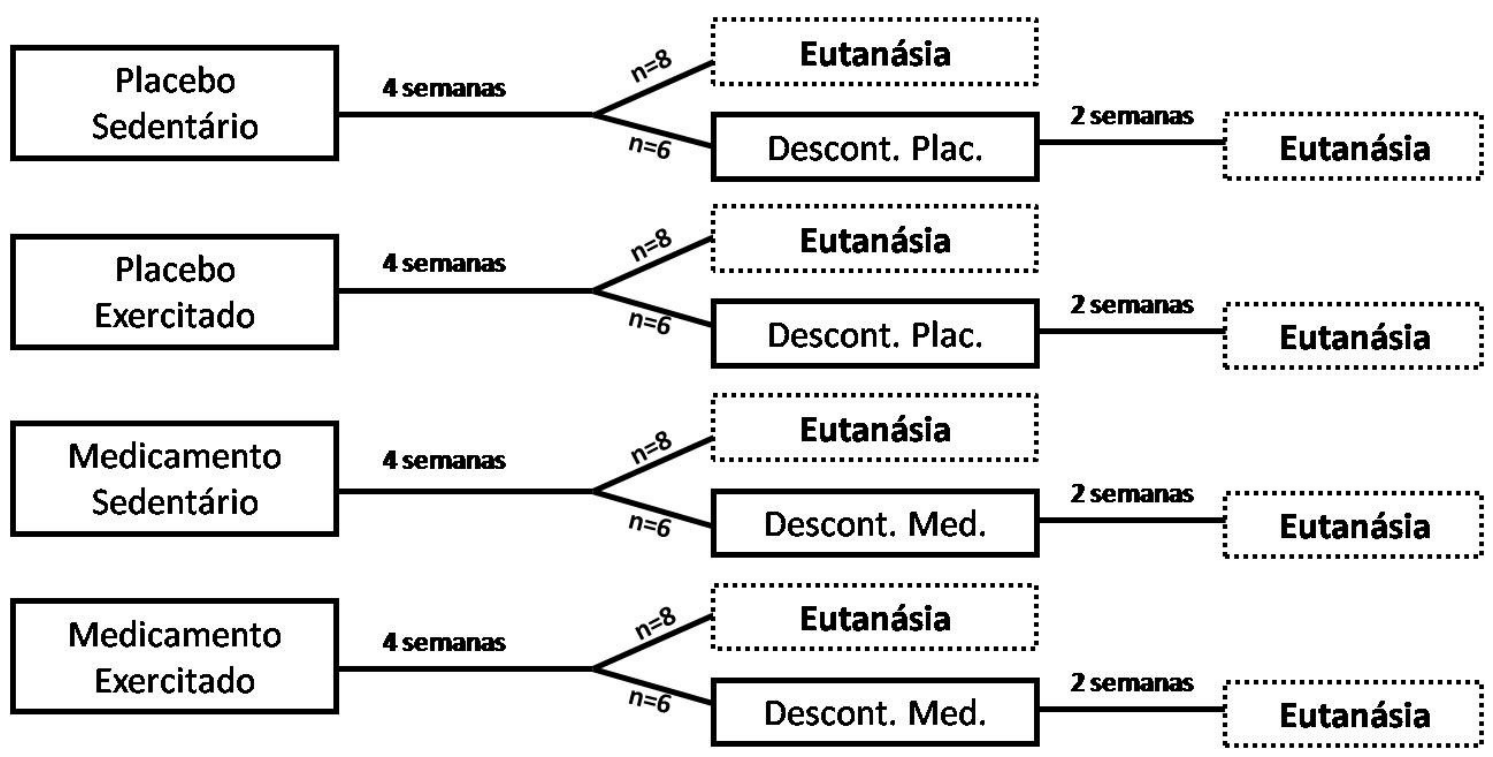

Figura 1. Representação do delineamento experimental do estudo 
FIGURA 2.

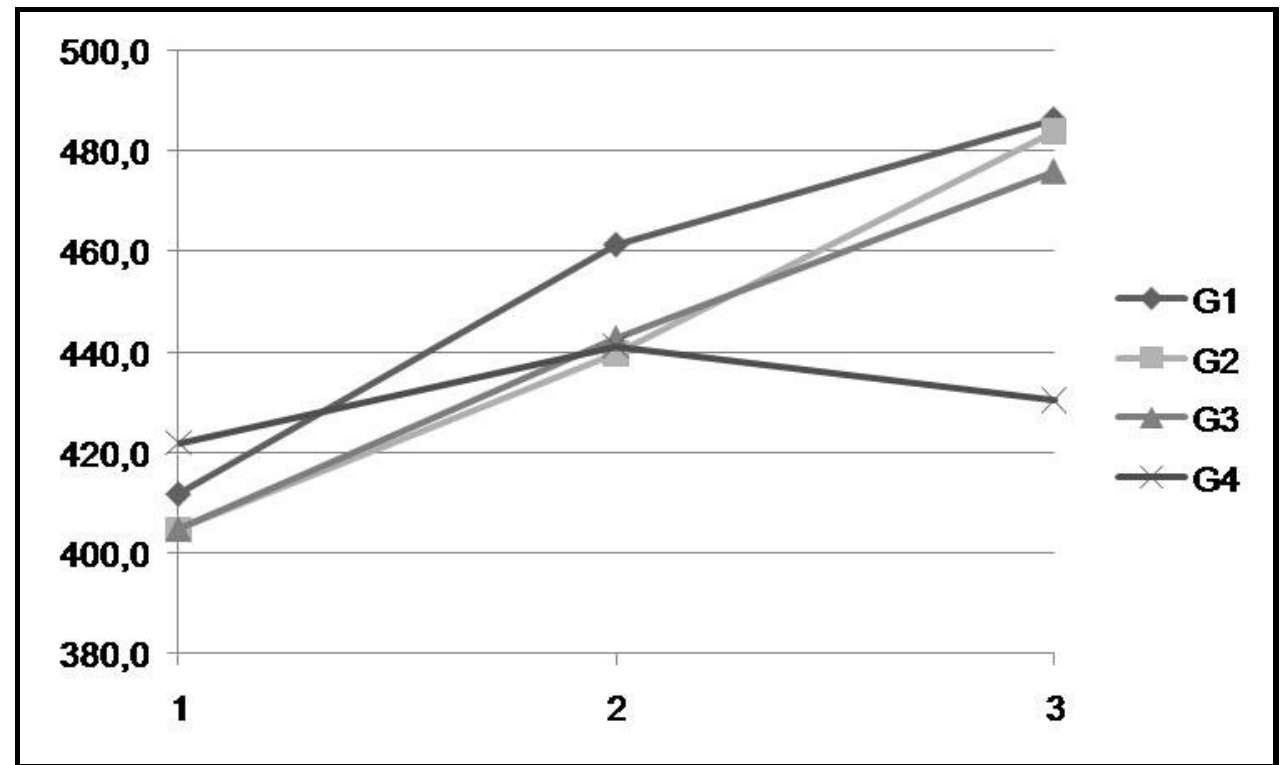

Figura 2. Gráfico do peso corporal (gramas) dos diferentes grupos no início do experimento (1), após 4 semanas de intervenção (2) e ao final do experimento (3). G1=Grupo placebo sedentário; G2=Grupo placebo atividade física; G3=Grupo estatina sedentário; G4=Grupo estatina atividade física. 
TABELA 1

Tabela 1. Perfil lipídico dos diferentes grupos no período basal (TO) e após intervenção de quatro semanas (T1).

\begin{tabular}{|c|c|c|c|c|}
\hline & $\begin{array}{c}\text { G1 } \\
(n=12)\end{array}$ & $\begin{array}{c}\text { G2 } \\
(n=14)\end{array}$ & $\begin{array}{c}\text { G3 } \\
(n=13)\end{array}$ & $\begin{array}{c}\text { G4 } \\
(n=14)\end{array}$ \\
\hline \multicolumn{5}{|c|}{ Colesterol Total (mg/dL) } \\
\hline Tempo 0 & $61,33 \pm 11,32$ & $61,64 \pm 9,05$ & $59,92 \pm 6,47$ & $58,43 \pm 11,42$ \\
\hline Tempo 1 & $54,87 \pm 13,54^{*}$ & $56,71 \pm 12,30$ & $54,21 \pm 6,32^{*}$ & $56,14 \pm 9,31$ \\
\hline \multicolumn{5}{|c|}{ Lipoproteína de Alta Densidade (HDL-c) (mg/dL) } \\
\hline Tempo 0 & $22,17 \pm 4,30$ & $24,50 \pm 3,39$ & $24,85 \pm 3,44$ & $23,64 \pm 3,52$ \\
\hline Tempo 1 & $22,83 \pm 4,28$ & $25,36 \pm 2,79$ & $25,36 \pm 3,57$ & $26,64 \pm 4,52^{\star}$ \\
\hline \multicolumn{5}{|c|}{ Fração Não HDL-c (NHDL-c) (mg/dL) } \\
\hline Tempo 0 & $39,17 \pm 8,19$ & $37,14 \pm 7,04$ & $35,09 \pm 4,65$ & $34,79 \pm 9,13$ \\
\hline Tempo 1 & $32,00 \pm 9,81^{*}$ & $31,36 \pm 11,59^{*}$ & $28,43 \pm 5,13^{\star}$ & $29,50 \pm 7,93$ \\
\hline \multicolumn{5}{|c|}{ Triacilglicerol (TAG) (mg/dL) } \\
\hline Tempo 0 & $91,25 \pm 32,40$ & $98,29 \pm 35,05$ & $87,38 \pm 21,42$ & $92,86 \pm 28,64$ \\
\hline Tempo 1 & $56,58 \pm 16,97^{*}$ & $78,14 \pm 32,07$ & $66,43 \pm 21,78^{*}$ & $75,50 \pm 29,06^{*}$ \\
\hline
\end{tabular}


TABELA 2

Tabela 2. Perfil lipídico dos diferentes grupos após intervenção de quatro semanas (T1) e após descontinuidade do fármaco ou placebo (T2).

\begin{tabular}{|c|c|c|c|c|}
\hline & $\begin{array}{c}\mathbf{G 1} \\
(\mathrm{n}=4)\end{array}$ & $\begin{array}{c}\mathbf{G 2} \\
(\mathrm{n}=6)\end{array}$ & $\begin{array}{c}\text { G3 } \\
(n=6)\end{array}$ & $\begin{array}{c}\mathbf{G 4} \\
(\mathrm{n}=6)\end{array}$ \\
\hline \multicolumn{5}{|c|}{ Colesterol Total (mg/dL) } \\
\hline Tempo 1 & $47,25 \pm 15,69$ & $54,33 \pm 5,61$ & $51,00 \pm 5,66$ & $60,83 \pm 7,52$ \\
\hline Tempo 2 & $53,25 \pm 10,87$ & $57,00 \pm 5,62$ & $60,33 \pm 9,25^{\star}$ & $61,17 \pm 6,24$ \\
\hline \multicolumn{5}{|c|}{ Lipoproteína de Alta Densidade (HDL-c) (mg/dL) } \\
\hline Tempo 1 & $19,50 \pm 4,66$ & $24,50 \pm 2,59$ & $25,00 \pm 4,56$ & $27,50 \pm 6,06$ \\
\hline Tempo 2 & $23,75 \pm 3,30$ & $24,67 \pm 1,86$ & $25,67 \pm 3,62$ & $26,67 \pm 2,50$ \\
\hline \multicolumn{5}{|c|}{ Fração Não HDL-c (NHDL-c) (mg/dL) } \\
\hline Tempo 1 & $27,75 \pm 11,82$ & $29,83 \pm 6,88$ & $26,00 \pm 4,73$ & $33,33 \pm 6,41$ \\
\hline Tempo 2 & $29,50 \pm 7,77$ & $32,33 \pm 5,43$ & $34,67 \pm 6,15^{\star}$ & $34,50 \pm 4,32$ \\
\hline \multicolumn{5}{|c|}{ Triacilglicerol (TAG) (mg/dL) } \\
\hline Tempo 1 & $52,50 \pm 16,52$ & $82,00 \pm 36,75$ & $69,00 \pm 17,58$ & $78,33 \pm 23,98$ \\
\hline Tempo 2 & $91,75 \pm 25,21$ & $77,83 \pm 22,97$ & $96,33 \pm 31,64$ & $70,33 \pm 24,13$ \\
\hline
\end{tabular}


TABELA 3

Tabela 3. Perfil dos biomarcadores de lesão dos tecidos muscular e hepático dos diferentes grupos. 3A. No período basal (T0) e após intervenção de quatro semanas (T1); 3B. Após quatro semanas (T1) e após descontinuidade (T2).

\begin{tabular}{|c|c|c|c|c|}
\hline 3A & $\begin{array}{c}\text { G1 } \\
(n=11)\end{array}$ & $\begin{array}{c}\text { G2 } \\
(n=12)\end{array}$ & $\begin{array}{c}\text { G3 } \\
(n=13)\end{array}$ & $\begin{array}{c}\text { G4 } \\
(n=13)\end{array}$ \\
\hline \multicolumn{5}{|c|}{ Creatina Fosfoquinase (CK-nac) (U/L) } \\
\hline Tempo 0 & $627,92 \pm 772,51$ & $368,21 \pm 324,19$ & $190,91 \pm 130,45$ & $354,64 \pm 151,00$ \\
\hline Tempo 1 & $363,42 \pm 311,46$ & $552,71 \pm 506,63$ & $212,79 \pm 106,00$ & $485,14 \pm 489,87$ \\
\hline \multicolumn{5}{|c|}{ Aspartato Aminotransferase (AST) (U/L) } \\
\hline Tempo 0 & $136,92 \pm 103,82$ & $104,00 \pm 36,60$ & $113,23 \pm 50,70$ & $108,92 \pm 32,69$ \\
\hline Tempo 1 & $99,58 \pm 25,61$ & $131,80 \pm 57,94$ & $92,64 \pm 15,00$ & $112,57 \pm 40,53$ \\
\hline \multicolumn{5}{|c|}{ Alanina Aminotransferase (ALT) (U/L) } \\
\hline Tempo 0 & $33,83 \pm 12,27$ & $34,71 \pm 7,29$ & $48,62 \pm 25,48$ & $34,00 \pm 5,67$ \\
\hline Tempo 1 & $45,58 \pm 8,45^{\star}$ & $59,57 \pm 17,94^{*}$ & $59,80 \pm 14,37$ & $54,79 \pm 10,75^{\star}$ \\
\hline 3B & $\begin{array}{c}\text { G1 } \\
(n=4)\end{array}$ & $\begin{array}{c}\text { G2 } \\
(n=6)\end{array}$ & $\begin{array}{c}\text { G3 } \\
(n=6)\end{array}$ & $\begin{array}{c}\text { G4 } \\
(n=6)\end{array}$ \\
\hline \multicolumn{5}{|c|}{ Creatina Fosfoquinase (CK-nac) (U/L) } \\
\hline Tempo 1 & $236,75 \pm 43,73$ & $498,17 \pm 281,16$ & $240,50 \pm 146,27$ & $737,33 \pm 605,09$ \\
\hline Tempo 2 & $656,75 \pm 284,761$ & $628,17 \pm 603,834$ & $342,33 \pm 101,91$ & $762,17 \pm 728,39$ \\
\hline \multicolumn{5}{|c|}{ Aspartato Aminotransferase (AST) (U/L) } \\
\hline Tempo 1 & $86,00 \pm 7,62$ & $123,17 \pm 29,50$ & $95,00 \pm 13,73$ & $136,83 \pm 44,58$ \\
\hline Tempo 2 & $114,00 \pm 25,39$ & $122,50 \pm 70,05$ & $99,67 \pm 26,07$ & $121,17 \pm 59,19$ \\
\hline \multicolumn{5}{|c|}{ Alanina Aminotransferase (ALT) (U/L) } \\
\hline Tempo 1 & $41,50 \pm 9,04$ & $57,67 \pm 13,10$ & $57,83 \pm 15,59$ & $55,17 \pm 12,38$ \\
\hline Tempo 2 & $44,00 \pm 8,12$ & $53,83 \pm 7,17$ & $52,50 \pm 19,41$ & $43,67 \pm 9,79$ \\
\hline
\end{tabular}

*Diferença estatística entre os tempos 0 e 1 (3A) e 1 e 2 (3B). G1=Grupo placebo sedentário; G2=Grupo placebo atividade física; G3=Grupo estatina sedentário; G4=Grupo estatina atividade física. 


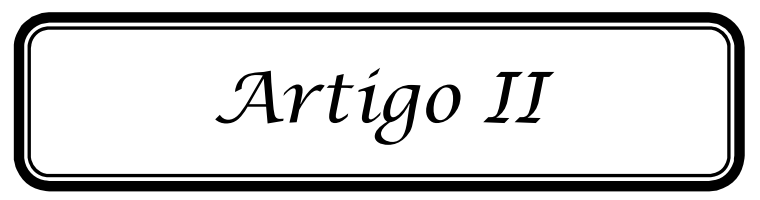


EFEITOS DA ADMINISTRAÇÃO DE ATORVASTATINA E SUA DESCONTINUIDADE ASSOCIADAS À ATIVIDADE FÍSICA NA MUSCULATURA ESQUELÉTICA DE RATOS

Mariana Rotta Bonfim ${ }^{1}$, Bruna Corral Garcia ${ }^{1}$, Fábio Yoshikazu Kodama ${ }^{1}$, Susimary Aparecida Trevizan Padulla ${ }^{1}$, José Carlos Silva Camargo Filho ${ }^{1}$

${ }^{1}$ Laboratório de Histologia, Departamento de Fisioterapia, Faculdade de Ciências e Tecnologia, Universidade Estadual Paulista (FCT/UNESP), Presidente Prudente, SP, Brasil.

Título Resumido: Descontinuidade de estatina, atividade física e músculo

Palavras chaves: Inibidores de Hidroximetilglutaril-CoA redutases, Atividade motora, Músculo Esquelético.

\section{Endereço para Correspondência:}

Mariana Rotta Bonfim

Laboratório de Histologia - FCT/Unesp

Rua Roberto Simonsen, 305. Vila Santa Helena.

CEP 19060-900 - Presidente Prudente/SP

Tel: (18) 3229-5388 - Ramal: 5466 / Fax: (18) 3229-5353

E-mail: mrb_unesp@yahoo.com.br 


\section{Resumo}

Apesar de se saber que a associação de estatina com a atividade física exacerba as lesões musculares e que a sua descontinuidade cessa os efeitos indesejáveis na musculatura, não se sabe ainda a resposta muscular da descontinuidade do medicamento associada à continuidade da atividade física. Este trabalho teve por objetivo analisar o efeito da descontinuidade do uso de estatina associada à continuidade de atividade física no músculo esquelético de ratos. Para tanto, 56 ratos machos Wistar foram divididos em 4 grupos de 14 animais: sedentário, exercitado, sedentário com estatina e exercitado com estatina. O fármaco $(10 \mathrm{mg} / \mathrm{Kg} /$ dia de Atorvastatina Cálcica) foi administrado via gavagem sete dias na semana por 4 semanas, no veículo e placebo Hidroxipropil Metilcelulose $(0,5 \%)$. A atividade física em esteira consistiu em 60 minutos diários, 5 dias na semana por 4 semanas. Após este período, 8 animais de cada grupo foram sacrificados; os demais foram submetidos à descontinuidade da estatina ou placebo, permanecendo a atividade física por 2 semanas. Foram feitas análise bioquímica da enzima creatina quinase e análise histológica e histoquímica dos músculos sóleo, extensor longo dos dedos e gastrocnêmio superficial. Os resultados indicaram que a descontinuidade do uso do medicamento com a continuidade da atividade física leve resultou na manutenção das alterações musculares verificadas nos animais submetidos a essa combinação, estimulando ainda processos regenerativos da musculatura, o que sugere que em casos de miopatia por estatinas tal estratégia pode ser utilizada quando houver condições de interrupção da terapêutica medicamentosa. 


\section{Abstract}

Although it's known that the association of statin with physical activity exacerbates the muscle injuries and that its discontinuity ceases the undesirable muscle effects, it's still unknown the muscle response for the drug discontinuity associated to the training continuity. The aim of this study was to analyze the effect of the statin use discontinuity associated to the continuity of the physical activity in the skeletal muscle of rats. For this, 56 Wistar male rats were divides into 4 groups of 14 animals: sedentary, exercised, statin sedentary and statin exercised. The drug (10 mg/Kg/Day of Atorvastatin Calcium) was administered by gavage 7 days during the week for 4 weeks, using for vehicle and placebo the Hidroxypropyl Methiycellulose $(0,5 \%)$. The treadmill physical activity consisted of 60 minutes daily, 5 days during the week for 4 weeks. After this period, 8 animals of each group were sacrificed; the others were submitted to statin or placebo discontinuity, with the continuity of physical activity for 2 weeks. It was done biochemistry analyses of the creatine kinase enzyme and the histological and histochemical analyses of the soleus, extensor digitorum longus and superficial gastrocnemius. The results indicate that the drug use discontinuity with the physical activity continuity resulted in the maintenance of the muscle alterations verified in the animals submitted to this combination, and stimulating regenerative processes of the muscle, what suggests that in cases of statin myopathy such strategy can be used when the interruption of the drug therapeutic is possible. 


\section{Introdução}

Os inibidores da enzima 3-hidroxi-3-metilglutaril coenzima A redutase (HMGCoA Redutase), também conhecidos como estatinas, são a classe de medicamentos mais vendidos em todo o mundo. Eles agem inibindo uma passagem precoce e limitante da biossíntese do colesterol, bem como a conversão de HMG-CoA em mevalonato, o que acarreta na atenuação da síntese endógena de colesterol e, consequentemente, na redução de seus níveis séricos e da taxa de mortalidade relacionada às doenças cardiovasculares $^{(1,2,3)}$.

Apesar dos benefícios da estatina na saúde cardiovascular, destaca-se entre seus efeitos colaterais indesejáveis a toxicidade hepática, que é dose-dependente e ocorre em 0,5 a $2,0 \%$ dos pacientes $^{(2)}$, e a toxicidade muscular, que pode variar desde miopatia leve, com incidência variando de 5 - 10\%, a casos mais severos como a rabdomiólise, ocorrendo em menos de $0,5 \%$ dos seus usuários ${ }^{(4,5)}$.

De acordo com os relatos da literatura, em torno de dez dias após o início da administração das estatinas a musculatura esquelética começa a apresentar os primeiros sinais de lesão ${ }^{(6,7)}$, concentrando-se no primeiro mês de uso a maior parte das queixas musculares pelos pacientes ${ }^{(8,9)}$. Os desconfortos musculares mais freqüentes são câimbras e rigidez muscular, sendo que a presença destes sintomas interfere de forma negativa na realização das atividades diárias dos pacientes, bem como na prática de atividade física $^{(8,9)}$.

Estudos indicam que pacientes em tratamento com as estatinas relatam exacerbação das dores musculares quando da prática de atividade física ${ }^{(8,9)}$, havendo em muitos casos a intolerância à sua prática ${ }^{(10)}$. Em alguns trabalhos foi verificado que essa associação acarreta no aumento da enzima marcadora de lesão muscular creatina 
quinase $(\mathrm{CK})^{(11,12)}$, tendo ainda sido confirmada a presença in situ dessa exacerbação $^{(13,14)}$.

Apesar disso, a interação de estatina e atividade física representa uma interessante estratégia terapêutica, visto que nessas condições a alteração nos níveis lipídicos séricos é mais significante que o uso isolado da estatina ${ }^{(15,16)}$. Todavia, não se pode descartar a existência das lesões musculares, fazendo-se assim necessário o estudo de novas estratégias terapêuticas, visando à manutenção das alterações lipídicas associada ao menor comprometimento da musculatura.

Na prática clínica, frente à ocorrência dos sintomas musculares associados ou não ao aumento dos níveis de creatina quinase $(\mathrm{CK})$, as condutas indicadas são a interrupção da atividade física ou do uso da estatina ${ }^{(4,5)}$. Apesar de se saber que tais atitudes proporcionam a melhora dos sintomas musculares ${ }^{(4,8)}$, não existem estudos in situ da resposta muscular à descontinuidade de medicamento ou da atividade física.

Sendo assim, visamos com esse trabalho analisar o efeito da interrupção do uso da estatina associada à continuidade de atividade física no músculo esquelético de ratos não portadores de hipercolesterolemia, realizando tanto a avaliação dos aspectos bioquímicos relacionados à musculatura, como a avaliação in situ. Optamos por essa estratégia terapêutica devido às inúmeras evidências dos benefícios da atividade física tanto na melhora do perfil lipídico como na saúde como um todo; é hipótese desse estudo a ocorrência da redução ou reparação das alterações musculares pela retirada do uso do medicamento.

\section{Materiais e métodos}


Os procedimentos adotados neste trabalho foram aprovados pelo Comitê de Ética em Pesquisa da Faculdade de Ciência e Tecnologia (UNESP - Processo n $^{\circ}$ 64/2009), e seguiram os "Princípios Éticos na Experimentação Animal” adotados pela Sociedade Brasileira de Ciência em Animais de Laboratório (SBCAL).

Para a realização dos experimentos foram utilizados 56 ratos machos, da linhagem Wistar (Rattus novergicus), com cinco meses de idade, os quais foram mantidos em gaiolas de polipropileno com quatro animais, em ambiente com temperatura $\left(22 \pm 2{ }^{\circ} \mathrm{C}\right)$ e umidade $(50 \pm 10 \%)$ controladas, e ciclo claro/escuro de 12 horas (7-19h). Os ratos foram alimentados com ração comercial padrão para roedores (Primor® - Moinho Primos S.A.) e água ad libitum.

Os animais foram divididos em quatro grupos de 14 animais, sendo constituídos como se segue: Placebo Sedentário (PS); Placebo Exercitado (PE); Medicamento Sedentário (MS); e Medicamento Exercitado (ME). A formação dos grupos foi determinada pelos resultados da fase de seleção de corredores do programa de atividade física, na qual os animais que apresentaram resposta positiva ao estímulo de corrida em esteira foram alocados nos grupos de atividade física. Este critério foi baseado em estudos prévios $^{(17,18)}$ e tem por objetivo evitar viés nos resultados, assegurando que o estresse do animal foi em resposta ao esforço e não a outros fatores. Além disso, tomouse o cuidado de obter o equilíbrio de peso corporal entre os grupos, o que foi verificado pela ausência de diferenças estatísticas no valor inicial desta variável $(\mathrm{p}=0,625)$.

Dentro de cada grupo, oito animais foram sacrificados após quatro semanas de intervenção, sendo que os seis restantes foram submetidos a um período de descontinuidade do uso do medicamento ou placebo, com continuidade da atividade física (PE e ME) por mais duas semanas. Nessa fase, a escolha dos animais foi aleatória e realizada por um pesquisador que não fazia parte da pesquisa. 
O tempo das intervenções foi estipulado a partir dos efeitos do medicamento na musculatura esquelética. De acordo com estudos prévios, após 10 dias de uso das estatinas já pode ser verificada a ocorrência de lesões musculares em $\operatorname{ratos}^{(6,7)}$, sendo que a maior parte das queixas de sintomas musculares pelos pacientes ocorre no primeiro mês de uso ${ }^{(8)}$, o que justifica a escolha de 4 semanas de intervenção. Quanto ao período de descontinuidade, não há um consenso sobre o tempo necessário para a recuperação da musculatura e, portanto, optamos verificar a resposta muscular após 2 semanas sem o uso do medicamento.

Os grupos medicados receberam Atorvastatina Cálcica (Lipitor®, Pfizer) via oral, pelo método de gavagem, sete dias na semana, durante quatro semanas. A dose utilizada foi de $10 \mathrm{mg} / \mathrm{Kg} / \mathrm{dia}^{(14)}$, e foi calculada a partir da média de peso corporal do grupo de estudo, tendo sido feito o reajuste semanal conforme a mudança de peso corporal dos animais. O medicamento foi preparado a partir de sua maceração e posterior dissolução em veículo composto de Hidroxipropil Metilcelulose (HPMC) a $0,5 \%{ }^{(6,7,11,14)}$, sendo administrado um volume de $2 \mathrm{~mL}$ por animal.

Os animais dos grupos não medicados (PS e PE) receberam solução placebo, constituída pelo mesmo meio de suspensão do medicamento (HPMC $-0,5 \%)^{(14)}$; a administração do placebo foi feita via gavagem, 7 dias na semana por 4 semanas, e volume de $2 \mathrm{~mL}$ por animal. Ambos, medicamento e placebo, foram administrados no período da manhã, sempre 30 minutos antes de iniciar o programa de atividade física ${ }^{(11)}$.

A atividade física foi realizada em uma esteira rolante para animais de pequeno porte, com velocidade fixada em 9,75 metros por minuto, sem adição de inclinação. $O$ protocolo utilizado foi baseado no trabalho de Padulla et al $(2006)^{(19)}$, e compreendeu três fases: 
I) Fase de Seleção dos Corredores: Consistiu em 3 dias consecutivos de 5 minutos de caminhada em esteira, com a finalidade de identificar os animais mais aptos a realizar o esforço, os quais foram distribuídos nos grupos dos animais que praticaram atividade física.

II) Fase de Adaptação: Consistiu em sessões diárias de caminhada com duração de 5, 15, 30, 45 e 60 minutos durante os cinco primeiros dias de experimento, com a finalidade de adaptação dos animais ao programa de atividade física.

III) Programa de Atividade Física: Consistiu em sessões diárias de 60 minutos de exercício em esteira, cinco dias por semana, durante quatro semanas. Os animais da fase de descontinuidade permaneceram neste programa por mais duas semanas, totalizando seis semanas de atividade física.

O desempenho dos animais foi monitorado todos os dias durante a sessão, observando-se a presença de recusa ao exercício ou o instinto de fuga, uma vez que tais comportamentos poderiam indicar a presença de desconforto ou fraqueza no membro afetado. A quantidade de animais que apresentaram tal característica no decorrer do programa e a frequência de ocorrência desses comportamentos foram relatadas ${ }^{(11)}$.

Após os períodos de intervenção previamente determinados, foram coletados 2 $\mathrm{mL}$ de sangue dos animais, os quais foram utilizados para mensuração das enzimas marcadoras de lesão muscular (Creatina Fosfoquinase - CK) e de lesão hepática (Aspartato Aminotransferase - AST e Alanina Aminotransferase - ALT). As análises foram feitas pelo método cinético (UV-IFCC), utilizando o analisador bioquímico Opera (Bayer®) e kits reagentes da Labtest ${ }^{\circledR}$. Para todas as análises adotou-se 12 horas de jejum e 72 horas de repouso, a fim de se obter os resultados do estado basal do animal. 
Imediatamente após a coleta de sangue, os animais foram eutanasiados pelo método de decapitação em guilhotina, seguida da retirada da musculatura esquelética. Foram retirados os músculos sóleo, gastrocnêmio e extensor longo dos dedos (EDL) do membro pélvico direito, que foram pesados e, posteriormente, congelados em n-Hexano resfriado e estocados em bujão de nitrogênio líquido a $-180^{\circ}$. Para o congelamento foram reservadas as porções do ventre central dos músculos sóleo e EDL, sendo que o músculo gastrocnêmio foi fragmentado em suas porções superficial e profunda, tendo sido reservado para análise o ventre central da porção superficial (Gastrocnêmio Superficial - GS). Estes músculos foram escolhidos devido às suas diferenças metabólicas, ou seja, músculos predominantemente oxidativos (sóleo) ou glicolíticos (EDL e GS), uma vez que estudos prévios verificaram seletividade muscular na ação da estatina $^{(6,11)}$.

Para preparação das lâminas os fragmentos musculares foram seccionados pelo método de cortes semi seriados, com obtenção de 3 cortes de $8 \mu \mathrm{m}$ a cada $50 \mu \mathrm{m}$; tais secções foram realizadas em micrótomo criostato (HM 505 E - Microm) a $-20^{\circ} \mathrm{C}$. Os cortes obtidos foram corados pelo método de Hematoxilina e Eosina (HE) e submetidos ao método histoquímico de demonstração da atividade Nicotinamida Adenina Dinucleotídeo Tetrazólio Reductase $(\mathrm{NADH}-\mathrm{TR})^{(20)}$; as análises das lâminas foram feitas no microscópio ótico Zeiss Jenapol (Carl Zeiss®).

Os cortes em HE foram utilizados para análise qualitativa, na qual se avaliou a morfologia geral do fragmento observando-se a forma e o tamanho das fibras, a posição dos núcleos, a coloração do sarcoplasma, presença de splitting e de processos degenerativos. A gravidade da degeneração foi graduada subjetivamente em mínima, leve, moderada e intensa, baseada na intensidade e/ou área das mudanças degenerativas por corte realizado ${ }^{(7,11)}$. 
Os cortes com reação histoenzimológica para NADH-TR foram utilizados para verificação da função mitocondrial, avaliando-se a intensidade da reação pelo teor de formazana no sarcoplasma, que indica a presença da atividade oxidativa ${ }^{(20)}$. Além disso, fez-se a análise quantitativa, que consistiu na contagem e na avaliação morfométrica do menor diâmetro das diferentes fibras musculares, com finalidade de avaliar a ocorrência de hipertrofia ou atrofia nas fibras musculares ${ }^{(20)}$ (software Image Pro-Plus - Media Cybernetics, Silver Spring, MD).

Para a análise do menor diâmetro do músculo sóleo utilizou-se o valor médio da medida de 120 fibras por animal ${ }^{(20)}$, não havendo diferenciação dos tipos de fibra uma vez que foi considerado totalmente oxidativo. Para os músculos EDL e GS, foi feita a mensuração e contagem de todas as fibras da secção escolhida, tendo sido utilizado para análise também o valor médio das medidas obtidas para cada tipo de fibra por animal. No GS foram considerados apenas as fibras tipo I e tipo II, sem fazer distinções entre IIa ou IIb.

Os dados quantitativos obtidos foram analisados pelo programa estatístico SPSS 13.0 for Windows, e foram primeiramente submetidos ao teste de normalidade (Shapiro-Wilk). A partir dos resultados da normalidade, a diferença entre os grupos foi mensurada pela análise de variância (ANOVA-One Way) para dados normais, seguido do pós teste de Tukey, ou pelo teste de Kruskal-Wallis para dados não normais. Para todas as análises utilizou-se nível de significância de $\mathrm{p}<0,05$.

\section{Resultados}

Durante o protocolo experimental foram a óbito três animais do grupo medicado e exercitado; um deles apresentou inquietude na prática da atividade física na parte da manhã, caracterizada pelo instinto de fuga, indo a óbito no período da tarde. Dentre os 
demais animais, um ocorreu sem causa aparente, e o outro com suspeita de pneumonia. Estes animais foram repostos. Já no grupo placebo sedentário, dois animais não resistiram ao procedimento da punção cardíaca no T1, porém não foram repostos; assim, este grupo ficou com apenas 12 animais, tendo sido prejudicada a fase de descontinuidade, uma vez que contou com apenas 4 animais.

\section{Observações clínicas}

A observação dos sinais clínicos associados à atividade física em esteira indicou a presença de comportamentos de fuga ou recusa ao esforço pelos animais, que podem indicar desconforto ou fraqueza dos membros; porém, tanto o número de ocorrências quanto o número de animais acometidos por esse comportamento foram reduzidos em todos os grupos estudados, não se podendo afirmar que as intervenções interferiram na prática da atividade física (Tabela 1).

\section{INSERIR TABELA 1}

\section{Parâmetros bioquímicos}

Os valores obtidos nas variáveis bioquímicas creatina fosfoquinase (CK), alanina aminotransferase (ALT) e aspartato aminotransferase (AST) estão apresentados na figura 1. Verificou-se que as variáveis apresentaram alto valor de desvio padrão, sendo que a análise de variância indicou que não houve diferença significante entre os grupos em nenhuma das três variáveis estudadas.

\section{INSERIR FIGURA 1}

\section{Efeitos no peso corporal e muscular}

A análise da comparação do peso corporal final, bem como do peso dos músculos sóleo, gastrocnêmio e EDL entre os diferentes grupos estudados, indicou que 
não houve diferença entre os grupos nas quatro semanas de utilização do medicamento, independente da intervenção. Além disso, a descontinuidade do medicamento ou placebo não alterou significantemente os valores de pesos, também não havendo diferenças entre os diferentes grupos estudados (tabela 2).

\section{INSERIR TABELA 2}

\section{Efeitos na histologia muscular}

A análise das lâminas indicou que os animais de todos os grupos, em ambos os períodos, apresentaram alterações caracterizadas por infiltrados inflamatórios perimisiais e endomisiais, fibras em processo degenerativo, e presença de núcleos internalizados e splittings (figura 2). Verificou-se que a quantidade de fibras que apresentaram estas alterações foi maior nos animais exercitados, tanto placebo quanto medicado, em ambos os períodos de intervenção, acometendo principalmente o músculo sóleo; nestes, verificou-se uma incidência de 10 a 20\% de núcleos internalizados, além de cerca de 20 a 30 fibras em processo de splitting por animal em toda extensão do corte.

\section{INSERIR FIGURA 2}

A análise quantitativa dos aspectos morfológicos, apresentados na tabela 3 , confirma que o músculo sóleo foi o mais comprometido, tanto no que diz respeito à quantidade de animais que apresentaram alterações, quanto na intensidade com que elas ocorreram. Verificou-se que o comprometimento das fibras foi diretamente relacionado ao tipo de intervenção a que o animal foi exposto, apresentando também diferenças no padrão de alterações. Nesse sentido, os animais exercitados placebo ou medicados apresentaram alterações mais intensas, e o grau de degeneração variou de mínimo a 
moderado, comparado aos animais somente medicados, o qual variou de mínimo a leve. Essa tendência foi mantida mesmo após o período de descontinuidade do medicamento.

\section{INSERIR TABELA 3}

Nos demais tecidos, verificou-se que o EDL foi o menos atingido, apresentando intensidade mínima de degeneração em todos os grupos em ambos os períodos de intervenção. Tal característica foi semelhante no músculo gastrocnêmio superficial, se diferenciando apenas pela maior quantidade de animais acometidos por processo degenerativo, e pela presença de degeneração leve no animal 48 no período de quatro semanas.

\section{Efeitos na histoquímica muscular}

A análise das lâminas com reação de NADH-TR indicou que houve alterações leves na maior parte dos grupos estudados. De maneira geral, para todos os músculos a reação obtida foi homogênea, apresentando agregados de formazana principalmente nas fibras oxidativas (Figura 3).

Dos três músculos estudados, o sóleo foi o que mais apresentou fibras com perda de atividade enzimática, ocorrendo com maior frequência e intensidade nos grupos exercitados, tanto placebo quanto medicados, em ambos os períodos de 4 semanas e de descontinuidade. Pôde-se verificar que estas alterações estiveram mais presentes nas fibras que sofreram splittings.

\section{INSERIR FIGURA 3}

Por sua vez, o músculo EDL apresentou menor quantidade de fibras com perda de reação, porém grande parte dos animais medicados e exercitados apresentou agregados de formazana em posição subsarcolemal bem intensos. Em contrapartida, 
poucas alterações foram encontradas no GS, sendo os grupos exercitados placebo ou medicamento os mais acometidos.

\section{Morfometria muscular}

A medida de menor diâmetro das fibras dos diferentes músculos estudados foi feita a partir da reação histoquímica de NADH-TR, considerando as diferenças metabólicas de cada um. Os valores de diâmetro bem como a porcentagem de cada tipo de fibra em cada músculo são apresentados como média seguida do respectivo desviopadrão na tabela 4.

\section{INSERIR TABELA 4}

De acordo com os resultados da análise de variância, verificou-se que não houve diferença nos valores de menor diâmetro entre os diferentes grupos estudados após o período de quatro semanas de intervenção, bem como após a descontinuidade do uso do medicamento ou placebo. Além disso, verificou-se que as intervenções utilizadas não exerceram influências na porcentagem dos tipos de fibra nos músculos EDL e GS, uma vez que não houve diferença significante entre os grupos experimentais.

\section{Discussão}

Verificou-se nesse estudo o efeito de um programa de atividade física associada ou não ao tratamento com estatina, bem como a descontinuidade do medicamento com a continuidade do esforço, por meio de parâmetros bioquímicos relacionados à condição muscular, além de avaliações qualitativas e quantitativas da morfologia do tecido e da histoquímica relacionada à função mitocondrial.

Apesar da creatina fosfoquinase (CK) ser o parâmetro clínico recomendado para identificação e acompanhamento das injúrias musculares pelas estatinas ${ }^{(4)}$, ainda há 
muita controvérsia acerca de seu uso. Isso porque os estudos mostram que não há uma relação estabelecida entre as manifestações clínicas e os valores de CK encontrados nos pacientes, podendo haver manifestações clínicas sem aumento das enzimas, assim como aumento das enzimas sem manifestações clínicas ${ }^{(21,22)}$.

Os resultados da enzima CK obtidos neste estudo vêm reforçar essa discussão, visto que não foram encontrados valores aumentados de $\mathrm{CK}$ para os grupos que apresentaram alterações mais intensas na morfologia muscular. Além disso, a análise de variância indicou que não houve diferença significante entre os grupos estudados, indicando que o uso de estatina não elevou os níveis de CK. Apesar de essa variável ter apresentado um desvio padrão elevado, o que poderia ter influenciado os resultados estatísticos encontrados, a ausência de elevação de CK poderia estar relacionado à forma de lesão provocada pelas estatinas.

De maneira geral as lesões musculares desencadeadas pelo uso das estatinas estão restritas ao espaço intracelular, envolvendo principalmente o sistema de túbulos T sem comprometer o sarcolema ${ }^{(22)}$. Visto que a CK é uma enzima intracelular, somente a lesão sarcolemal poderia acarretar no seu extravasamento para o meio extracelular e, consequentemente, no aumento de seus níveis séricos; como a estatina não lesa sarcolema, justifica-se o não aumento desses níveis.

Nesse sentido, a análise direta do tecido muscular, quando possível, se faz de extrema importância, uma vez que se pode avaliar com maior fidedignidade a presença de lesões e sua intensidade. No caso do uso das estatinas, alguns trabalhos que avaliaram seus efeitos sobre o tecido muscular verificaram a presença de alterações degenerativas como necrose e fagocitose, ocorrendo cerca de dez dias após seu uso e acometendo principalmente as fibras do tipo $\mathrm{IIb}^{(6,7)}$. Verificou-se ainda que nestas fibras a mitocôndria é a primeira organela que apresenta alterações morfológicas, porém os 
autores não conseguiram encontrar justificativas para a seletividade da lesão por estatinas. Além disso, nesses estudos houve aumento dos níveis de CK após o décimo dia do uso das estatinas, fato que pode estar relacionado à dose de estatina administrada, visto que em ambos foi utilizada a máxima dose tolerada de $\operatorname{rosuvastatina}^{(7)}$, sinvastatina e cerivastatina ${ }^{(6)}$.

No presente estudo verificou-se que os animais medicados (MS) apresentaram alterações histológicas mais intensas que os animais que usavam placebo (PS). Apesar das evidências, as formas de desencadeamento de lesão muscular por estatina não são bem definidas, havendo teorias sobre as alterações na excitabilidade da membrana celular, devido à redução da quantidade de colesterol de membrana; alterações mitocondriais, devido à redução de intermediários da cadeia respiratória (Ubiquinona Coenzima Q10); e ocorrência de apoptose, devido ao aumento de cálcio citosólico e, consequentemente, ativação de sua sinalização via mitocondrial ${ }^{(23,24)}$.

As evidências das pesquisas indicam que provavelmente o prejuízo mitocondrial poderia interferir na regulação do cálcio citosólico, causando apoptose e degeneração das fibras musculares pelas estatinas ${ }^{(23,25)}$. De fato, alguns trabalhos apontam que o uso das estatinas acarreta em lesão mitocondrial ${ }^{(6,7,26)}$.

No presente trabalho, a atividade mitocondrial foi analisada pela reação NADHTR mostrando que nos animais medicados houve maior ocorrência de fibras com perda de reação em relação aos animais placebo, indicando efeito do medicamento na mitocôndria. Entretanto, as alterações morfológicas e histoquímicas ocorreram com maior frequência e intensidade nos animais exercitados, principalmente com uso de medicamento.

A atividade física por si só está relacionada à ocorrência de microlesões na musculatura esquelética que, por sua vez, causam processos $\operatorname{adaptativos}^{(27,28)}$, 
modificando tanto a forma como a estrutura das fibras, bem como promovendo resposta inflamatória. Nesse sentido, os resultados da presente pesquisa sugerem que o tecido muscular está em processo de adaptação ao maior estresse imposto pela associação de dois fatores lesivos, sendo que tais alterações podem estar relacionadas ao fornecimento energético celular uma vez que foram encontradas alterações mitocondriais, fatos verificados pelas análises histológica e histoquímica.

Na pesquisa de Seachrist et al. (2005) $)^{(11)}$, desenvolvida a fim de verificar os mecanismos desta exacerbação da lesão muscular, foi estudado o efeito da administração de cerivastatina concomitante à prática de exercício em esteira na musculatura de ratos. Os autores verificaram que esta interação acarretou na exacerbação das alterações, que foram caracterizadas como moderadas e incluiu presença de núcleos internalizados, fragmentação de sarcoplasma, vacúolos, presença de infiltrado de células inflamatórias, degeneração e lesão de mitocôndria principalmente nas fibras tipo II, sendo esta o efeito primário da estatina na fibra. De acordo com os autores, os resultados obtidos indicaram que a exacerbação da lesão muscular observada não ocorreu em decorrência de maior concentração do medicamento na musculatura ativa, mas sim pelo metabolismo oxidativo prejudicado, uma vez que a lesão mitocondrial se fez presente ${ }^{(11)}$.

No presente estudo, verificou-se que as alterações morfológicas encontradas estão de acordo com as alterações do trabalho de Seachrist et al. (2005) ${ }^{(11)}$, onde se verificou maior intensidade das degenerações para o grupo medicado e exercitado em comparação com os demais grupos. Todavia, algumas diferenças podem ser destacadas, como a menor intensidade das alterações relatadas no presente estudo, assim como o músculo mais afetado possuir característica metabólica predominantemente oxidativa. 
Essas diferenças observadas entre os estudos podem estar relacionadas tanto ao medicamento utilizado quanto à intensidade do exercício a que o animal foi exposto. No trabalho supracitado ${ }^{(11)}$ a estatina administrada foi a cerivastatina, a qual foi retirada do mercado em 2006 pela alta taxa de óbito por rabdomiólise associada ao seu uso; além disso, os autores optaram por utilizar uma concentração de medicamento previamente verificada como promotora de graves lesões musculares. Quanto ao esforço realizado, utilizou-se uma intensidade de $20 \mathrm{~m} / \mathrm{min}$ em esteira, enquanto que no presente estudo a velocidade não atingia os $10 \mathrm{~m} / \mathrm{min}$.

De maneira geral, é descrito na literatura que a descontinuidade do medicamento leva à cessação das alterações musculares ocasionadas pelo seu uso ${ }^{(4,5,29)}$. De fato, após duas semanas de descontinuidade do medicamento verificou-se que os animais sedentários apresentaram menos alterações em relação aos animais medicados sacrificados após 4 semanas e, portanto, que não sofreram descontinuidade. Por sua vez, os animais que continuaram se exercitando apresentaram mesmo padrão de alterações que aqueles que foram medicados por 4 semanas, sem descontinuidade, se diferenciando apenas pela maior quantidade de fibras com presença de núcleos internalizados e splittings.

Assim, apesar da intensidade das alterações não ter sofrido modificações, a maior presença de núcleos internalizados e splittings pode ser indicativo de processos regenerativos das fibras destes animais, sugerindo que a continuidade do esforço após cessação do medicamento não apresenta danos adicionais à musculatura, podendo tal estratégia ser utilizada nos casos em que a terapêutica medicamentosa possa ser interrompida.

A conduta acima proposta se faz interessante visto que a prática de atividade física também está relacionada à adequação do perfil lipídico, podendo reduzir os níveis 
de triglicérides, colesterol total e suas frações maléficas, bem como aumentar os níveis da sua fração benéfica. Dessa forma, além da otimização dessas alterações por meio do uso conjunto de estatinas e atividade física ${ }^{(15,16)}$, a cessação do medicamento com a continuidade do esforço poderia resultar em melhora ou, no mínimo, manutenção dos níveis lipídicos, sendo esta uma proposta pertinente de estudo.

Em síntese, a descontinuidade do uso do medicamento com a continuidade da atividade física leve resultou na manutenção das alterações musculares verificadas nos animais submetidos a essa combinação, estimulando ainda processos regenerativos da musculatura considerados respostas normais ao exercício, caracterizando assim um quadro benéfico ao organismo. Tais resultados sugerem que a prática de atividade física leve pode ser coadjuvante no tratamento com as estatinas, podendo, no âmbito muscular, ser mantida mesmo com a cessação do seu uso.

\section{Agradecimentos}

Agradecemos o Laboratório de Análises Clínicas da Universidade do Oeste Paulista (Unoeste) pela realização das análises deste trabalho; o técnico de laboratório Sidney Siqueira Leirião pela colaboração no desenvolvimento da pesquisa; e a Coordenação do Curso de Mestrado em Fisioterapia da Universidade Estadual Paulista (Unesp) campus de Presidente Prudente pelo apoio durante a realização deste trabalho.

\section{Referências}

1. Sociedade Brasileira de Cardiologia. IV Diretrizes brasileira sobre dislipidemias e prevenção da aterosclerose. Arquivos Brasileiros de Cardiologia. 2007; 88(1):2-19. 
2. Third report of the national cholesterol education program (NCEP) expert panel on detection, evaluation, and treatment of high blood cholesterol in adults (Adult Treatment Panel III) final report. Circulation. 2002;106:3143-3421.

3. Goldenberg N, Glueck C. Efficacy, effectiveness and real life goal attainment of statins in managing cardiovascular risk. Vascular Health and Risk Management. 2009;5:369-376.

4. Thompson PD, Clarkson PM, Rosenson RS. An assessment of statin safety by muscle experts. The American Journal of Cardiology. 2006; 97(8A).

5. Joy TR, Hegele RA. Narrative review: statin-related myopathy. Annals of Internal Medicine. 2009; 150:858-868.

6. Westwood FR, Bigley A, Randall K, Marsden AM, Scott RC. Statin-induced muscle necrosis in the rat: distribution, development, and fibre selectivity. Toxicol Pathol. 2005;33(2):246-257.

7. Westwood FR, Scott RC, Marsden AM, Bigley A, Randall K. Rosuvastatin: characterization of induced myopathy in the rat. Toxicologic Pathology. 2008; $36: 345$.

8. Bruckert E, Hayem G, Dejager S, Yau C, B’egaud B. Mild to moderate muscular symptoms with high-dosage statin therapy in hyperlipidemic patients - the primo study. Cardiovascular Drugs and Therapy. 2005; 19:403-414.

9. Franc S, Dejager S, Bruckert E, Chauvenet M, Giral P, Turpin G. A Comprehensive description of muscle symptoms associated with lipid-lowering drugs. Cardiovascular Drugs and Therapy. 2003;17:459-465.

10. Sinzinger H, O’Grady J. Professional athletes suffering from familial hypercholesterolaemia rarely tolerate statin treatment because of muscular problems. British Journal of Clinical Pharmacology. 2004;57(4):525-528. 
11. Seachrist JL, Loi C, Evans MG, Criswell KA, Rothwell CE. Roles of exercise and pharmacokinetics in cerivastatin-induced skeletal muscle toxicity. Toxicological Sciences. 2005; 88(2):551-561.

12. Kearns AK, Bilbie CL, Clarkson PM, White CM, Sewright KA, O’Fallon KS, et. al. The creatine kinase response to eccentric exercise with atorvastatin $10 \mathrm{mg}$ or 80 mg. Atherosclerosis. 2008;200:121-125.

13. Thompson PD, Zmuda JM, Domalik LJ, Zimet RJ, Staggers J, Guyton JR. Lovastatin increases exercised-induced skeletal muscle injury. Metabolism. 1997; 46(10):1206-1210.

14. Pierno S, Didonna MP, Cippone V, De Luca A, Pisoni M, Frigeri A, Nicchia GP, Svelto M, Chiesa G, Sirtori C, Scanziani E, Rizzo C, De Vito D, Camerino DC. Effects of chronic treatment with statins and fenofibrate on rat skeletal muscle: a biochemical, histological and electrophysiological study. British Journal of Pharmacology. 2006;149:909-919.

15. Wittke R. Effect of fluvastatin in combination with moderate endurance training on parameters of lipid metabolism. Sports Medicine Institute. 1999; 27(5):329-335.

16. Coen PM, Flynna MG, Markofskia MM, Pencea BD, Hannemannb RE. Adding exercise training to rosuvastatin treatment: influence on serum lipids and biomarkers of muscle and liver damage. Metabolism Clinical and Experimental. 2009; 58:1030-1038.

17. Manchado FB, Gobatto CA, Contarteze RVL, Papoti M, Mello MAR. Máxima fase estável de lactato é ergômetr-dependente em modelo experimental utilizando ratos. Rev Bras Med Esporte. 2006;12(5):259-262. 
18. Manchado FB, Gobatto CA, Contarteze RVL, Papoti M, Mello MAR. Maximal lactate steady state in running rats. Journal of Exercise Physiology Online. 2005;5(4): 29-35.

19. Padulla AST, Azoubel R, Bonfim MR, Accioly MF, Camargo Filho JCS, Padovani JA, Souza DRS. Effects of statin and aerobic physical exercise association in the cardiomyocites of the rat: morphometric study. Int J Morphol. 2009;27(1):83-88.

20. Dubowitz V, Sewry CA. Histological and histochemical stains and reactions. In: Dubowitz V, Sewry CA, Muscle biopsy: a practical approach. 3rd ed. Elsevier; 2007. p 21-39.

21. Glueck CJ, Rawal B, Khan NA, Yeramaneni S, Goldenberg N, Wang P. Should high creatine kinase discourage the initiation or continuance of statins for the treatment of hypercholesterolemia? Metabolism Clinical and Experimental. 2009; $58: 233-238$.

22. Mohaupt MG, Karas RH, Babiychuk EB, Sanchez-Freire V, Monastyrskaya K, Iyer L, et al. Association between statin-associated myopathy and skeletal muscle damage. CMAJ. 2009;181:E11-E18.

23. Vaklavas C, Chatzizisis YS, Ziakas A, Zamboulis C, Giannoglou GD. Molecular basis of statin-myopathy. Atherosclerosis. 2009;202:18-28.

24. Dirks AJ, Jones KM. Statin-indiced apoptosis and skeletal muscle myopathy. Am J Physiol Cell Physiol. 2006;291:C1208-1212.

25. Sirvent P, Mercier J, Lacampagne A. New insights into mechanisms of statinassociated myotoxicity. Curr Pharmacol. 2008;3:333-338.

26. Schaefer WH, Lawrence JW, Loughlin AF, Stoffregen DA, Mixson LA, Dean DC, et. al. Evaluation os ubiquinone concentration and mitochondrial function relative 
to cerivastatin-induced skeletal myopathy in rats. Toxicol Appl Pharmacol. 2004;194:10-23.

27. Camargo Filho JCS, Vanderlei LCM, Camargo RCT, Francischeti FA, Belangero WD, Dal Pai V. Efeitos do esteróide anabólico nandrolona sobre o músculo sóleo de ratos submetidos a treinamento físico através de natação: estudo histológico, histoquímico e morfométrico. Rev Bras Med Esporte. 2006; 12(5).

28. Ciabattari O, Dal Pai A, Dal Pai V. Effect of swimming associated with diet on the anterior tibial muscle of rats: morphological and hystochemical study. Rev Bras Med Esporte. 2005; 11(2).

29. Venero CV, Thompson PD. Managing statin myopathy. Endocrinol Metab Clin N Am. 2009;38:121-136. 
TABELA 1.

Tabela 1. Observações clínicas durante a caminhada na esteira.

\section{Intervenções}

\begin{tabular}{lcccc}
\cline { 2 - 5 } Observações & Placebo & Atorvastatina & $\begin{array}{c}\text { Descontinuidade } \\
\text { Placebo }\end{array}$ & $\begin{array}{c}\text { Descontinuidade } \\
\text { Atorvastatina }\end{array}$ \\
\hline Recusa ou fuga ao Esforço & & & & \\
\# Observações & 3 & 3 & 4 & 7 \\
\# Animais & $1^{\mathrm{b}}$ & $3^{\mathrm{b}}$ & $1^{\mathrm{c}}$ & $1^{\mathrm{c}}$
\end{tabular}

\footnotetext{
${ }^{\mathrm{a} A n i m a i s ~ q u e ~ t e n t a v a m ~ s a i r ~ d e ~ s u a s ~ r a i a s ~ e ~ d a ~ e s t e i r a ~ o u ~ q u e ~ f i c a v a m ~ a p e n a s ~ a p o i a d o s ~}$ no final da esteira durante a realização do esforço; ${ }^{b} n=8 ;{ }^{c} n=6$.
} 


\section{FIGURA 1.}
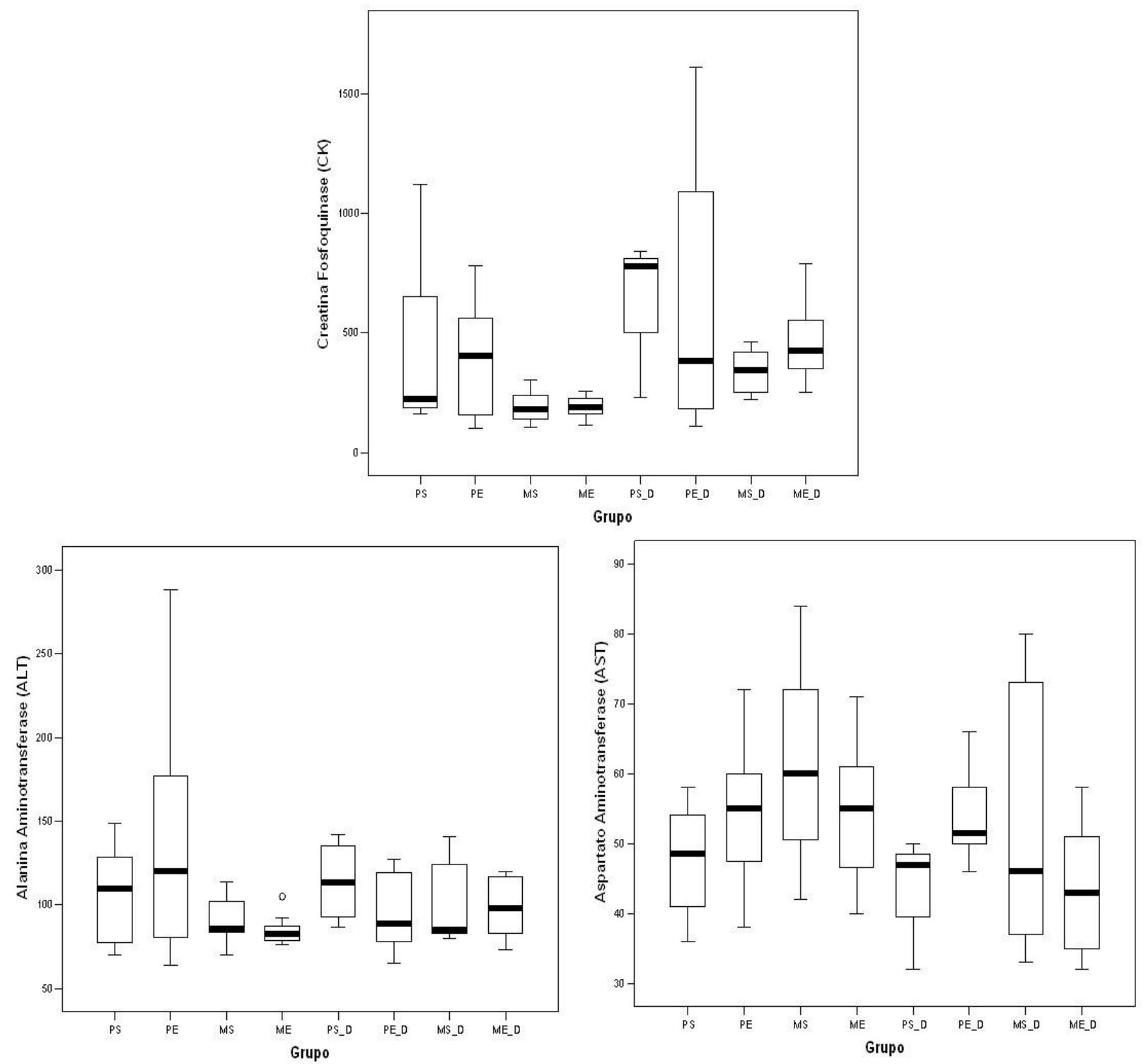

Figura 1. Parâmetros bioquímicos séricos (U/L) após as intervenções.

PS = Placebo Sedentário; PE = Placebo Exercitado; MS = Medicamento Sedentário; $\mathrm{ME}=$ Medicamento Exercitado $;$ PS_D = Placebo Sedentário Descontinuidade $;$ PE_D = Placebo Exercitado Descontinuidade; MS_D = Medicamento Sedentário Descontinuidade; ME_D = Medicamento Exercitado Descontinuidade. 
TABELA 2.

Tabela 2. Peso corporal e muscular dos grupos estudados após intervenções.

\begin{tabular}{ccccc}
\hline Grupos & Peso Corporal $(\mathbf{g})$ & Sóleo $(\mathbf{g})$ & GS $(\mathbf{g})$ & EDL $(\mathbf{g})$ \\
\hline 4 semanas de medicamento & & & \\
PS & $467,81 \pm 57,60$ & $0,22 \pm 0,03$ & $3,00 \pm 0,38$ & $0,20 \pm 0,03$ \\
PE & $433,04 \pm 25,01$ & $0,23 \pm 0,03$ & $2,56 \pm 0,16$ & $0,20 \pm 0,02$ \\
MS & $448,00 \pm 54,51$ & $0,23 \pm 0,04$ & $2,82 \pm 0,40$ & $0,21 \pm 0,03$ \\
ME & $478,35 \pm 31,67$ & $0,25 \pm 0,02$ & $2,98 \pm 0,22$ & $0,22 \pm 0,02$ \\
\hline Descontinuidade do medicamento & & & \\
PS & $486,18 \pm 33,72$ & $0,23 \pm 0,02$ & $2,85 \pm 0,10$ & $0,22 \pm 0,02$ \\
PE & $479,58 \pm 45,94$ & $0,27 \pm 0,03$ & $2,98 \pm 0,30$ & $0,20 \pm 0,05$ \\
MS & $475,90 \pm 39,70$ & $0,22 \pm 0,04$ & $2,72 \pm 0,32$ & $0,20 \pm 0,03$ \\
ME & $430,38 \pm 59,95$ & $0,21 \pm 0,04$ & $2,56 \pm 0,31$ & $0,17 \pm 0,05$ \\
\hline PS = Placebo Sedentário; PE = Placebo Exercitado; MS $=$ Medicamento Sedentário; & & \\
ME = Medicamento Exercitado. & & &
\end{tabular}




\section{FIGURA 2}

Figura 2. Secção transversal do músculo sóelo (A-D), extensor longo dos dedos (EDL E e F) e gastrocnêmio superficial $(\mathrm{G}$ e $\mathrm{H})$. Amostras dos animais placebo exercitado (A e E) e descontinuidade (B); estatina exercitado (C e G) e descontinuidade (D, F e H).

Hemattoxilina e Eosina (HE). In = Infiltado Inflamatório; * = Fibra em degeneração; Seta cheia $=$ Núcleo Internalizado $;$ Seta Vazada $=$ Splitting. $500 \mathrm{X}$. 


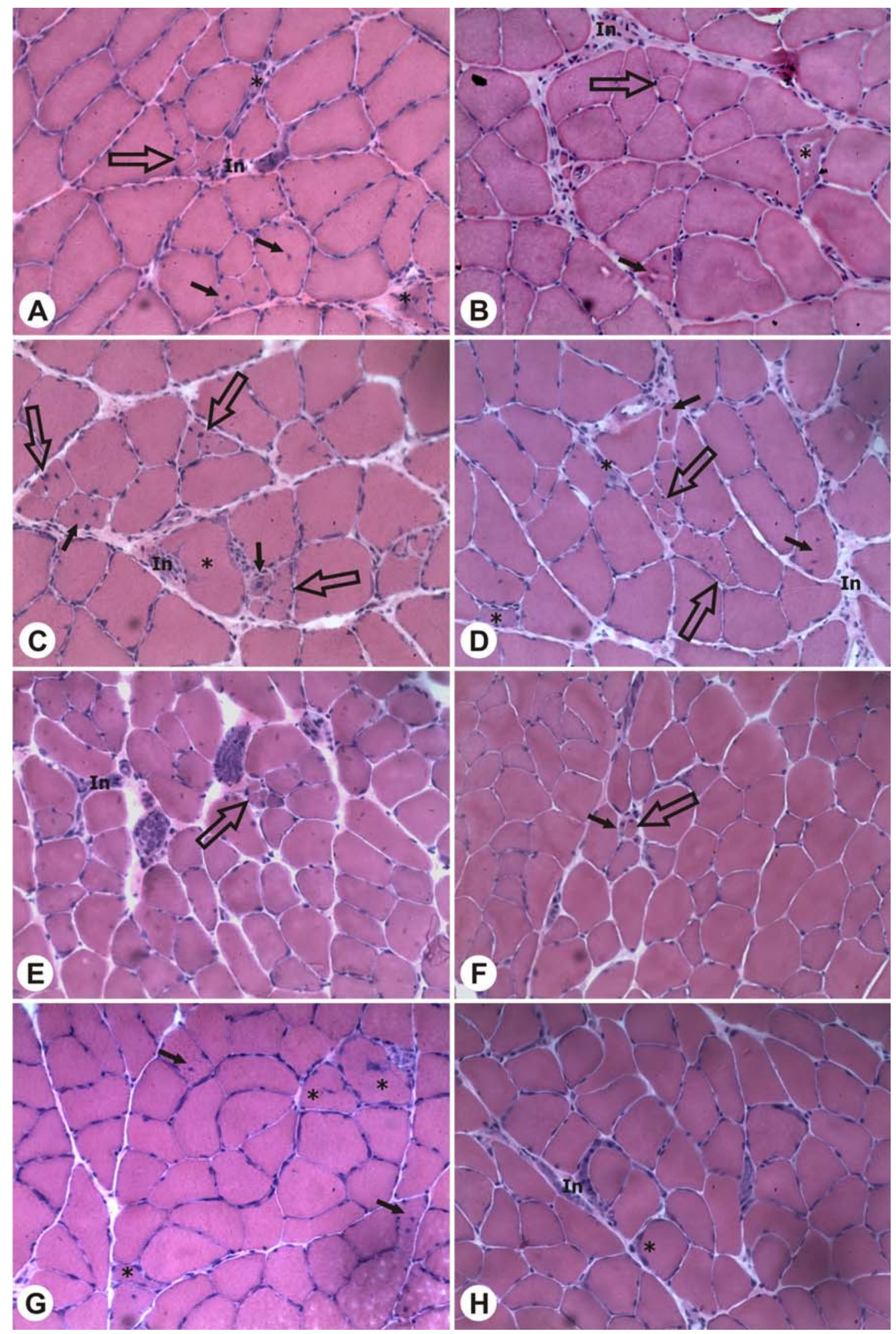




\section{TABELA 3}

Tabela 3. Incidência e severidade das alterações degenerativas das fibras musculares dos grupos estudados.

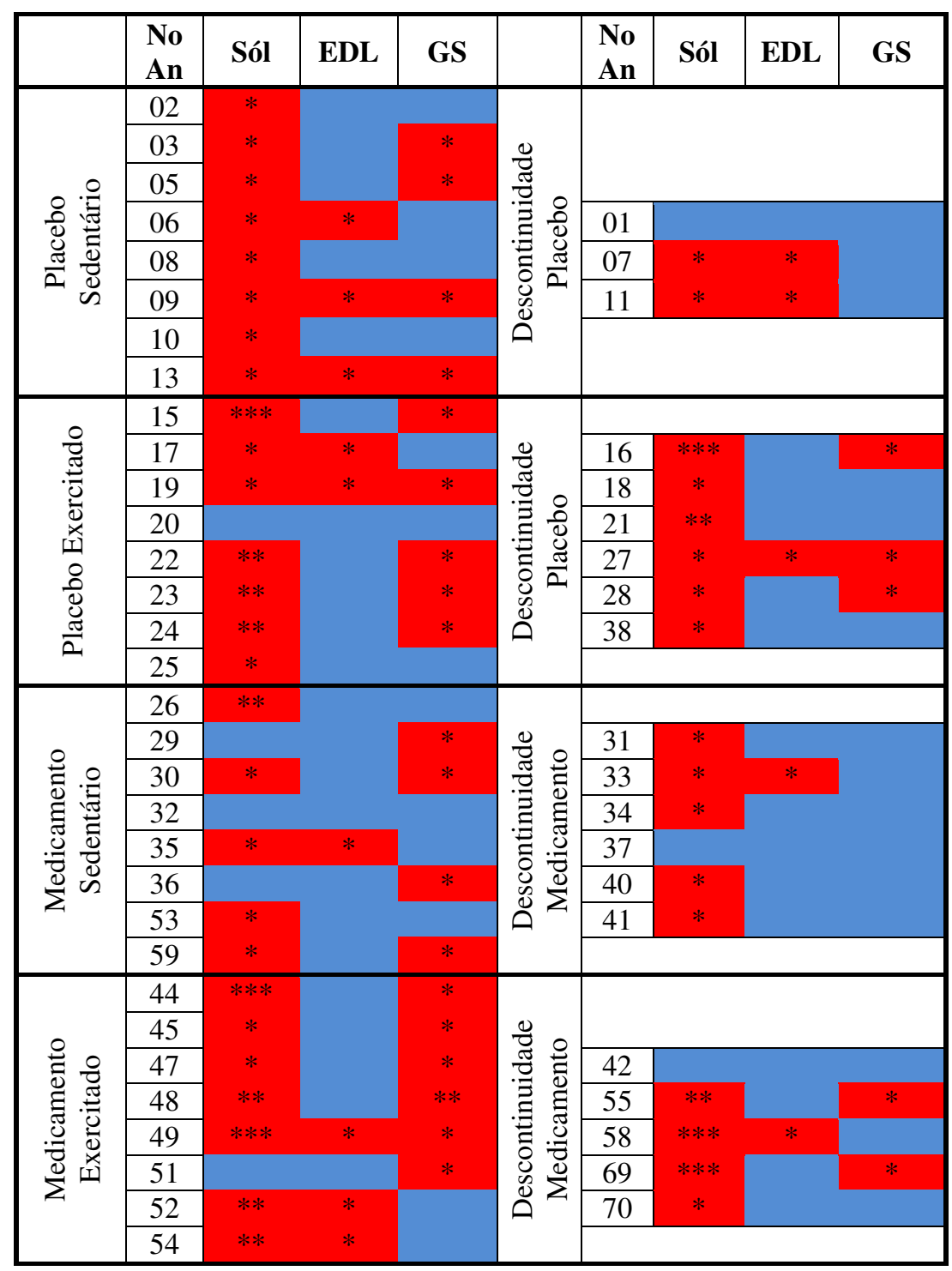

Sól = Sóleo; EDL = Extensor Longo dos Dedos; GS = Gastrocnêmio Superficial. No An = Número do Animal. Vermelho = Presença de Necrose. Azul = Ausência de Necrose. *Mínima alteração; **Leve alteração; ***Moderada alteração. 


\section{FIGURA 3.}

Figura 3. Secção transversal do músculo sóelo (A-F) e extensor longo dos dedos (EDL

- $\mathrm{G}$ e H). Amostras dos animais placebo exercitado (A e G) e descontinuidade (B); estatina sedentário (C) e descontinuidade (D); estatina exercitado (E) e descontinuidade (F e H). NADH-TR. Setas = Fibras com perda de reação. 500X. 


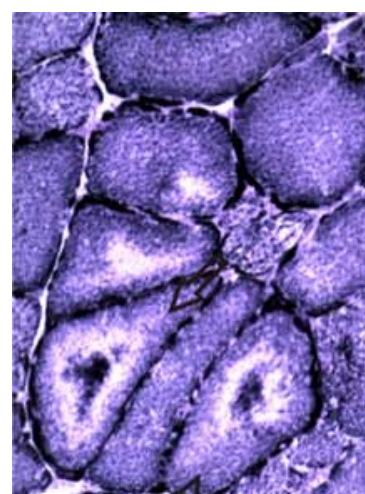

(A)

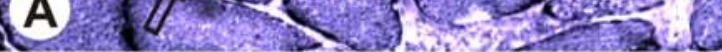
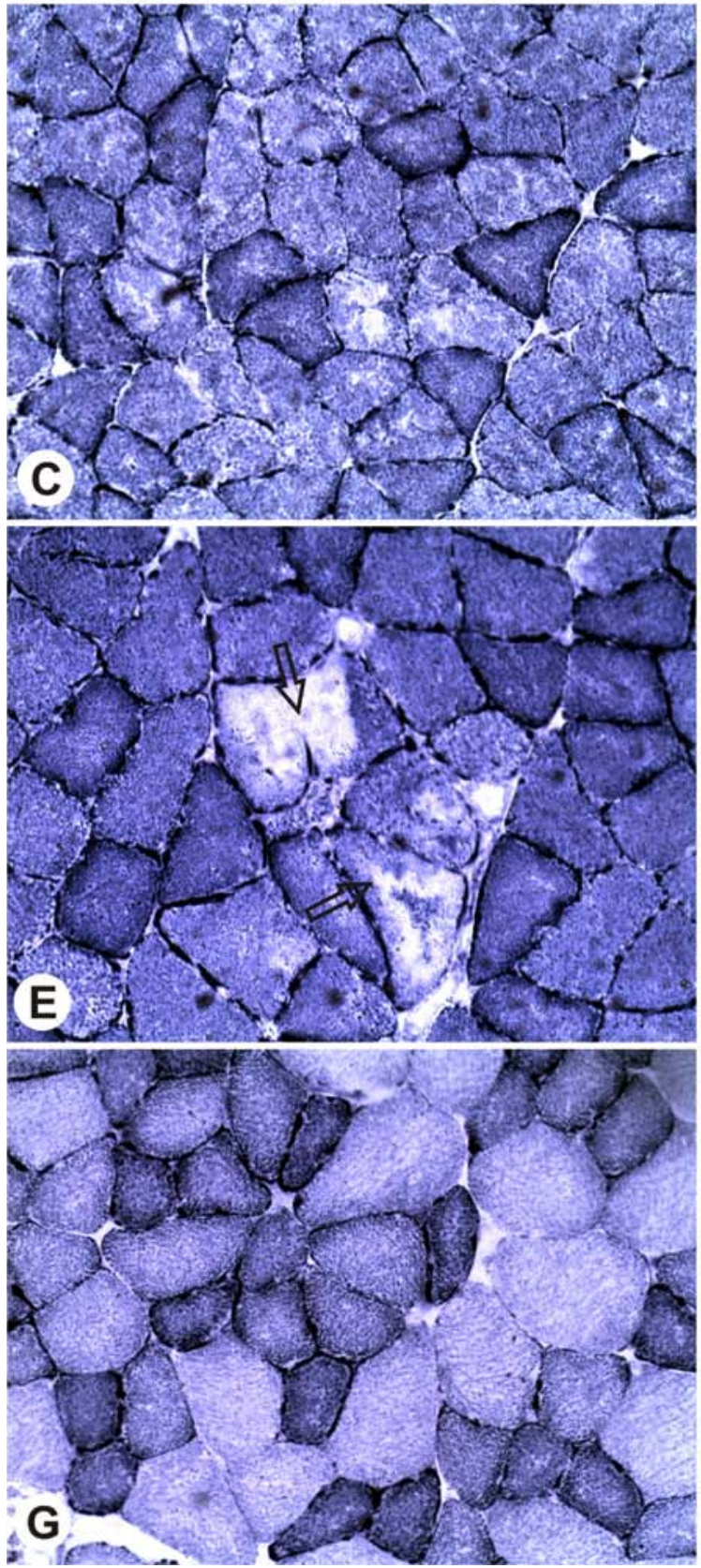
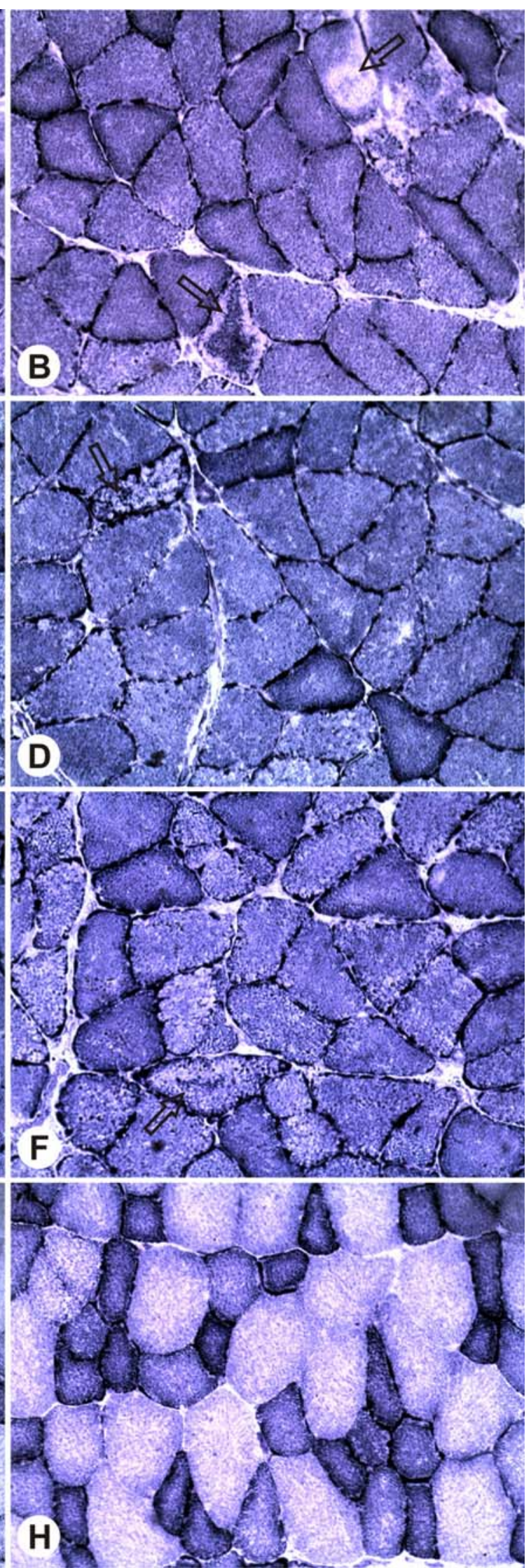
TABELA 4

Tabela 4. Valores do menor diâmetro das fibras $(\mu \mathrm{m})$ dos músculos estudados.

\begin{tabular}{|c|c|c|c|c|c|c|c|c|c|c|c|}
\hline & & \multirow{2}{*}{ Sól } & \multicolumn{6}{|c|}{ EDL } & \multicolumn{3}{|c|}{ GS } \\
\hline & & & I & $\% I$ & IIA & \% IIA & IIB & $\%$ III & $\mathbf{I}$ & II & $\%$ II \\
\hline \multicolumn{12}{|c|}{4 semanas de medicamento } \\
\hline \multirow{2}{*}{ PS } & $X$ & 54,41 & 31,67 & 21,21 & 39,52 & 38,50 & 56,50 & 40,29 & 43,61 & 59,49 & 97,87 \\
\hline & $\mathrm{DP}$ & 3,85 & 2,80 & 4,64 & 3,90 & 10,01 & 5,02 & 10,01 & 5,80 & 5,02 & 1,91 \\
\hline \multirow{2}{*}{ PE } & $\mathrm{X}$ & 54,62 & 30,24 & 20,71 & 36,57 & 33,67 & 52,20 & 45,62 & 42,57 & 56,33 & 96,43 \\
\hline & DP & 4,96 & 1,62 & 6,70 & 3,32 & 12,78 & 3,73 & 16,54 & 8,30 & 5,37 & 4,62 \\
\hline \multirow{2}{*}{ MS } & $X$ & 51,33 & 30,86 & 21,68 & 38,44 & 31,81 & 54,51 & 46,50 & 44,02 & 59,74 & 98,44 \\
\hline & DP & 5,29 & 2,52 & 3,13 & 4,20 & 7,35 & 3,36 & 8,57 & 7,77 & 3,86 & 3,73 \\
\hline \multirow{2}{*}{ ME } & $X$ & 56,94 & 33,54 & 17,06 & 40,05 & 28,40 & 59,88 & 54,54 & 46,20 & 61,13 & 94,35 \\
\hline & DP & 3,89 & 3,17 & 6,12 & 4,91 & 9,23 & 4,44 & 11,45 & 5,26 & 4,41 & 5,70 \\
\hline \multicolumn{12}{|c|}{ Descontinuidade do medicamento } \\
\hline \multirow{2}{*}{ PS } & $X$ & 48,60 & 31,36 & 20,24 & 37,35 & 38,89 & 59,86 & 40,87 & 40,52 & 57,09 & 98,05 \\
\hline & $\mathrm{DP}$ & 14,55 & 1,67 & 5,15 & 2,22 & 12,98 & 7,88 & 9,90 & $0^{\mathrm{a}}$ & 2,81 & 3,38 \\
\hline \multirow{2}{*}{ PE } & $X$ & 57,48 & 31,75 & 22,75 & 40,13 & 25,98 & 59,08 & 51,26 & 43,82 & 56,14 & 93,88 \\
\hline & $\mathrm{DP}$ & 3,25 & 1,32 & 8,77 & 1,93 & 14,15 & 5,57 & 21,22 & 2,50 & 1,65 & 9,33 \\
\hline \multirow{2}{*}{ MS } & $X$ & 54,17 & 33,93 & 17,07 & 40,84 & 31,36 & 60,91 & 51,56 & 44,33 & 59,29 & 98,59 \\
\hline & DP & 4,82 & 2,70 & 2,75 & 2,74 & 8,96 & 4,08 & 9,30 & 8,09 & 3,50 & 1,09 \\
\hline \multirow{2}{*}{ ME } & $X$ & 52,00 & 32,39 & 18,54 & 40,87 & 27,19 & 57,76 & 54,27 & 41,73 & 57,56 & 93,52 \\
\hline & DP & 2,92 & 2,59 & 4,94 & 3,22 & 5,76 & 10,17 & 4,91 & 3,61 & 5,19 & 3,60 \\
\hline
\end{tabular}

\footnotetext{
${ }^{\mathrm{a}}$ Apenas um animal apresentou fibras tipo I e, portanto, não há desvio padrão. Sól = Sóleo; EDL

$=$ Extensor Longo dos Dedos; GS = Gastrocnêmio Superficial. PS = Placebo Sedentário; PE = Placebo Exercitado; MS = Medicamento Sedentário; ME = Medicamento Exercitado.
} 


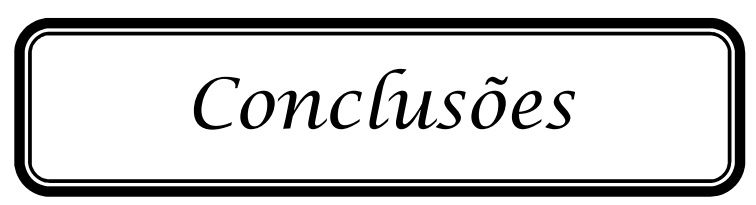


Em síntese, tomando o conjunto de resultados obtidos, o presente trabalho verificou que a adição da atividade física ao tratamento com estatinas alterou de forma positiva os níveis lipídicos sanguíneos, destacando-se o aumento significante de HDL-c, levando à ocorrência de alterações musculares de leves a moderadas. Além disso, verificou-se que a descontinuidade do medicamento com a continuidade da atividade física permitiu que não houvesse aumento das concentrações séricas dos lipídios, levando à melhora das alterações musculares estimulando processos regenerativos da musculatura.

Tais resultados sugerem que o uso da estatina em conjunto com a prática de atividade física promove efeitos benéficos no perfil lipídico que são sustentados até mesmo após a descontinuidade do fármaco, a qual também ameniza as alterações musculares provenientes desta interação. Sendo assim, pode-se considerar a prática de atividade física leve um coadjuvante no tratamento com as estatinas, que poderá ser mantida mesmo com a cessação do seu uso em casos onde haja a presença de lesões musculares pelo medicamento. 
Referências 
1. Framinghan Heart Study. Epidemiological background and design: the $\begin{array}{llll}\text { Framingham } & \text { study. }\end{array}$ http://www.framinghamheartstudy.org/about/background.html, acesso em Outubro de 2009.

2. Endo A. A gift from nature: the birth of the statins. Nat Med. 2008; 14(5):1050-1052.

3. Sociedade Brasileira de Cardiologia. IV Diretrizes brasileira sobre dislipidemias e prevenção da aterosclerose. Arq Bras Cardiol. 2007; 88(1):2-19.

4. Endo A. The origin of the statins. Atherosclerosis Supplements. 2004; $5: 125-130$

5. Hou R, Goldberg AC. Lowering Low-Density Lipoprotein Cholesterol: Statins, Ezetimibe, Bi le Acid Sequestrants, and Combinations: Comparative Efficacy and Safety. Endocrinol Metab Clin. 2009; 38:79-97.

6. Veillard NR, Mach F. Statins: the new aspirin?. Cel Mol Life Sci. 2002; 59:1771-1786.

7. Pasternak RC, Smith SC Jr, Bairey-Merz CN, Grundy SM, Cleeman JI, Lefant C, American College of Cardiology. ACC/AHA/NHLBI clinical advisory on the use and safety of statins. J Am Coll Cardiol. 2002;40:567572.

8. Goldenberg N, Glueck C. Efficacy, effectiveness and real life goal attainment of statins in managing cardiovascular risk. Vasc Health Risk Manag. 2009;5:369-376.

9. Brown WV. Safety of statins. Curr Opin Lipidol. 2008; 19:558-562. 
10. Joy TR, Hegele RA. Narrative review: statin-related myopathy. Ann Intern Med. 2009;150:858-868.

11. Thompson PD, Clarkson PM, Rosenson RS. An assessment of statin safety by muscle experts. Am J Cardiol. 2006; 97(8A).

12. Glueck CJ, Rawal B, Khan NA, Yeramaneni S, Goldenberg N, Wang P. Should high creatine kinase discourage the initiation or continuance of statins for the treatment of hypercholesterolemia? Metabolism. 2009; 58:233-238.

13. Thompson PD, Claekson P, Karas RH. Statin-associated myopathy. JAMA. 2003;289:1681-1690.

14. Sirvent $P$, Mercier J, Lacampagne A. New insights into mechanisms of statin-associated myotoxicity. Curr Pharmacol. 2008;3:333-338.

15. Dirks AJ, Jones KM. Statin-indiced apoptosis and skeletal muscle myopathy. Am J Physiol Cell Physiol. 2006;291:C1208-1212.

16. Vaklavas C, Chatzizisis YS, Ziakas A, Zamboulis C, Giannoglou GD. Molecular basis of statin-myopathy. Atherosclerosis. 2009;202:18-28.

17. Bruckert E, Hayem G, Dejager S, Yau C, B'egaud B. Mild to moderate muscular symptoms with high-dosage statin therapy in hyperlipidemic patients - the primo study. Cardiovasc Drugs Ther. 2005; 19:403-414.

18. Franc S, Dejager S, Bruckert E, Chauvenet M, Giral P, Turpin G. A Comprehensive description of muscle symptoms associated with lipidlowering drugs. Cardiovasc Drugs Ther. 2003;17:459-465.

19. Sinzinger H, O’Grady J. Professional athletes suffering from familial hypercholesterolaemia rarely tolerate statin treatment because of muscular problems. Br J Clin Pharmacol. 2004;57(4):525-528. 
20. Seachrist JL, Loi C, Evans MG, Criswell KA, Rothwell CE. Roles of exercise and pharmacokinetics in cerivastatin-induced skeletal muscle toxicity. Toxicol Sci. 2005; 88(2):551-561.

21. Coen PM, Flynna MG, Markofskia MM, Pencea BD, Hannemannb RE. Adding exercise training to rosuvastatin treatment: influence on serum lipids and biomarkers of muscle and liver damage. Metabolism. 2009; 58:10301038.

22. Wittke R. Effect of fluvastatin in combination with moderate endurance training on parameters of lipid metabolism. Sports Medicine Institute. 1999; 27(5):329-335. 


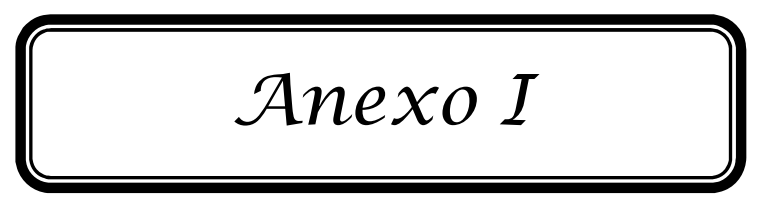




\title{
REVISTA DE NUTRIÇÃO
}

\author{
- INSTRUÇÕES AOS AUTORES -
}

\section{Escopo e Política}

A Revista de Nutrição/Brazilian Journal of Nutrition é um periódico especializado que publica artigos que contribuem para o estudo da Nutrição em suas diversas subáreas e interfaces; com periodicidade bimestral, está aberta a contribuições da comunidade científica nacional e internacional.

\section{Categoria dos Artigos}

A Revista aceita artigos inéditos em português, espanhol ou inglês, com título, resumo e termos de indexa-ção no idioma original e em inglês, nas seguintes categorias:

Original: contribuições destinadas à divulgação de resultados de pesquisas inéditas, tendo em vista a relevância do tema, o alcance e o conhecimento gerado para a área da pesquisa (limite máximo de 6 mil palavras).

Especial: artigos a convite sobre temas atuais (limite máximo de 7 mil palavras).

Revisão (a convite): síntese de conhecimentos disponíveis sobre determinado tema, mediante análise e interpretação de bibliografia pertinente, de modo a conter uma análise crítica e comparativa dos trabalhos na área, que discuta os limites e alcances metodológicos, permitindo indicar perspectivas de continuidade de estudos naquela linha de pesquisa (limite máximo de 8 mil palavras). Serão publicados até dois trabalhos por fascículo.

Comunicação: relato de informações sobre temas relevantes, apoiado em pesquisas recentes, cujo mote seja subsidiar o trabalho de profissionais que atuam na área, servindo de apresentação ou atualização sobre o tema (limite máximo de 5 mil palavras).

Nota Científica: dados inéditos parciais de uma pesquisa em andamento (limite máximo de 4 mil palavras).

Ensaio: trabalhos que possam trazer reflexão e discussão de assunto que gere questionamentos e hipóteses para futuras pesquisas (limite máximo de 5 mil palavras).

Seção temática (a convite): seção destinada à publicação de 2 a 3 artigos coordenados entre si, de diferentes autores, e versando sobre tema de interesse atual (máximo de 12 mil palavras no total).

Pesquisas envolvendo seres vivos

Resultados de pesquisas relacionadas a seres vivos devem ser acompanhados de cópia do parecer do Comitê de Ética da Instituição de origem, ou outro credenciado junto ao Conselho Nacional de Saúde. Além disso, deverá constar, no último parágrafo do item Métodos, uma clara afirmação do cumprimento dos princípios éticos contidos na Declaração de Helsinki (2000), além do atendimento a legislações específicas do país no qual a pesquisa foi realizada.

Nos experimentos com animais devem ser seguidos os guias da Instituição dos Conselhos Nacionais de Pesquisa sobre o uso e cuidado dos animais de laboratório.

Registros de Ensaios Clínicos

Artigos com resultados de pesquisas clínicas devem apresentar um número de identificação em um dos Registros de Ensaios Clínicos validados pelos critérios da Organização Mundial da Saúde (OMS) e do Intemational Committee of Medical Journal Editors (ICMJE), cujos endereços estão disponíveis no site do ICMJE. O número de identificação deverá ser registrado ao final do resumo.

\section{Procedimentos Editoriais Autoria}

O número de autores deve ser coerente com as dimensões do projeto. O crédito de autoria deverá ser baseado em contribuições substanciais, tais como concepção e desenho, ou análise e interpretação dos dados. Não se justifica a inclusão de nomes de autores cuja contribuição não se enquadre nos critérios acima, podendo, neste caso, figurar na seção Agradecimentos. Os manuscritos devem conter, na página de identi-ficação, explicitamente, a contribuição de cada um dos autores.

\section{Processo de julgamento dos manuscritos}

A revisão dos textos submetidos à Revista, que atenderem à política editorial, só terá início se os manuscritos encaminhados estiverem de acordo com as Instruções aos Autores. Caso 
contrário, serão devolvidos para adequação às normas, inclusão de carta ou de outros documentos eventualmente necessários.

Recomenda-se fortemente que o(s) autor(es) busque(m) assessoria lingüística profissional (revisores e/ou tradutores certificados em língua portuguesa e inglesa) antes de submeter(em) originais que possam conter incorreções e/ou inadequações morfológicas, sintáticas, idiomáticas ou de estilo Devem ainda evitar o uso da primeira pessoa "meu estudo...", ou da terceira pessoa do plural "percebemos....", pois em texto científico o discurso deve ser impessoal, sem juízo de valor e na terceira pessoa do singular.

Originais identificados com incorreções e/ou inade-quações morfológicas ou sintáticas serão devolvidos antes mesmo de serem submetidos à avaliação quanto ao mérito do trabalho e à conveniência de sua publicação.

Aprovados nesta fase, os manuscritos serão encaminhados aos revisores ad hoc selecionados pelos editores. Cada manuscrito será enviado para dois revisores de reconhecida competência na temática abordada. Em caso de desacordo, o original será enviado para uma terceira avaliação.

O processo de avaliação por pares é o sistema de blind review, em procedimento sigiloso quanto à identidade tanto dos autores quanto dos revisores. Por isso os autores deverão empregar todos os meios possíveis para evitar a identificação de autoria do manuscrito.

Os pareceres dos consultores comportam três possibilidades: a) aceitação integral; b) aceitação com reformulações; c) recusa integral. Em quaisquer desses casos, o autor será comunicado.

A decisão final sobre a publicação ou não do manuscrito é sempre dos editores, aos quais é reservado o direito de efetuar os ajustes que julgarem necessários. Na detecção de problemas de redação, o manuscrito será devolvido aos autores para as alterações devidas; o trabalho reformulado deve retornar no prazo máximo determinado.

Manuscritos aceitos: manuscritos aceitos poderão retornar aos autores para aprovação de eventuais alterações, no processo de editoração e normalização, de acordo com o estilo da Revista.

Provas: serão enviadas provas tipográficas aos autores para a correção de erros de impressão. As provas devem retornar ao Núcleo de Editoração na data estipulada. Outras mudanças no manuscrito original não serão aceitas nesta fase.

\section{Preparo do Manuscrito}

\section{Submissão de trabalhos}

Serão aceitos trabalhos acompanhados de carta assinada por todos os autores, com descrição do tipo de trabalho e da área temática, declaração de que o trabalho está sendo submetido apenas à Revista de Nutrição e de concordância com a cessão de direitos autorais.

Caso haja utilização de figuras ou tabelas publi-cadas em outras fontes, deve-se anexar documento que ateste a permissão para seu uso.

Enviar os manuscritos para o Núcleo de Editoração da Revista em quatro cópias, preparados em espaço entrelinhas 1,5, com fonte Arial 11, acompanhados de cópia em disquete ou CDROM. O arquivo deverá ser gravado em editor de texto similar ou superior à versão 97-2003 do Word (Windows). Os nomes do(s) autor(es) e do arquivo deverão estar indicados no rótulo do disquete ou CD-ROM.

Das quatro cópias descritas no item anterior, três deverão vir sem nenhuma identificação dos autores, para que a avaliação possa ser realizada com sigilo; porém, deverão ser completas e idênticas ao original, omitindo-se apenas esta informação. É fundamental que o escopo do artigo não contenha qualquer forma de identificação da autoria, o que inclui referência a trabalhos anteriores do(s) autor(es), da instituição de origem, por exemplo.

O texto deverá ter de 15 a 20 laudas. As folhas deverão ter numeração personalizada desde a folha de rosto (que deverá apresentar o número 1). O papel deverá ser de tamanho A4, com formatação de margens superior e inferior (no mínimo 2,5cm), esquerda e direita (no mínimo $3 \mathrm{~cm})$.

Os artigos devem ter, aproximadamente, 30 referências, exceto no caso de artigos de revisão, que podem apresentar em torno de 50.

Todas as páginas devem ser numeradas a partir da página de identificação. Para esclarecimentos de eventuais dúvidas quanto à forma, sugere-se consulta a este fascículo.

Versão reformulada: a versão reformulada deverá ser encaminhada em três cópias completas, em papel, e em disquete ou CD-ROM etiquetado, indicando o número do protocolo, 
o número da versão, o nome dos autores e o nome do arquivo. $\mathbf{O}(\mathbf{s})$ autor(es) deverá(ão) enviar apenas a última versão do trabalho.

O texto do artigo deverá empregar fonte colorida (cor azul) para todas as alterações, juntamente com uma carta ao editor, reiterando o interesse em publicar nesta Revista e informando quais alterações foram processadas no manuscrito. Se houver discordância quanto às recomendações dos revisores, o(s) autor(es) deverão apresentar os argumentos que justificam sua posição. O título e o código do manuscrito deverão ser especificados.

Página de título: deve conter:

a) título completo - deve ser conciso, evitando excesso de palavras, como "avaliação do....", "considerações acerca de..." 'estudo exploratório....";

b) short title com até 40 caracteres (incluindo espaços), em português (ou espanhol) e inglês;

c) nome de todos os autores por extenso, indicando a filiação institucional de cada um. Será aceita uma única titulação e filiação por autor. O(s) autor(es) deverá(ão), portanto, escolher, entre suas titulações e filiações institucionais, aquela que julgar(em) a mais importante.

d) Todos os dados da titulação e da filiação deverão ser apresentados por extenso, sem siglas.

e) Indicação dos endereços completos de todas as universidades às quais estão vinculados os autores;

f) Indicação de endereço para correspondência com o autor para a tramitação do original, incluindo fax, telefone e endereço eletrônico;

Observação: esta deverá ser a única parte do texto com a identificação dos autores.

Resumo: todos os artigos submetidos em português ou espanhol deverão ter resumo no idioma original e em inglês, com um mínimo de 150 palavras e máximo de 250 palavras.

Os artigos submetidos em inglês deverão vir acompanhados de resumo em português, além do abstract em inglês.

Para os artigos originais, os resumos devem ser estruturados destacando objetivos, métodos básicos adotados, informação sobre o local, população e amostragem da pesquisa, resultados e conclusões mais relevantes, considerando os objetivos do trabalho, e indicando formas de continuidade do estudo.

Para as demais categorias, o formato dos resumos deve ser o narrativo, mas com as mesmas informações.

O texto não deve conter citações e abreviaturas. Destacar no mínimo três e no máximo seis termos de indexação, utilizando os descritores em Ciência da Saúde - DeCS - da Bireme.

Texto: com exceção dos manuscritos apresentados como Revisão, Nota Científica e Ensaio, os trabalhos deverão seguir a estrutura formal para trabalhos científicos:

Introdução: deve conter revisão da literatura atualizada e pertinente ao tema, adequada à apresentação do problema, e que destaque sua relevância. Não deve ser extensa, a não ser em manuscritos submetidos como Artigo de Revisão.

Métodos: deve conter descrição clara e sucinta do método empregado, acompanhada da correspondente citação bibliográfica, incluindo: procedimentos adotados; universo e amostra; instrumentos de medida e, se aplicável, método de validação; tratamento estatístico.

Em relação à análise estatísitca, os autores devem demonstrar que os procedimentos utilizados foram não somente apropriados para testar as hipóteses do estudo, mas também corretamente interpretados. Os níveis de significância estatística (ex. $p<0,05 ; p<0,01 ; p<0,001$ ) devem ser mencionados.

Informar que a pesquisa foi aprovada por Comitê de Ética credenciado junto ao Conselho Nacional de Saúde e fornecer o número do processo.

Ao relatar experimentos com animais, indicar se as diretrizes de conselhos de pesquisa institucionais ou nacionais - ou se qualquer lei nacional relativa aos cuidados e ao uso de animais de laboratório - foram seguidas.

Resultados: sempre que possível, os resultados devem ser apresentados em tabelas ou figuras, elaboradas de forma a serem auto-explicativas e com análise estatística. Evitar repetir dados no texto.

Tabelas, quadros e figuras devem ser limitados a cinco no conjunto e numerados consecutiva e independentemente com algarismos arábicos, de acordo com a ordem de menção dos dados, e devem vir em folhas individuais e separadas, com indicação de sua localização no texto. É imprescindível a informação do local e ano do estudo. A cada um se deve atribuir um título breve. Os quadros e tabelas terão as bordas laterais abertas.

$\mathrm{O}(\mathrm{s})$ autor(es) se responsabiliza $(\mathrm{m})$ pela qualidade das figuras (desenhos, ilustrações, tabelas, quadros e gráficos), que deverão permitir redução sem perda de definição, para os tamanhos 
de uma ou duas colunas ( 7 e $15 \mathrm{~cm}$, respectivamente); não é permitido o formato paisagem. Figuras digitalizadas deverão ter extensão JPEG e resolução mínima de $300 \mathrm{DPI}$.

A publicação de imagens coloridas, após avaliação da viabilidade técnica de sua reprodução, será custeada pelo(s) autor(es). Em caso de manifestação de interesse por parte do(s) autor(es), a Revista de Nutrição providenciará um orçamento dos custos envolvidos, que poderão variar de acordo com o número de imagens, sua distribuição em páginas diferentes e a publicação concomitante de material em cores por parte de outro(s) autor(es).

Uma vez apresentado ao(s) autor(es) o orçamento dos custos correspondentes ao material de seu interesse, este(s) deverá(ão) efetuar depósito bancário. As informações para o depósito serão fornecidas oportunamente.

Discussão: deve explorar, adequada e objetivamente, os resultados, discutidos à luz de outras observações já registradas na literatura.

Conclusão: apresentar as conclusões relevantes, considerando os objetivos do trabalho, e indicar formas de continuidade do estudo. Não serão aceitas citações bibliográficas nesta seção.

Agradecimentos: podem ser registrados agradecimentos, em parágrafo não superior a três linhas, dirigidos a instituições ou indivíduos que prestaram efetiva cola-boração para o trabalho. Anexos: deverão ser incluídos apenas quando imprescindíveis à compreensão do texto. Caberá aos editores julgar a necessidade de sua publicação.

Abreviaturas e siglas: deverão ser utilizadas de forma padronizada, restringindo-se apenas àquelas usadas convencionalmente ou sancionadas pelo uso, acompanhadas do significado, por extenso, quando da primeira citação no texto. Não devem ser usadas no título e no resumo. Referências de acordo com o estilo Vancouver

Referências: devem ser numeradas consecutiva-mente, seguindo a ordem em que foram mencionadas pela primeira vez no texto, conforme o estilo Vancouver.

Nas referências com dois até o limite de seis autores, citam-se todos os autores; acima de seis autores, citam-se os seis primeiros autores, seguido de et al.

As abreviaturas dos títulos dos periódicos citados deverão estar de acordo com o Index Medicus.

Não serão aceitas citações/referências de monografias de conclusão de curso de graduação, de trabalhos de Congressos, Simpósios, Workshops, Encontros, entre outros, e de textos não publicados (aulas, entre outros).

Se um trabalho não publicado, de autoria de um dos autores do manuscrito, for citado (ou seja, um artigo in press), será necessário incluir a carta de aceitação da revista que publicará o referido artigo.

Se dados não publicados obtidos por outros pesquisadores forem citados pelo manuscrito, será necessário incluir uma carta de autorização, do uso dos mesmos por seus autores.

Citações bibliográficas no texto: deverão ser expostas em ordem numérica, em algarismos arábicos, meia linha acima e após a citação, e devem constar da lista de referências. Se forem dois autores, citam-se ambos ligados pelo "\&"; se forem mais de dois, cita-se o primeiro autor, seguido da expressão et al.

A exatidão e a adequação das referências a trabalhos que tenham sido consultados e mencionados no texto do artigo são de responsabilidade do autor. Todos os autores cujos trabalhos forem citados no texto deverão ser listados na seção de Referências.

Exemplos

Artigo com mais de seis autores

Nascimento E, Leandro CVG, Amorim MAF, Palmeiras A, Ferro TC, Castro CMMB, et al. Efeitos do estresse agudo de contenção, do estresse crônico de natação e da administração de glutamina sobre a liberação de superóxido por macrófagos alveolares de ratos. Rev Nutr. 2007; 20(4): 387-96.

Artigo com um autor

Traverso-Yépez MA. Dilemas na promoção da saúde no Brasil: reflexões em torno da política nacional. Interface: Comunic, Saúde, Educ. 2007; 11(22):223-38.

Artigo em suporte eletrônico

Mendonça MHM, Giovanella L. Formação em política pública de saúde e domínio da informação para o desenvolvimento profissional. Ciênc Saúde Coletiva [periódico na Internet]. 2007 Jun [acesso 2009 jan 28]; 12(3):601-610. Disponível em: <http://www.scielo.br>. doi:10.1590/S1413-81232007000 300010.

Livro

Rouquayrol MZ, Almeida Filho N. Epidemiologia \& saúde. 6a. ed. Rio de Janeiro: Medsi; 2005. 
Livro em suporte eletrônico

World Health Organization. The world health report 2007: a safer future: global public health security in the 21st century [monograph online]. Geneva: WHO; 2007. [cited 2009 Jan 30]. Available from: <http://www.who.int/whr/2007/en/index.html>.

Capítulos de livros

Monteiro CA. Ther underweight/overweight double burden for the poorest in low-income countries. In: Dube L, Bechara A, Dagher A, Drewnowski V, LeBel, James P, et al., editors. Obesity prevention: the role of society and brain on individual behavior. New York: Elsevier; 2007. v.1.

Capítulo de livro em suporte eletrônico

New health threats in the 21st century. In: World Health Organization. The world health report 2007: a safer future: global public health security in the 21st century [monograph online]. Geneva: WHO; 2007. [cited 2009 Jan 30]. Available from: $<$ http://www.who.int/whr/2007/chapter3/en/index.html>.

Dissertações e teses

Franco AC. Educação nutricional na formação do nutricionista: bases teóricas e relação teoriaprática [mestrado]. Campinas: Universidade Estadual de Campinas; 2006.

Texto em formato eletrônico

World Health Organization. Malaria elimination: a field manual for low and moderate endemic countries. Geneva, 2007. [cited 2007 Dec 21]. Available from: <http://www. who.int/malaria/docs/elimination/MalariaElimination BD.pdf>.

Programa de computador

Dean AG, Dean JA, Coulombier D, Brendel KA, SmithDC, Burton AH, et al. Epi Info, version 6: a word processing, database, and statistics program for public health on IBM-compatible microcomputers. Atlanta (Georgia): Centers for Disease Control and Prevention; 1996.

Para outros exemplos recomendamos consultar as normas do Committee of Medical Journals Editors (Grupo Vancouver) <http://www.icmje.org $>$.

\section{Lista de Checagem}

Declaração de responsabilidade e transferência de direitos autorais assinada por cada autor.

- Enviar ao editor quatro vias do original (um original e três cópias) e um disquete ou CD-ROM, etiquetado com as seguintes informações: nome do(s) autor(es) e nome do arquivo. $\mathrm{Na}$ reapresentação incluir o número do protocolo.

- Verificar se o texto, incluindo resumos, tabelas e referências, está reproduzido com letras Arial, corpo 11 e entrelinhas 1,5 e com formatação de margens superior e inferior (no mínimo $2,5 \mathrm{~cm}$ ), esquerda e direita (no mínimo $3 \mathrm{~cm}$ ).

- Verificar se estão completas as informações de legendas das figuras e tabelas.

- Preparar página de rosto com as informações solicitadas.

- Incluir o nome de agências financiadoras e o número do processo.

- Indicar se o artigo é baseado em tese/dissertação, colocando o título, o nome da instituição, o ano de defesa e o número de páginas.

- Incluir título do manuscrito, em português e inglês.

- Incluir título abreviado (short title), com 40 caracteres, para fins de legenda em todas as páginas.

- Incluir resumos estruturados para trabalhos oringinais e narrativos para manuscritos que não são de pesquisa, com até 150 palavras nos dois idiomas, português e inglês, ou em espanhol, nos casos em que se aplique, com termos de indexação.

- Verificar se as referências estão normalizadas segundo estilo Vancouver, ordenadas na ordem em que foram mencionadas pela primeira vez no texto e se todas estão citadas no texto.

- Incluir permissão de editores para reprodução de figuras ou tabelas publicadas.

- Parecer do Comitê de Ética da Instituição.

\section{Conflito de Interesses}

No caso da identificação de conflito de interesse da parte dos revisores, o Comitê Editorial encaminhará o manuscrito a outro revisor ad hoc.

\section{Documentos}

Declaração de responsabilidade e transferência de direitos autorais

Cada autor deve ler e assinar os documentos (1) Declaração de Responsabilidade e (2) Transferência de Direitos Autorais, nos quais constarão: 
- Título do manuscrito:

- Nome por extenso dos autores (na mesma ordem em que aparecem no manuscrito).

- Autor responsável pelas negociações:

1. Declaração de responsabilidade: todas as pessoas relacionadas como autoras devem assinar declarações de responsabilidade nos termos abaixo:

- "Certifico que participei da concepção do trabalho para tornar pública minha responsabilidade pelo seu conteúdo, que não omiti quaisquer ligações ou acordos de financiamento entre os autores e companhias que possam ter interesse na publicação deste artigo";

- "Certifico que o manuscrito é original e que o trabalho, em parte ou na íntegra, ou qualquer outro trabalho com conteúdo substancialmente similar, de minha autoria, não foi enviado a outra Revista e não o será, enquanto sua publicação estiver sendo considerada pela Revista de Nutrição, quer seja no formato impresso ou no eletrônico".

2. Transferência de Direitos Autorais: "Declaro que, em caso de aceitação do artigo, a Revista de Nutrição passa a ter os direitos autorais a ele referentes, que se tornarão propriedade exclusiva da Revista, vedado a qualquer reprodução, total ou parcial, em qualquer outra parte ou meio de divulgação, impressa ou eletrônica, sem que a prévia e necessária autorização seja solicitada e, se obtida, farei constar o competente agradecimento à Revista".

Assinatura do(s) autores(s) Data / / 
Anexo II 


\section{BRAZILIAN JOURNAL OF MEDICAL AND BIOLOGICAL RESEARCH} - INSTRUÇÕES AOS AUTORES -

\section{Objetivo e Política}

O Brazilian Journal of Medical and Biological Research é uma revista de publicação eletrônica mensal que conta com processo de avaliação pelos pares, especialistas das diferentes áreas.

A Revista é de responsabilidade da Associação Brasileira de Divulgação Científica (ABDC).

A finalidade do Brazilian Journal of Medical and Biological Research é publicar resultados de pesquisas originais que contribuam significativamente para o conhecimento das ciências médicas e biológicas.

Será dada preferência para manuscritos que desenvolvam novos conceitos ou abordagens experimentais e que não sejam meramente agrupamento de dados científicos.

Trabalhos metodológicos poderão ser submetidos para publicação desde que descrevam novos princípios ou um aperfeiçoamento significativo de métodos já existentes.

Não serão aceitos para publicação, à menos que os autores demonstrem a originalidade do trabalho:

- trabalhos em seres humanos sem aprovação de comitê de ética ou sem declaração de consentimento do interessado ou guardião legal

- trabalhos não aprovados pelo comitê de ética e cuidados com animais

- trabalhos que relatem resultados preliminares ou que apenas confirmem resultados anteriores.

- Trabalhos que tratem da tradução para o portugues de um teste já publicado sem envolver investigação original.

- Trabalhos que utilizem questionários traduzidos de uma línguagem para outra e sua validação em pacientes locais

- Trabalhos que abordem a adaptação transcultural e validação de instrumentos de medida.

Quando apropriado, trabalhos na área de Investigação Clínica deverão conter uma declaração indicando que o protocolo foi aprovado pela Comissão de Ética do hospital (Hospital no qual pelo menos parte da pesquisa tenha sido desenvolvida e ao qual pelo menos um dos autores seja associado) e que o consentimento escrito foi obtido de todos os participantes.

O encaminhamento de um manuscrito ao Brazilian Journal implica que os dados não tenham sido previamente publicados e que, enquanto estiver em processo de revisão, não está sendo submetido concomitantente à consideração de outras revistas. A Revista considera "publicação anterior" as seguintes situações: qualquer material impresso com mais de 500 palavras descrevendo resultados ou métodos de um manuscrito enviado para publicação ou já na fase de impressão; tabelas ou ilustrações publicadas que apresentem o conteúdo do manuscrito; manuscritos ou pôsteres disponíveis na Internet. Quando parte do material foi apresentado em uma comunicação preliminar ou em um simpósio sem revisores, este fato deve ser citado como uma nota de rodapé na página do título e uma cópia deve acompanhar o trabalho.

\section{Page Charges}

Os autores serão responsáveis pelo pagamento de "page charges" que será cobrada do autor de correspondência ou de pessoa ou instituição por ele indicados, no momento em que o trabalho for aceito para publicação.

Para trabalhos submetidos depois de 5 de Janeiro de 2009 o custo será de $\mathrm{R} \$ 1.250,00 /$ trabalho de autores brasileiros e de US $\$ 550,00 /$ trabalho para autores fora do Brasil independentemente do número de páginas do trabalho.

Sugerimos que os autores solicitem a assistência do Chefe de Departamento, Diretor da Instituição, Pró-Reitor de Pesquisa ou de Pós-Graduação da Universidade, ou localize verbas relacionadas à pesquisa ou reserva técnica de bolsas de pós-graduação, quando aplicável. $A$ publicação de um trabalho contribui com o prestígio do Departamento, da Faculdade, da Universidade e da área de Pós-Graduação.

No Brasil o pagamento de "page charges" será feito através da quitação de boleto bancário que será remetido ao autor de correspondência quando o trabalho for aceito. No exterior, será solicitado ao autor de correspondência a emissão de cheque em dólares, contra um banco americano.

Qualquer dúvida favor entrar em contato com Reinaldo de Souza, via email (bjournal@fmrp.usp.br). 
Submissão de Manuscritos

Complete e envie o formulário de submissão.

Envie um email ao bjournal@terra.com.br ou bjournal@fmrp.usp.br com a carta de submissão e o manuscrito em anexo.

A carta de submissão deve conter as seguintes informações:

- Título do trabalho que está sendo submetido

- Nome do(s) autor(es).

- Enviar via fax para 0xx-16-3633-3825 ou 0xx-16-3630-2778 uma declaração assinada pelo autor de correspondência de que foi obtida permissão das pessoas mencionadas em "agradecimentos"

- Se uma versão do manuscrito foi previamente submetida à publicação pelo Brazilian Journal ou outra revista, inclua comentários dos revisores e a indicação de como os autores responderam a esses comentários.

- Quando adequado

1. os trabalhos na área de Investigação Clínica devem incluir uma declaração indicando que o protocolo foi aprovado pela Comissão de Ética do hospital (hospital a que pelo menos um dos autores esteja associado) e devem ser obtidos consentimento por escrito de todos os participantes,

2. que a utilização dos animais de experimentação seguiu as regras estabelecidas pela instituição local

Apresentar a permissão para a reprodução de figuras e tabelas de outros trabalhos.

Categorias de Artigos

Oito ou nove números do Brazilian Journal serão dedicados à Biociências e o autor deverá especificar no formulário de submissão, em qual das seguintes sessões ele prefere publicar seu trabalho:

- Biologia Celular

- Biologia Experimental

- Bioquímica e Biologia Molecular

- Farmacologia

- Fisiologia e Biofísica

- Imunologia

- Neurociências e Comportamento

Três ou quatro números por ano serão dedicados à Investigação Clínica e o autor deve especificar no formulário de submissão, em qual das seguintes sessões ele prefere publicar seu trabalho:

- Técnicas e instrumentos analíticos, diagnósticos ou terapêuticos

- Sangue, imunologia e transplante de órgãos

- Aparelho cardiovascular e respiratório, e medicina esportiva

- Aparelho disgestivo

- Doenças endócrinas, nutrição e metabolismo

- Fatores ambientais das doenças

- Atenção à saúde

- Agentes e doenças infecciosas

- Rim e meio extracelular

- Medicina neonatal, crescimento e desenvolvimento

- Oncologia

- Processos psicológicos, comportamento e doenças mentais

- Medicina reprodutiva

- Sistemas esquelético, muscular e nervoso

- Pele e tecido conjuntivo

- Procedimentos cirúrgicos, anestesia e analgesi

Trabalho completo (full-length paper). Deve especificar claramente um objetivo ou hipótese, o projeto experimental e métodos (inclusive o local de origem do estudo e o período de realização, pacientes ou participantes com critérios de inclusão e exclusão, ou fontes de dados e como eles foram selecionados para o estudo). Deve fornecer os dados essenciais de quaisquer intervenções, os resultados mais importantes do estudo, as avaliações mais 
importantes dos resultados, uma seção de comentários colocando os resultados no contexto da literatura existente e as conclusões. Esses trabalhos devem conter:

- resumo (não mais de 250 palavras)

- palavras chaves (não mais que 6)

- título resumido a ser usado no topo das páginas, não deve exceder 60 letras e espaços

- o texto deve ser dividido em sessões ( Introduction, Material and Methods, Results, Discussion), sem separação específica para conclusões.

- não mais que 40 referências

- autores devem especificar na carta de submissão que o trabalho está sendo submetido como full paper.

Comunicação breve (short communication). Comunicações breves são relatos a respeito de um único assunto que deve ser conciso mas definitivo. Pares ou seqüências de trabalhos não serão aceitos. Pretende-se que esta seção tenha grande abrangência e englobe metodologia e dados experimentais a respeito de assuntos de interesse dos leitores da Revista. Deve conter:

- $\quad$ abstract não mais de 250 palavras

- palavras chaves, não mais que 6

- título resumido a ser usado no topo das páginas, não deve exceder 60 letras e espaços

- o texto deve ser dividido em sessões ( Introduction, Material and Methods, Results, Discussion), sem separação específica para conclusões.

- deve ter no máximo 2 figuras ou tabelas (ou uma de cada).

- não mais que 20 referências

- autores devem especificar na carta de submissão que o trabalho está sendo submetido como Short communication.

Artigo de revisão ou Mini-revisão. Um artigo de revisão deve conter uma análise sintética e crítica de uma área relevante e não deve conter meramente uma descrição cronológica da literatura. $\mathrm{O}$ artigo de revisão devem ser elaborado por pesquisador que tenha contribuições importantes para uma área específica das ciências médicas e biológicas e será publicado à convite dos Editores. Contudo, um esboço de um artigo de revisão pode ser enviado aos Editores para análise, sem consulta prévia. Se for julgado adequado o autor será comunicado e poderá preparar uma revisão para ser julgada pelos pares, com vistas à publicação.

Não serão aceitos "relatos" do tipo encontrado em introduções de dissertação ou tese ou pesquisas de assuntos efetuados em Medline ou Pubmed.

Deve conter:

- Um resumo com no máximo 250 palavras

- Não mais que 6 palavras-chave

- título resumido a ser usado no topo das páginas, não deve exceder 60 letras e espaços

- O texto deve ser dividido em sessões com títulos e subtítulos paropriados.

- não mais que 60 referências

- autores devem especificar na carta de submissão que o trabalho está sendo submetido como Review article

- Informação na carta de submissão se o trabalho deverá ser publicado em um número dedicado a Biociências ou à Investigação Clínica.

Concepts and Comments

A Sessão de Concepts and Comments é uma plataforma para apresentação de idéias, teorias e visões. A apresentação deve seguir as instruções de Short Communication e deve ter um resumo, 6 palavras chaves, running title, não mais que 20 referências e não mais que duas tabelas ou figuras.

Case Report

Deve ter pelo menos uma das seguintes características para ser publicado pela revista

- ser de especial interesse da comunidade clínica.

- um caso raro, particularmente útil para demonstrar o mecanismo ou a dificuldade no diagnóstico

- um novo método diagnóstico

- um novo tratamento ou um tratamento modificado

Overview

- um texto que demonstre achados relevantes, bem documentado e sem ambiguidade

- Não deve comter dados não publicados

Deve apresentar o ponto de vista do autor de uma forma menos rigorosa que em uma revisão regular ou em uma mini-revisão, e ser do interesse do leitor geral. 


\section{Biologia Celular}

A principal característica dos trabalhos de pesquisa na área de Biologia Celular é a ênfase na integração de informações de natureza bioquímica, molecular, genética, fisiológica ou patológica no contexto da célula. Esta sessão considera trabalhos relacionados a quaisquer sistemas biológicos, procariótico ou eucariótico, em qualquer fase de seu desenvolvimento.

Para o Brazilian Journal, todos os trabalhos que abordem aspectos da estrutura e função celular são considerados dentro do escopo da Biologia Celular. Os Editores encorajam a submissão de trabalhos que explorem a Biologia Celular como uma área de convergência de diversas áreas de pesquisa, especialmente aqueles que permitam uma melhor compreensão das bases celulares da imunologia, neurobiologia, interação parasita-hospedeiro, desenvolvimento e bases celulares das doenças.

Trabalhos com observações puramente descritivas não serão publicados. Trabalhos descrevendo novas técnicas serão publicados somente quando adequadamente validados e julgados pelos Editores como representativos de avanços de excepcional significado.

\section{Atividade biológica de produtos naturais}

A Revista considerará para publicação trabalhos que descrevam atividade de substâncias de origem biológica, somente se os seguintes critérios forem preenchidos:

- Os trabalhos devem descrever a separação do material bruto em frações (não necessariamente em materias homogêneos) com as frações contendo atividade biológica identificada claramente no esquema de separação.

- Estudos fitoquímicos devem ser acompanhados por testes biológicos.

- Explorações descritivas de atividades farmacológicas de extratos de plantas ou chás não serão considerados para publicação.

- Além da demonstração da atividade em um ou mais sistemas biológicos, deverão ser realizados experimentos visando fornecer informação sobre os mecanismos de ação das substâncias que estão sendo testadas.

- Para permitir repetição da preparação de frações e ensaios biológicos usados, suficiente Informação experimental deve ser fornecida.

- A origem deve ser completamente identificada, e, se o material for planta, a espécie deve ser classificada por um especialista e depositada em um jardim botânico local, universidade ou instituto de pesquisa.

- O nome e instituição da pessoa que classificou a planta e o número de registro em que se encontra depositada deve ser fornecido na sessão de Material e Métodos.

A Revista não publica estudos toxicológicos

\section{Informações quanto à autoria}

Requisitos para autoria. Apenas aquelas pessoas que contribuíram diretamente para o conteúdo intelectual do trabalho devem ser listadas como autores. Os autores devem satisfazer a todos os seguintes critérios, de forma a poderem ter responsabilidade pública pelo conteúdo do trabalho:

- ter concebido e planejado as atividades que levaram ao trabalho ou interpretado os resultados a que ele chegou, ou ambos.

- ter escrito o trabalho ou revisado versões sucessivas e tomado parte no processo de revisão.

- ter aprovado a versão final.

Exercer posição de chefia administrativa, contribuir com pacientes e coletar e agrupar dados, embora importantes para a pesquisa, não são, por si só, critérios para autoria. Outras pessoas que tenham feito contribuições substanciais e diretas para o trabalho mas que não possam ser consideradas autores podem, com sua permissão, ser citadas na seção "Agradecimento", poderá ser feito com permissão da pessoa que está sendo agradecida e se possível, a contribuição específica deve ser descrita. Incluir os esclarecimentos sobre os critérios de autoria e responsabilidade na carta de submissão, que deve ser lida por todos os autores e assinada por pelo menos um deles.

Direitos autorais. A maioria das determinações do Decreto Norte-Americano sobre Direitos Autorais de 1976 tornaram-se efetivas em $1^{\circ}$ de janeiro de 1978. Portanto, os manuscritos devem ser acompanhados por declaração escrita, assinada pelos autores e encaminhada via correio nomal (ver modelo abaixo). 
"O(s) autor(es) abaixo assinado(s) transfere $(\mathrm{m})$ todos os direitos autorais do manuscrito (título do artigo) a Brazilian Journal of Medical and Biological Research, caso o trabalho seja publicado. $\mathrm{O}(\mathrm{s})$ signatário(s) garante $(\mathrm{m})$ que o artigo é original, que não infringe os direitos autorais ou qualquer outro direito de propriedade de terceiros, que não foi enviado para publicação em nenhuma outra revista e que não foi publicado anteriormente. $\mathrm{O}(\mathrm{s})$ autor(es) confirma $(\mathrm{m})$ que a versão final do manuscrito foi revisada e aprovada por ele(s)".

Todos os manuscritos publicados tornam-se propriedade permanente de Brazilian Journal of Medical and Biological Research e não podem ser publicados sem permissão escrita da revista.

Permissão para reprodução. A Revista foi registrada no Copyright Clearance Center, Inc., 222 Rosewood Dr., Danvers, MA 01923. Consentimento para a cópia de artigos para uso pessoal ou interno pode ser dado para clientes específicos. Este consentimento é dado com a condição de que o interessado na cópia pague diretamente ao Copyright Clearance Center para cópias além do permitido pela Lei Norte-americana de Direitos Autorais. Este consentimento não se estende a outros tipos de direitos autorais, tais como para distribuição geral, revenda, propaganda e propósitos promocionais, ou para a criação de novos trabalhos coletivos.

Todas as outras solicitações relacionadas a material protegido pelos direitos autorais desta publicação, que não possam ser resolvidas através do Copyright Clearance Center, devem ser dirigidas por escrito a Brazilian Journal of Medical and Biological Research, Av. Bandeirantes, 3900, 14049-900 Ribeirão Preto, SP, Brasil. Fax: +55-16-3633-3825. E-mail: bjournal@fmrp.usp.br ou bjournal@terra.com.br

Para solicitar permissão, por favor envie-nos uma requisição via e-mail, via fax ou pelo correio com as seguintes informações:

- Seu nome, título e instituição

- Seu endereço completo para correspondência, número do telefone, número do fax e email

- Ano da publicação, número do volume e data do artigo

- Título do artigo

- Nomes dos autores

- Número das páginas em que o material aparece

- Número da figura ou porção específica do texto (ou forneça uma fotocópia)

- Inclua as seguintes informações sobre o uso que se pretende:

- Título do livro/revista em que o material do Brazilian Journal aparecerá

- Autor(es)/editor(es)

- Editora

Revisão editorial e processamento

Para informações mais completas sobre a política de revisão editorial veja "Editorial policies.htm"

O recebimento de manuscritos é acusado imediatamente. Quando o trabalho é avaliado, os autores são notificados à respeito da decisão editorial.

Os manuscritos aceitos são editados e as provas gráficas serão enviadas aos autores para a correção de erros de impressão. Os autores são responsáveis por todas as afirmações feitas em seu trabalho, incluindo alterações feitas pelo editor e autorizadas pelo autor de correspondência.

As datas de recebimento e aceitação serão publicadas em cada artigo. Espera-se que os autores retornem os trabalhos em 15 dias após o recebimento para modificações ou na correção de Estilo e que retornem as provas gráficas em 72 horas após o recebimento. 0 número total de dias adicionais dispendidos pelos autores serão acrescentados à data de submissão no momento da publicação.

\section{Preparação de Manuscritos}

Os manuscritos devem ser escritos em Inglês. Solicita-se aos autores que usem o inglês americano, exceto, naturalmente, nas referências, cujos títulos devem aparecer exatamente como publicadas. Orientações sobre gramática, pontuação e escrita científica podem ser encontradas nas seguintes fontes: Scientific Style and Format: The CSE Manual for Authors, Editors, and Publishers. 7th edn. Rockefeller University Press, Reston, 2006; Medical Style and Format. Huth EJ (Editor). ISI Press, Philadelphia, 1987, Marketed by Williams \& Wilkins, Baltimore, MD. 
O Brazilian Journal of Medical and Biological Research segue o formato de referências de "Uniform Requirements for Manuscripts Submitted to Biomedical Journals", que pode ser encontrado no website de National Library of Medicine (http://www.nlm.nih.gov/bsd/uniform requirements.html).

\section{Formato do texto}

Solicitamos que os textos sejam remetidos sob a forma de arquivo do Microsoft Word criado com MS Word versão 6.5 ou uma versão posterior.

- Mande o manuscrito por e-mail, em folha tamanho carta $(8,5 \times 11 ")$, com margens com pelo menos 1 polegada $(2,54 \mathrm{~cm})$ de largura, 23 linhas por página, que contenha cerca de 2156 caracteres, incluindo espaços.

- Use fonte serifada, preferivelmente Times New Roman, com 12 pontos e espaço duplo em todo o trabalho, incluindo página de título, resumo, texto, agradecimentos, referências bibliográficas, legendas das figuras e tabelas.

- A numeração das páginas deve ficar no canto superior direito, começando com a página de título como página 1.

- Exprimir todas as medidas em Système International (SI) e unidades padrão quando apropriado (http://www.physics.nist.gov/cuu/units).

- Não use abreviações no título ou no resumo e limite seu uso no texto.

- A extensão do manuscrito e o número de tabelas e figuras devem ser os menores possíveis.

- Verifique se todas as referências bibliográficas forma citadas no texto.

- Nomes genéricos devem ser usados para todas as drogas. Os instrumentos podem ser citados pelo nome comercial; o nome e a localização do fabricante (cidade, estado, país e email) devem ser dados entre parênteses no texto.

Rodapé, se for imprescindível deve ser numerado, super-escrito, consecutivamente no texto e deve ser apresentado em uma página à parte após o resumo.

Títulos e Subtítulos

- Utilize somente três tipos de títulos no texto. Indique claramente o nível do título usando as convenções tipográficas abaixo.

- A posição de todos os títulos e subtítulos deve ser à esquerda da margem.

- Procure usar títulos breves (3 ou 4 palavras), não utilize abreviações.

Primeiro Nível: Bold, somente com a primeira letra da primeira palavra em maiúsculo, fonte tamanho 11.

Segundo Nível: Bold, com a primeira letra da primeira palavra em maiúsculo, fonte tamanho 9 Terceiro Nível: Itálico, somente a primeira letra da primeira palavra em maiúsculo.

\section{Abreviações e símbolos}

- Favor utilizar o mínimo de abreviações possível.

- Quando uma abreviação aparece pela primeira vez, no texto, figura ou legenda de tabela, explique seu significado.

- Não é necessário explicar abreviações de unidades de medida: 3 milliliters, simplesmente $3 \mathrm{ml}$ ou simbolos científicos comuns como sodium, basta dizer $\mathrm{Na}$.

- Abrevie nomes longos ou substâncias químicas e termos utilizados para combinações terapêuticas.

- Abrevie nomes de testes e procedimentos que são conhecidos mais por suas abreviaturas do que por seus nomes completos (VDRL test, SMA-12).

- Use abreviações em figuras e tabelas para ganhar espaço, mas as abreviações devem ser sempre definas na legenda.

Unidades. O Système International (SI) (http://physics.nist.gov/cuu/Units) em unidades métricas é usado para unidades e abreviações de unidades

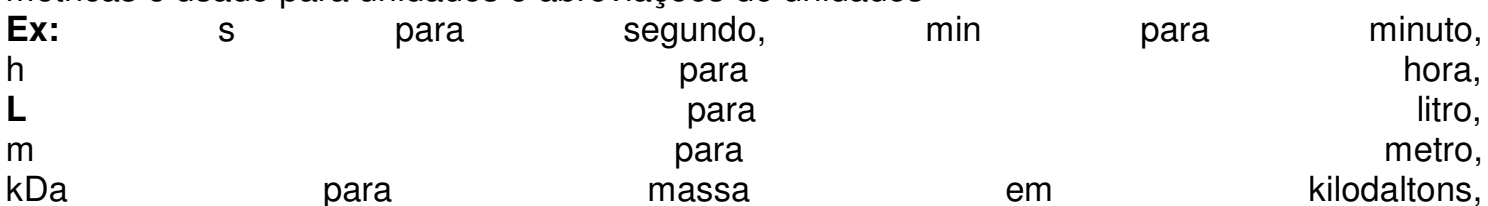

$5 \mathrm{mM}$ ao invés de $5 \times 10-3 \mathrm{M}$ or 0.005

Primeira Página

Título do trabalho. O título deve ser tão breve e informativo quanto possível, não deve conter abreviações. 
Ex: Beneficial effect of recombinant human growth hormone on the intestinal mucosa barrier of septic rats

Autores: Iniciais do nome e sobrenome de todos os autores com números super-escritos identificando a instituição de cada autor.

Ex: M.I. Hiyane ${ }^{1,2}$, S.B. Boscardin ${ }^{2}$ and M.M. Rodrigues ${ }^{1,2}$

Instituição: Instituição de cada autor, identificada com o número super-escrito (Departamento, Faculdade, Universidade, Cidade, Estado e País). Quando um autor for do Brasil, o nome da instituição deve estar em português.

Ex: ${ }^{1}$ Centro Interdisciplinar de Terapia Gênica, ${ }^{2}$ Departamento de Microbiologia, Imunologia e Parasitologia, Escola Paulista de Medicina, Universidade Federal de São Paulo, São Paulo, SP, Brasil

Título Resumido: O título resumido será utilizado no topo das páginas. Não deve exceder 60 letras e espaços.

Ex: A pyrazolyl-thiazole derivative causes antinociception

Palavras Chaves: Deve ser incluida uma lista de não mais que 6 palavras chaves ou termos de indexação. A revista recomenda o uso de termos utilizados no Index Medicus para evitar o uso de sinônimos para indexar diferentes trabalhos sobre um mesmo assunto. Lembre-se, as palavras chaves serão utilizadas pelo Banco de Dados do Scielo para indexar seu trabalho (veja o "search" em http://www.bjournal.com.br ou http://www.scielo.br/bjmbr).

Ex: NPA-PCR method, T-cell receptor, Trypanosoma cruzi, Trans-sialidase

Agradecimento: Agradecimento a financiadoras de pesquisa e bolsas (agência e número do grant).

Ex: Research supported by FAPESP and CNPq. M.I. Hiyane and M.M. Rodrigues are recipients of fellowships from CNPq. S.B. Boscardin was the recipient of a fellowship from FAPESP.

Endereço de correspondência: Nome, endereço de correspondência incluindo CEP da cidade , telefone, fax e email do autor que receberá toda correspondência relacionada ao trabalho em questão.

\begin{tabular}{lccrr} 
Ex: & \multicolumn{2}{c}{ Address } & for & correspondence: \\
M.M. & Rodrigues, & CINTERGEN, & EPM, & UNIFESP \\
Rua & Mirassol, & & 207 \\
04044-010 & São & Paulo, & SP, & Brasil. \\
Fax: & & & & $+55-11-5571-1095$
\end{tabular}

E-mail: mrodrigues@ecb.epm.br

Resumo

- Como o resumo é publicado separadamente por serviços de informação, ele deve ser compreensível e despertar o interesse na leitura do artigo completo, deve conter dados numéricos suficientes que possam ser avaliados pelo leitor que pode não ter acesso ao artigo completo.

- O resumo deve apresentar breve e claramente o problema, a abordagem experimental, os novos resultados, sobre a forma de dados quantitativos.

- Dados estatisticamente significantes devem ser reportados em forma numérica com mean \pm SEM or SD.

- Deve indicar Objetivos, Métodos e Resultados mais importantes, sem destacar os tópico. Após Resultados deve ser informado o que é novo na pesquisa e sua importância.

- O resumo não deve exceder 250 palavras e deve ser escrito em parágrafo único com espaço duplo, em uma folha separada após a página de título.

- abreviações devem ser evitadas e se necessárias precisam ter a explicação correspondente.

- Se o uso de uma referência bibliográfica for inevitável, a citação completa deve ser dada dentro do resumo.

- Note que o Brazilian Journal não publica resumos estruturados.

- Sugestões mais detalhadas de como escrever um bom resumo

Introdução. Deve informar o objetivo da investigação, a relação com outros trabalhos na área e as razões para realizar a pesquisa. Não é recomendada uma extensa revisão da literatura.

Materiais e Métodos. Informações suficientes devem ser dadas no texto ou por citação de trabalhos em revistas geralmente disponíveis, de modo a permitir que o trabalho possa ser repetido. 
Resultados. Os resultados devem ser apresentados clara e concisamente. Tabelas e figuras devem ser usadas apenas quando necessárias para a efetiva compreensão dos dados. Em algumas situações pode ser desejável combinar Resultados e Discussão em uma única seção.

Discussão. O objetivo da Discussão é interpretar os resultados e relacioná-los com conhecimentos existentes. Informações dadas em outros locais do texto podem ser citadas mas não repetidas em detalhes na Discussão.

Agradecimentos. Se necessário, agradeça brevemente assistência de cunho técnico, conselhos e assistência de colegas, etc. Apoio financeiro para a pesquisa e bolsas de estudo devem ser citados na página de título.

Tabelas

- As tabelas devem ser numeradas consecutivamente com algarismos arábicos e reunidas após a seção de Referências.

- Todas as tabelas devem ser citadas no texto em ordem numérica.

- Cada tabela deve ser digitada com espaço duplo em uma folha separada (ou, se for excepcionalmente grande ou que requeira símbolos especiais ou algum arranjo não usual, a tabela deve ser enviada como uma imagem em um arquivo .tif ou .jpg).

- Um título descritivo e uma legenda, conforme as regras da revista, devem tornar as tabelas compreensíveis sem necessidade de consulta ao texto (veja www.bjournal.com.br).

- Defina todas as abreviações nas legendas das tabelas, mesmo que estejam definidas no texto.

Linhas verticais e diagonais não devem ser usadas nas tabelas; ao invés disso, afastamentos e espaçamento vertical ou horizontal devem ser usados para agrupar os dados.

Gráficos

- Aceitamos figuras no formato .tif, .jpg, .cdr ou .eps preparadas preferentemente com Adobe Photoshop ou Corel Draw. Gráficos criados com Microsoft Word ou Excel, devem ser salvos na extensão original do arquivo (.doc ou .xls) Não devem ser copiadas ou coladas de um programa para outro.

- Não aceitamos imagens elaboradas em alguns programas tais como Microsoft Office (Access), Corel Perfect Office (WordPerfect, Quattro Pro, Presentations), Lotus SmartSuite (Freelance Graphics, 1-2-3, Approach, WordPro), Harvard Graphics e SigmaPlot porque elas não são geradas com a resolução necessária para uma publicação impressa. Mesmo quando salvas como .jpg ou similar não poderão ser aceitos pois a resolução não tem qualidade.

- Atenção - As figuras devem ser desenhadas profissionalmente ou preparadas usando um computador e impressora de alta resolução e não devem ter mais que 21,5 x 28,0 $\mathrm{cm}$.

Devem ser enviadas no formato .tif, .eps ou .jpg, com 300 dpi de resolução.

Todas a imagens devem:

- Ter pelo menos $12.5 \mathrm{~cm}$ de largura.

- Serem numeradas na ordem em que são citadas no texto usando números arábicos consecutivos.

- Não inserir as figuras dentro do texto

- Somente serão aceitos anexos no formato PC por E-mail ou em CD via correio. Para sua informação na preparação de figuras no formato .tif, .jpg or .eps veja http://cjs.cadmus.com/da/.

- Informação de abscissas e ordenadas ou outras informações nas figuras devem ter somente a primeira letra da palavra em maiúscula e as demais letras devem ser minúsculas. O tamanho e formato da letra deve ser uniformizado.

Confira cuidadosamente as figuras antes de enviar o trabalho, para garantir que as versões adequadas estão sendo enviadas.

- Fotomicrografias devem incluir dados sobre a coloração e a ampliação no final da legenda para cada parte da figura. Uma barra de ampliação deve ser adicionada a cada fotomicrografia. Se não aparecer nenhum marcador com escala na figura, a ampliação original deve ser informada na legenda.

- Adaptação/reprodução de tabelas e figuras e correspondentes permissões Citações das fontes originais de materiais adaptados devem usar os termos especificados pelo editor original do material. Se não houver especificação, cite os 
autores, o número da referência e o editor. Cartas de permissão do portador dos direitos autorais devem acompanhar os materiais citados.

- Legendas Digite todas as legendas em espaço duplo consecutivamente em uma folha separada. Comece cada legenda com um pequeno título. Defina todas as abreviações e símbolos usados na figura, mesmo se eles estiverem definidos no texto. Numere as figuras na ordem em que elas são citadas no texto, usando algarismos arábicos consecutivos.

- Figuras Coloridas Imagens coloridas devem ser RGB, com pelo menos com 300 dpi e serão publicadas sem custo adicional.

- Figuras em "Grayscale" Imagens com tonalidades entre o branco e o preto devem ter pelo menos 300 dpi de resolução.

Gráfico (preto e branco ou colorido) deve ser 300 dpi de resolução

\section{Referências}

Autores são responsáveis pela acuracia, completa e correta citação das referências ao longo texto. Sempre que possível as citações de referência devem estar em inglês.

A lista de referência deve estar em espaço duplo em ordem numérica em uma folha separada. Numere as referências na ordem em que elas forem citadas no texto pela primeira vez, usando algarismos arábicos entre parênteses. Duas ou mais referências devem ser separadas por vírgula sem espaço $(1,5,7)$ e três ou mais referências consecutivas devem ser separadas por um hífen (4-9).

O Brazilian Journal of Medical and Biological Research segue o formato de referências de "Uniform Requirements for Manuscripts Submitted to Biomedical Journals", que pode ser encontrado no website de National Library of Medicine (http://www.nlm.nih.gov/bsd/uniform requirements.html).

Utilize a abreviação de revistas de Medline/PubMed.

Se o autor usar o programa "Reference Manager", clique aqui para fazer o download do arquivo "OS" com o estilo do Brazilian Journal of Medical and Biological Research e salve em seu computador e o coloque na pasta de "Styles" do programa Reference Manager. Importante: Quando submeter o trabalho, envie como anexo o arquivo (".rmd") produzido pelo Reference Manager.

As seguintes informações devem ser dadas na citação:

- último nome e iniciais dos 6 primeiros autores (sem pontuação). Se houver mais de 6 autores, depois do 6o. nome coloque "et al."

- título do artigo.

- nome da revista em itálico abreviado.

- ano da publicação, volume e páginas

- se a referência for um livro, dê também os nomes e as iniciais dos editores, da editora e a cidade.

Cite artigos de simpósios apenas se os anais foram publicados.

Ao citar um artigo ou livro aceito para publicação mas ainda não publicado, inclua o título da revista (ou o nome da editora) e o provável ano de publicação.

Referências a matérias não publicadas - por exemplo, apresentações orais em simpósios ou trabalhos não publicados (comunicações pessoais, trabalhos em preparação) - devem ser incluídas no texto e não na lista de referência. Envie uma carta de permissão das pessoas citadas autorizando tais citações. Artigos enviados para publicação é considerado material não publicado e não devem aparecer na lista de referências. Exemplo: (Santos CS, da-Silva GB, Martins LT, unpublished results).

Dê os dados completos de cada referência, incluindo uma nota do tipo "disponível em" para os documentos que podem não ser facilmente acessíveis.

Esteja certo de que as URLs usadas como referências estejam ativas e disponíveis (a data em que $o$ autor acessou a URL deve ser incluída na referência). Para um exemplo, ver Citações de Referências Eletrônicas, abaixo.

Os autores devem apresentar as referências bibliográficas de modo correto e completo, assim como citá-las no texto corretamente.

\section{Exemplos:}

Revista

- Xu J, Liu M, Liu J, Caniggia I, Post M. Mechanical strain induces constitutive and regulated secretion of glycosaminoglycans and proteoglycans in fetal lung cells. $J$ Cell Sci 1996; 109 (Pt 6): 1605-1613. 
- Poirier P, Lemieux I, Mauriege P, Dewailly E, Blanchet C, Bergeron J, et al. Impact of waist circumference on the relationship between blood pressure and insulin: the Quebec Health Survey. Hypertension 2005; 45: 363-367.

- The Cardiac Society of Australia and New Zealand. Clinical exercise stress testing. Safety and performance guidelines. Med J Australia 1996; 164: 282-284.

Artigo aceito para publicação mas ainda não publicado.

- Janiszewski M, Lopes LR, Carmo AO, Pedro MA, Brandes RP, Santos CXC, et al. Regulation of $\mathrm{NAD}(\mathrm{P}) \mathrm{H}$ oxidase by associated protein disulfide isomerase in vascular smooth muscle cells. J Biol Chem 2005 (in press).

"Resultados não publicados", "Comunicação Pessoal" e "trabalhos submetidos"

- (Santos CS, da-Silva GB, Martins LT, unpublished results).

- It is assumed that the author has obtained permission from the source when "personal communication" is cited.

Livro completo

- Norman IJ, Redfern SJ. Mental health care for elderly people. New York: Churchill Livingstone; 1996.

Capítulo de livro

- Kintzios SE. What do we know about cancer and its therapy? In: Kintzios SE, Barberaki MG (Editors), Plants that fight cancer. New York: CRC Press; 2004. p 1-14.

- Scheuer PJ, Lefkowitch JH. Drugs and toxins. In: Scheuer PJ, Lefkowitch JH (Editors), Liver biopsy interpretation. 6th edn. London: WB Saunders; 2000. p 134-150.

Resumo

- Lima SM, Bonci DM, Grotzner SR, Ribeiro CA, Ventura DF. Loss of amacrine cells in MeHg-treated retinae in a tropical fish. Invest Ophthalmol Vis Sci 2003; 44: E-5172 (Abstract).

Material Audio Visual

- Physician's Desk Reference (PDR). Release 2003.1AX. [CD-ROM]. Montvale: Thomson PDR; 2003.

Programa de Computador

- Dean AG, Dean JA, Coulombier D, Brendel KA, Smith DC, Burton AH, et al. Epi info, version 6.04: a word processing database and statistics program for public health on IBM-compatible microcomputers. [Computer program]. Atlanta: Centers of Disease Control and Prevention; 1998.

- Statistical Package for the Social Sciences (SPSS). Version 12.0. [Computer program]. Chicago: SPSS Inc.; 2006.

Conferência, Symposium Proceedings

- Hejzlar RM, Diogo PA. The use of water quality modelling for optimising operation of a drinking water reservoir. Proceedings of the International Conference Fluid Mechanics and Hydrology. 1999 Jun 23-26; Prague. Prague: Institute of Hydrodynamics AS CR; 1999. $\mathrm{p}$ 475-482.

Citação Eletrônica

- American Academy of Ophthalmology. Diabetic retinopathy disease severity scale. Am Acad Ophthalmol http://www.aao.org/education/ library/recommendations/international dr.cfm; 2005.

- Simon JA, Hudes ES. Relationship of ascorbic acid to blood lead levels. JAMA http://jama.ama-assn.org/cgi/content/abstract/281/24/2289; 1999.

Comunicação na Internet

- Developmental toxicology. http://www.devtox.org/nomenclature/organ.php. Accessed June 27, 2005. CAPES Statistics. http://www.capes.gov.br/capes/portal. Accessed March 16, 2006.

- CNPq Plataforma Lattes, "Investimentos do CNPq em CT\&l". http://fomentonacional.cnpq.br/dmfomento/home/index.jsp. Accessed March 16, 2006.

Tese/Dissertação

- Joselevitch C. Visão no ultravioleta em Carassius auratus (Ostariophysi, Cypriformes, Cyprinidae): estudo eletrofisiológico do sistema cone - células horizontais. [Master's thesis]. São Paulo: Instituto de Psicologia, USP; 1999.

Patente

- Larsen CE, Trip R, Johnson CR. Methods for procedures related to the electrophysiology of the heart. Patent No. 5.529.067. Novoste Corporation; 1995. 
"Report"

- WHO (World Health Organization), IPCS (International Program in Chemical Safety). Environmental health criteria: 118 Inorganic mercury. Geneva: World Health Organization; 1991.

National Commission on Sleep Disorders Research. Wake up America: a national sleep alert. Washington: Government Printing Office; 1993.

Outros Links

- Writing

a Good

Abstract

(http://www.bjournal.com.br/Instructions/html/writing a good abstract.htm)

- Uniform Requirements for Manuscripts Submitted to Biomedical Journals: Writing and Editing for Biomedical Publication (http://www.icmje.org/index.html)

- The Système International (SI) (http://physics.nist.gov/cuu/Units) in metric units is used for units and abbreviations of units.

- Instructions to make quality images for publications - http://cjs.cadmus.com/da/

- The Editorial Policies of the Brazilian Journal of Medical and Biological Research (http://www.bjournal.com.br/Instructions/html/policies.htm)

- Writing papers for scientific journals (http://www.bjournal.com.br/lectures.htm)

- How editors evaluate scientific papers for publication (http://www.bjournal.com.br/lectures.htm)

- Effect of Scielo open access on Brazilian scientific journals (http://www.bjournal.com.br/lectures.htm)

- Sense About (http://www.senseaboutscience.org.uk/index.php/site/project/30/)

Science

- How to Read a (http://www.biochem.arizona.edu/classes/bioc568/papers.htm)

Paper

- PLOS Biology Guidelines for Table and Figure Preparation (http://journals.plos.org/plosbiology/figure quidelines.php 


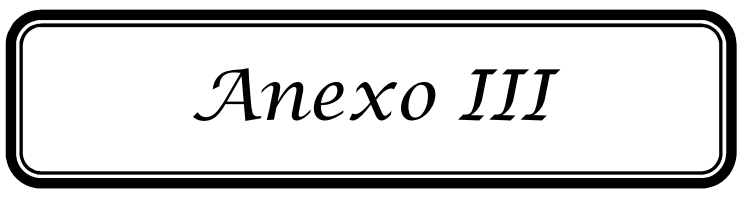




\section{$\begin{array}{llllll}\text { EFFECTS OF ATORVASTATIN ADMINISTRATION AND ITS } & \text { ATS }\end{array}$ DISCONTINUITY ASSOCIATED WITH PHYSICAL ACTIVITY IN SKELETAL MUSCLES OF RATS.}

Mariana Rotta Bonfim ${ }^{1}$, Bruna Corral Garcia ${ }^{1}$, Fábio Yoshikazu Kodama ${ }^{1}$, Susimary Aparecida Trevizan Padulla ${ }^{1}$, José Carlos Silva Camargo Filho ${ }^{1}$

${ }^{1}$ Laboratório de Histologia, Departamento de Fisioterapia, Faculdade de Ciências e Tecnologia, Universidade Estadual Paulista (FCT/UNESP), Presidente Prudente, SP, Brasil.

Short Title: Statin Discontinuity, Physical Activity and Muscle

Key-words: Hydroxymethylglutaryl-CoA Reductase Inhibitors, Motor Activity, Skeletal Muscle.

\section{Correspondence Adress:}

Mariana Rotta Bonfim

Laboratório de Histologia - FCT/Unesp

Rua Roberto Simonsen, 305. Vila Santa Helena.

CEP 19060-900 - Presidente Prudente/SP

Tel: (18) 3229-5388 - Ramal: 5466 / Fax: (18) 3229-5353

E-mail: mrb_unesp@yahoo.com.br 


\section{Abstract}

Although it's known that the association of statin and exercise exacerbates the muscle injuries and that its discontinuity ceases the undesirable muscle effects, it's still unknown the muscle response for the drug discontinuity associated to physical activity. The aim of this study was to analyze the effect of statin use discontinuity associated to physical activity practice in skeletal muscles of rats. For this, 56 Wistar male rats were divided into 4 groups of 14 animals: sedentary, exercised, atorvastatin sedentary and atorvastatin exercised. The drug (10 mg/Kg/Day of Atorvastatin Calcium) was administered by gavage 7 days during the week for 4 weeks, using as vehicle and placebo the solution of Hidroxypropyl Methiycellulose $(0,5 \%)$. Treadmill physical activity consisted of 60 minutes daily, 5 days during the week for 4 weeks. After this period, 8 animals of each group were sacrificed; the others were submitted to statin or placebo discontinuity, with the continuity of physical activity for 2 weeks. Biochemical analyses of creatine kinase enzyme and the histological and histochemical analyses of the soleus, extensor digitorum longus and superficial gastrocnemius muscles were performed. The results indicate that the drug use discontinuity associated with physical activity resulted in the maintenance of muscle alterations verified in the animals submitted to this combination, and stimulating regenerative processes of the muscle, what suggests that in cases of statin myopathy such strategy can be used when the interruption of the drug therapeutic is possible. 


\section{Introduction}

Three-hydroxi-3-methylglutaryl coenzyme A (HMG-CoA) reductase inhibitors, also known as statins, are the most marketed class of drugs worldwide. They act inhibiting an early and limiting step of cholesterol biosynthesis, the conversion of HMG-CoA in mevalonate, leading to the endogenous cholesterol synthesis attenuation, and then to the reduction of its serum levels as well as the rate of mortality related to cardiovascular diseases $^{(1,2,3)}$.

Despite statin benefits to cardiovascular health, it can be highlighted among its undesirable side effects the liver toxicity, which is dose-dependent and occurs in 0,5 to $2,0 \%$ of the patients, and muscle toxicity, which can range from mild myopathy, with an incidence of $5-10 \%$, to more severe cases such as rhabdomyolysis, occurring in less than $0,5 \%$ of its users ${ }^{(4,5)}$.

According to the literature reports, about ten days after the beginning of statin administration skeletal muscles show the first signs of injury ${ }^{(6,7)}$, and the most muscle complaints occurs in the first month of use ${ }^{(8,9)}$. The most common muscle discomforts are cramps and muscle stiffness, and the presence of its symptoms interfere negatively in the execution of daily activities, as well as the physical activity practice ${ }^{(8,9)}$.

Studies indicate that patients in statin treatment report muscle pain exacerbation with physical activity practice ${ }^{(8,9)}$, and in many cases there is intolerance of its practice $^{(10)}$. In some researches it was found that this association led to the increase of creatine kinase $(\mathrm{CK})^{(11,12)}$, a marker enzyme of muscle injury, and also to the in situ presence of this exacerbation $^{(13,14)}$.

Nevertheless, the interaction of statin and physical activity represents an interesting therapeutic strategy, since in this conditions the alterations of serum lipids levels are more significants than the use of statin alone ${ }^{(15,16)}$. However, it can not be 
discarded the existence of muscle injuries, then becoming necessary the study of some therapeutic strategies aiming the maintenance of lipids alterations associated with the minor injury of the muscles.

In clinical practice, when muscle symptoms are associated or not to increased levels of creatine kinase $(\mathrm{CK})$, it is indicated to interrupt the physical activity practice or the use of $\operatorname{statin}^{(4,5)}$. Although it is known that such attitudes lead to improvement in muscle symptoms ${ }^{(4,8)}$, there are no in situ studies of muscle response to the discontinuation of statin or physical activity.

Therefore, the aim of this study was to analyze the effect of statin use discontinuity associated with physical activity in skeletal muscle of rats without hypercholesterolemia, performing both the evaluation of biochemical aspects related to muscle injury, so as the in situ evaluation. This therapeutic strategy was chosen because of the various evidences about the benefits of physical activity to the improvement of lipid profile and to the health as a whole. So, the hypothesis of this study is the reduction or reparation of muscle injuries as a response to the drug withdrawal.

\section{Material and Methods}

The procedures adopted in this study were approved by the Ethics Committee of the Faculdade de Ciências e Tecnologia (UNESP - process n64/2009), and respected the guidelines adopted by the "Sociedade Brasileira de Ciência em Animais de Laboratório (SBCAL)

For the experiment it was used 56 male Wistar rats (Rattus novergicus), with five months of age, which were housed in propylene cages with four animals, in temperature $\left(22 \pm 2{ }^{\circ} \mathrm{C}\right)$ and humidity $(50 \pm 10 \%)$ controlled room, with a 12-h light/dark cycle (7-19h). Animals were fed a standard chow (Primor® - Moinho Primos S.A.) and water ad libitum. 
Rats were allocated in four groups of 14 animals each, and were constituted as Placebo Sedentary (PS), Placebo Exercise (PE), Atorvastatin Sedentary (AS) and Atorvastatin Exercise (AE). Group formation was determined by the results of the selective phase of runners that was part of the physical activity program, in which the animals that presented positive response to treadmill running stimulus were allocated in the exercised groups. This criterion was based in previous studies ${ }^{(17,18)}$ and aims to avoid bias in the results, ensuring that the animal stress was in response to the effort and not to other factors. It was tried to obtain the balance of body weight between groups, what was verified by the absence of significant differences in the initial value of this variable $(\mathrm{p}=0,625)$.

Within each group, eight animals were sacrificed after four weeks of intervention, and the other six animals were submitted to statin or placebo discontinuity period associated with physical activity continuity for two weeks (PE and AE). In this phase, the selection of animals was randomly and conducted by a researcher who was not part of the study.

Interventions period was stipulated by the effects of the drug in muscle. According to previous studies ${ }^{(6,7)}$, the occurrence of muscle injuries in rats can be verified after ten days of statin use, what justifies four weeks of drug intervention. With respect to the discontinuity period, there is no consensus about the necessary time to muscle repair, so it was opted to verify the muscle response after two weeks drug use interruption.

Atorvastatin groups received the drug (Atorvastatin Calcium - Lipitor@, Pfizer) orally via gavage, during seven days per week, for four weeks. The dose was based in previous studies and was stipulated $10 \mathrm{mg} / \mathrm{Kg}$ per day ${ }^{(14)}$, which was calculated by mean body weight of the group, considering weekly readjustment in accordance to body 
weight change of the animals. Atorvastatin was dissolved in Hydroxipropyl Methylcellulose (HPMC $-0,5 \%$ ) vehicle ${ }^{(6,7,11,14)}$, administering a volume of $2 \mathrm{~mL}$ per animal.

Animals in placebo groups (PS and PE) received the same solution of the vehicle $(\text { HPMC }-0,5 \%)^{(14)}$ via gavage, seven days per week for four weeks, and the same volume $(2 \mathrm{~mL}$ per animal). Both atorvastatin and placebo solutions were administered during the morning, 30 minutes before the beginning of physical activity program ${ }^{(11)}$.

Physical activity was performed in a treadmill for small animals, with speed set at 9,75 meters per minute with no incline. Protocol was based in previous study ${ }^{(19)}$ and consisted of three phases:

I) Runners Selection Phase: Consisted of treadmill exercise for five minutes during three consecutive days, aiming to identify the most able animals to perform the effort, which were allocated in the exercise groups.

II) Adaptation Phase: Consisted in daily sessions of 5, 15, 30, 45 and 60 minutes of walking during the five initial days of the program, with the purpose of adaptation to physical activity program.

III) Physical Activity Program: Consisted in daily sessions of treadmill exercise for 60 minutes, five days per week during four weeks. Animals in the discontinuity phase remained in the program for more two weeks, totalizing six weeks of physical activity.

Animals performance was monitored everyday during the session, observing the presence of refusal to exercise or escape instinct, since such behavior could indicate the presence of discomfort or weakness in the affected limb. The number of animals that presented such characteristic during the program and the frequency in which these behaviors occurred were reported ${ }^{(11)}$. 
After the intervention periods it was collected $2 \mathrm{~mL}$ of blood, which was used to measure the marker enzymes of muscle (Creatine Kinase) and liver (Aspartate Aminotransferase - AST and Alanine Aminotransfarate - ALT) injuries. Analyzes were performed by kinetic method (UV-IFCC) using the biochemical analyzer Opera (Bayer®) and Labtest ${ }^{\circledR}$ reagent kits. For all analyses it was adopted 12 hours of fasting and 72 of resting, with the purpose to obtain the basal state of the animals.

Immediately after blood collection, animals were euthanized by guillotine decapitation, followed by skeletal muscle removal. Soleus, gastrocnemius and extensor digitorum longus (EDL) muscles were removed from the right hindlimb, weighed, frozen in refreshed $n-H e x a n$ and stored in liquid nitrogen $\left(-180^{\circ} \mathrm{C}\right)$. For freezing it was reserved the central belly portions of soleus and EDL, and gastrocnemius muscle was split up into its deep and superficial parts, being reserved for analyses the central belly of the superficial portion (GS). These muscles were chosen because of their metabolic differences, predominantly oxidative (soleus) or glycolytic (EDL and GS) muscles, once previous studies verified muscle selectivity in statin action ${ }^{(6,11)}$.

Tissues were sectioned (transversal) by semi serial cuts method, obtaining cuts of $8 \mu \mathrm{m}$ in cryostat micrometer (HM 505 E - Microm $\left.\left[-20^{\circ} \mathrm{C}\right]\right)$. Sections were stained with Haematoxylin and Eosin (H\&E) and submitted to the histochemical method for demonstration of Nicotinamide Adenine Dinucleotide Tetrazolium Reductase (NADHTR) activity ${ }^{(20)}$; analyses of the slides were done in the optical microscope Zeiss Jenapol (Carl Zeiss®).

The cuts in HE were used for qualitative analysis, which evaluated the general morphology of the fragment by observing the shape and size of fibers, the position of nuclei, sarcoplasm staining, the presence of splitting and degenerative processes. The 
severity of degeneration was graded subjectively as minimal, mild, moderate and severe based on the intensity and / or area of the degeneration ${ }^{(7,11)}$.

The cuts with the histochemical reaction for NADH-TR were used to verify mitochondrial function, evaluating the intensity of reaction by the content of formazan in the sarcoplasm, which indicates the presence of oxidative activity ${ }^{(20)}$. The quantitative analysis consisted of fiber counting and the morphometric evaluation of the lesser diameter of muscle fibers, aiming to assess the occurrence of hypertrophy or atrophy in muscle fibers $^{(20)}$ (software Image Pro-Plus - Media Cybernetics, Silver Spring, MD).

For the lesser diameter of soleus muscle analysis it was used the mean value of 120 fibers per animal ${ }^{(20)}$, without differentiation of fiber types as it was considered highly oxidative. For EDL muscles and GS, it was made the measurement and counting of all fibers in the chosen section, using the mean value obtained for each fiber type per animal for analyses. In GS it was considered only the fiber type I and type II, without distinctions between IIa or IIb.

Quantitative data were analyzed by SPSS 13.0 for Windows, and were first submitted to normality test (Shapiro-Wilk). According to the results of normality, the differences of weights and morphometry values between groups were measured by analysis of variance (ANOVA - One Way) followed by Tukey's post test, and for the biochemical values it was used the Kruskal-Wallis test followed by Dunn's post test. For all analysis it was adopted as significance level $\mathrm{p}<0.05$.

\section{Results}

During the experimental protocol three animals of atorvastatin exercised group died; one of them showed disquietude during exercise in the morning, characterized by the instinct of escape, and died in the afternoon. The second occurred without an apparent cause, and the other one presented pneumonia. These animals were replaced. 
In placebo sedentary group, two animals died during the cardiac puncture procedure in T1, but they were not replaced, so this group had a reduced number of animals in the discontinuity phase (only 4 animals).

\section{Clinical Observations}

Clinical observations during physical activity practice indicated the presence of refusal and escape to exercise behavior, which could indicate the presence of discomfort or weakness in the limb. However, both the number of occurrences and the number of animals affected by this behavior were reduced in all studied groups, which suggest that physical activity did not interfered in muscles (Table 1).

\section{INSERT TABLE 1}

\section{Biochemical Parameters}

The values obtained in the biochemical variables creatine phosphokinase (CK), alanine aminotransferase (ALT) and aspartate aminotransferase (AST) are shown in figure 1. It was verified that the variables presented high standard deviation, and the variance analysis indicated no significant differences between groups in any of the variables.

\section{INSERT FIGURE 1}

\section{Effects on body and muscle weights}

Comparison analysis of final body and soleus, gastrocnemius and EDL muscles weights indicated no difference among the groups after the first four weeks of intervention. In addition, after drug or placebo discontinuity period the values of body and muscles weights were not significantly altered and no differences were observed between groups (Table 2).

\section{INSERT TABLE 2}

\section{Effects on muscle histology}


Slide analyses indicated that animals of all groups in both periods had changes characterized by endomysial and perimysium inflammatory infiltrates, fibers in degenerative process, presence of internalized nuclei and splittings (Figure 2). It was verified that the amount of fibers that showed these changes was greater in the exercised animals, both in placebo or atorvastatin treatment, after the two periods of intervention, mainly affecting the soleus muscle; in these, there was an incidence of 10 to $20 \%$ of internalized nuclei, and about 20 to 30 fibers in splitting process through the entire length of the section per animal.

\section{INSERT FIGURE 2}

Quantitative analysis of morphological features is presented in table 3, and confirms that soleus was the most affected muscle, as regards the number of animals that showed the changes and the intensity with which they occurred. It was found that fibers alterations were directly related to the type of intervention that the animal was exposed, also having differences in the pattern of changes. So, the animals of exercised atorvastatin or placebo groups showed more severe changes, which ranged from minimal to moderate, when compared to atorvastatin Sedentary animals, which ranged from minimal to mild. This trend was maintained even after the drug discontinuity period.

\section{INSERT TABLE 3}

In the other tissues, it was found that EDL was the less affected, with minimum intensity of degeneration in all groups in both intervention periods. This characteristic was similar in the superficial gastrocnemius muscle, differing only by the largest amount of animal suffering from a degenerative process, and by the presence of mild degeneration in animal 48 in the period of four weeks.

\section{Effects on muscle histochemistry}


The analysis of NADH-TR reaction slides indicated mild changes in most studied groups. In general, for all muscles the reaction obtained was homogenous, showing formazan aggregates mainly in oxidative fibers (Figure 3).

Of the three studied muscles, soleus had more fibers with loss of enzyme activity then the others, occurring with greater frequency and intensity in the exercised groups, atorvastatin or placebo, in both periods of 4 weeks and discontinuity. It was verified that these changes were more frequent in fibers that have suffered splittings.

\section{INSERT FIGURE 3}

On the other hand, EDL muscle showed a lower amount of fibers with loss of reaction, but most of the medicated and exercised animals showed intense formazan aggregates in subsarcolemmal position. In contrast, few changes were found in the GS and the most affected animals were part of placebo and atorvastatin exercised groups.

\section{Muscle morphometry}

Lesser diameter measure of fibers was performed using the histochemical reaction of NADH-TR, considering the metabolic differences of each muscle. The diameter values and the percentage of each fiber type in the different muscles are presented as mean followed by respective standard deviation in Table 4.

\section{INSERT TABLE 4}

According to the results of variance analysis, no differences in the lesser diameter values among the different studied groups were observed, both after four weeks of intervention and after drug or placebo discontinuity. Moreover, it was found that the interventions did not influence the percentage of fiber types in EDL and GS muscles, since there were no significant differences among experimental groups.

\section{Discussion}


The present study verified the effect of a physical activity program associated or not with statin treatment, so as the drug discontinuity with the continuity of physical activity, using biochemical profiles related to muscle condition, so as quantitative or qualitative evaluations of muscle morphology and histochemical pattern related to mitochondria function.

Although the recommended clinical profile to identify and manage statin muscle injury is the measurement of creatine kinase, its use is very controversial. According to some studies ${ }^{(21,22)}$, there is no established relation between clinical manifestations of muscle injuries and $\mathrm{CK}$ values, so it is possible to have clinical manifestations without enzyme levels increase, or the increase of enzymes levels without clinical manifestations.

Creatine Kinase results of the present study reinforce this discussion, since the groups with more intense muscle alterations did not have increased values of CK. Moreover, variance analysis showed absence of significant differences between groups, indicating that statin use did not increased CK levels. Although the high standard deviation of this variable, which could influence the statistic results, the absence of CK elevation could be related to the form of injury caused by statin.

Generally, muscle injuries caused by statins are restricted to intracellular space, involving mainly the $\mathrm{T}$ tubular system without sarcolemma damage ${ }^{(22)}$. Once $\mathrm{CK}$ is an intracellular enzyme, only sarcolemmal injuries could cause its leakage to extracellular environment and, consequently, its increased serum levels; as statins do not injure sarcolemma, the absence of increased CK levels is justified.

So, performing a direct analysis of muscle tissue is very important, because the evaluation of injury presence and its intensity is more reliable. In the case of statin use, some studies that evaluated its effects on muscle tissue verified the presence of 
degenerative alterations as necrosis and phagocytosis, which occurred about ten days after statin use and damaged mainly the fiber type $\mathrm{IIb}^{(6,7)}$. It was also verified that in these fibers mitochondria was the first organelle to present morphological alterations, but the authors failed to justify the selectivity of statin lesions. Moreover, in these studies the increase in CK levels occurred after ten days of statins use, what may be related to drug dose, since both studies used the maximum tolerated dose of $\operatorname{rosuvastatin}^{(7)}, \operatorname{simvastatin}^{(6)}$ and cerivastatin $^{(6)}$.

In the present study the animals of atorvastatin group (AS) presented more intense alterations than the animals in placebo (PS). Despite the evidences, how statin triggers muscle injury is not totally defined. Some theories are proposed, such as alterations in cellular membrane excitability due to membrane cholesterol reduction, or mitochondrial alterations due to some respiratory chain intermediates reduce, or apoptosis occurrence due to increase of cytosolic calcium and then activation of its mitochondrial signaling ${ }^{(23,24)}$.

Research evidences indicate that mitochondrial damage caused by statin use could probably interfere in the regulation of cytosolic calcium, causing apoptosis and then muscle fibers degeneration ${ }^{(23,25)}$. In fact, some studies suggest that statins use causes mitochondrial injury ${ }^{(6,7,26)}$.

In the present study, mitochondria activity was analyzed by NADH-TR reaction, which demonstrated that the animals in the atorvastatin groups (AS and AS) had more fibers with lost of reaction than the animals in placebo treatment (PS and PE), indicating the effect of statins in the mitochondria. However, morphological and hystochemical alterations were more frequent and intense in exercised animals, mainly those in use of atorvastatin (PE and AE). 
It is known that physical activity alone is related to the occurrence of skeletal muscle injuries which, in turn, cause adaptive processes ${ }^{(27,28)}$, modifying the shape and the structure of the fibers, so as promoting inflammatory response. So, the results of this study suggest that muscle tissue is under an adaptation process in response to the greater stress imposed by the association of two injury factors, and that the alterations found in the histological analysis may be related to cellular energy supply, since the alterations in the histochemistry analysis indicate mitochondria alterations.

In a previous research ${ }^{(11)}$ that verified the mechanisms of muscle injury exacerbation, the effects of cerivastatin use associated with treadmill exercise practice by rats were studied. The authors verified that this interaction caused exacerbation of the changes, characterized as moderates and included the presence of internalized nuclei, sarcoplasm fragmentation, vacuoles, inflammatory cells infiltration, degenerations and mitochondria injury mainly in fiber type II, which was the primary effect of statin in the fiber. According to the authors, the results indicate that muscle injury exacerbation was not due to increased drug medication in the active muscles, but by impaired oxidative metabolism since mitochondria injury was presented ${ }^{(11)}$.

The present study verified that the morphological changes found are in agreement to the alterations verified in the study cited above ${ }^{(11)}$, with the more intense degenerations occurring for the atorvastatin exercised group (AE) in relation to the others. However, some differences can be highlighted, such as the less intense alterations reported in the present study, so as the metabolic characteristic of the most affected muscle, in this case oxidative.

These differences may be related to the class of the drug that was used and to the exercise intensity. In the above study ${ }^{(11)}$ the administered statin was cerivastatin, which was withdrawal from the market in 2006 due to high rates of death by rhabdomyolysis; 
furthermore, the authors opted to use a drug concentration previously related as promoter of serious muscle damage. In addition, it was used a treadmill intensity of 20 $\mathrm{m} / \mathrm{min}$, while in the present study the speed not reached $10 \mathrm{~m} / \mathrm{min}$.

Generally, literature reports that statin discontinuity leads to the cessation of muscle alterations caused by its use ${ }^{(4,5,29)}$. In fact, after two weeks of the drug discontinuity the sedentary animals presented fewer changes than the animals that were sacrificed after four weeks of drug administration. The animals that continued exercising (AE_D) presented the same alterations pattern of those that received statin and were sedentary for 4 weeks (AS), differing only by the largest amount of fibers with internalized nuclei and splittings. This response pattern may be an indicative of fibers regenerative processes, suggesting that the continuity of the exercise after the discontinuity of the drug do not present additional damage to the musculature, and such strategy could be used in the cases that drug therapeutic can be stopped.

Such management proposed above is interesting because physical activity is also related to lipid profile adequacy, reducing triglycerides, total cholesterol and its maleficent fractions levels so as increasing the levels of its benefic fraction. So, based on previous related improvement of these changes by the association of statins and physical activity ${ }^{(15,16)}$, the drug discontinuity with physical activity continuity could result, at least, in the maintenance of lipid levels, which constitute an interesting research topic.

In summary, drug use discontinuity associated with physical activity resulted in an improvement of muscle changes verified in the animals submitted to this intervention for 4 weeks, further stimulating muscle regenerative processes considered normal responses to exercise, so characterizing a benefic state to the body. Such results suggest 
that physical activity practice can be an adjuvant in statin treatment, and that in muscle scope it can be maintained even after drug use cessation.

\section{Acknowledgments}

Clinical Analysis Laboratory of Universidade do Oeste Paulista (Unoeste) for performing the analysis of this study; the laboratory technician Sidney Siqueira Leirião for collaboration in research development; and coordination of the Masters Course in Physiotherapy of Universidade Estadual Paulista (UNESP) Campus Presidente Prudente for their support during this work.

\section{References}

1. Sociedade Brasileira de Cardiologia. IV Diretrizes brasileira sobre dislipidemias e prevenção da aterosclerose. Arquivos Brasileiros de Cardiologia. 2007; 88(1):2-19.

2. Third report of the national cholesterol education program (NCEP) expert panel on detection, evaluation, and treatment of high blood cholesterol in adults (Adult Treatment Panel III) final report. Circulation. 2002;106:3143-3421.

3. Goldenberg N, Glueck C. Efficacy, effectiveness and real life goal attainment of statins in managing cardiovascular risk. Vascular Health and Risk Management. 2009;5:369-376.

4. Thompson PD, Clarkson PM, Rosenson RS. An assessment of statin safety by muscle experts. The American Journal of Cardiology. 2006; 97(8A).

5. Joy TR, Hegele RA. Narrative review: statin-related myopathy. Annals of Internal Medicine. 2009;150:858-868.

6. Westwood FR, Bigley A, Randall K, Marsden AM, Scott RC. Statin-induced muscle necrosis in the rat: distribution, development, and fibre selectivity. Toxicol Pathol. 2005;33(2):246-257. 
7. Westwood FR, Scott RC, Marsden AM, Bigley A, Randall K. Rosuvastatin: characterization of induced myopathy in the rat. Toxicologic Pathology. 2008; $36: 345$.

8. Bruckert E, Hayem G, Dejager S, Yau C, B`egaud B. Mild to moderate muscular symptoms with high-dosage statin therapy in hyperlipidemic patients - the primo study. Cardiovascular Drugs and Therapy. 2005; 19:403-414.

9. Franc S, Dejager S, Bruckert E, Chauvenet M, Giral P, Turpin G. A Comprehensive description of muscle symptoms associated with lipid-lowering drugs. Cardiovascular Drugs and Therapy. 2003;17:459-465.

10. Sinzinger H, O’Grady J. Professional athletes suffering from familial hypercholesterolaemia rarely tolerate statin treatment because of muscular problems. British Journal of Clinical Pharmacology. 2004;57(4):525-528.

11. Seachrist JL, Loi C, Evans MG, Criswell KA, Rothwell CE. Roles of exercise and pharmacokinetics in cerivastatin-induced skeletal muscle toxicity. Toxicological Sciences. 2005; 88(2):551-561.

12. Kearns AK, Bilbie CL, Clarkson PM, White CM, Sewright KA, O’Fallon KS, et. al. The creatine kinase response to eccentric exercise with atorvastatin $10 \mathrm{mg}$ or 80 mg. Atherosclerosis. 2008;200:121-125.

13. Thompson PD, Zmuda JM, Domalik LJ, Zimet RJ, Staggers J, Guyton JR. Lovastatin increases exercised-induced skeletal muscle injury. Metabolism. 1997; 46(10):1206-1210.

14. Pierno S, Didonna MP, Cippone V, De Luca A, Pisoni M, Frigeri A, Nicchia GP, Svelto M, Chiesa G, Sirtori C, Scanziani E, Rizzo C, De Vito D, Camerino DC. Effects of chronic treatment with statins and fenofibrate on rat skeletal muscle: a 
biochemical, histological and electrophysiological study. British Journal of Pharmacology. 2006;149:909-919.

15. Wittke R. Effect of fluvastatin in combination with moderate endurance training on parameters of lipid metabolism. Sports Medicine Institute. 1999; 27(5):329-335.

16. Coen PM, Flynna MG, Markofskia MM, Pencea BD, Hannemannb RE. Adding exercise training to rosuvastatin treatment: influence on serum lipids and biomarkers of muscle and liver damage. Metabolism Clinical and Experimental. 2009; 58:1030-1038.

17. Manchado FB, Gobatto CA, Contarteze RVL, Papoti M, Mello MAR. Máxima fase estável de lactato é ergômetr-dependente em modelo experimental utilizando ratos. Rev Bras Med Esporte. 2006;12(5):259-262.

18. Manchado FB, Gobatto CA, Contarteze RVL, Papoti M, Mello MAR. Maximal lactate steady state in running rats. Journal of Exercise Physiology Online. 2005;5(4): 29-35.

19. Padulla AST, Azoubel R, Bonfim MR, Accioly MF, Camargo Filho JCS, Padovani JA, Souza DRS. Effects of statin and aerobic physical exercise association in the cardiomyocites of the rat: morphometric study. Int J Morphol. 2009;27(1):83-88.

20. Dubowitz V, Sewry CA. Histological and histochemical stains and reactions. In: Dubowitz V, Sewry CA, Muscle biopsy: a practical approach. 3rd ed. Elsevier; 2007. p 21-39.

21. Glueck CJ, Rawal B, Khan NA, Yeramaneni S, Goldenberg N, Wang P. Should high creatine kinase discourage the initiation or continuance of statins for the treatment of hypercholesterolemia? Metabolism Clinical and Experimental. 2009; 58:233-238. 
22. Mohaupt MG, Karas RH, Babiychuk EB, Sanchez-Freire V, Monastyrskaya K, Iyer L, et al. Association between statin-associated myopathy and skeletal muscle damage. CMAJ. 2009;181:E11-E18.

23. Vaklavas C, Chatzizisis YS, Ziakas A, Zamboulis C, Giannoglou GD. Molecular basis of statin-myopathy. Atherosclerosis. 2009;202:18-28.

24. Dirks AJ, Jones KM. Statin-indiced apoptosis and skeletal muscle myopathy. Am J Physiol Cell Physiol. 2006;291:C1208-1212.

25. Sirvent P, Mercier J, Lacampagne A. New insights into mechanisms of statinassociated myotoxicity. Curr Pharmacol. 2008;3:333-338.

26. Schaefer WH, Lawrence JW, Loughlin AF, Stoffregen DA, Mixson LA, Dean DC, et. al. Evaluation os ubiquinone concentration and mitochondrial function relative to cerivastatin-induced skeletal myopathy in rats. Toxicol Appl Pharmacol. 2004;194:10-23.

27. Camargo Filho JCS, Vanderlei LCM, Camargo RCT, Francischeti FA, Belangero WD, Dal Pai V. Efeitos do esteróide anabólico nandrolona sobre o músculo sóleo de ratos submetidos a treinamento físico através de natação: estudo histológico, histoquímico e morfométrico. Rev Bras Med Esporte. 2006; 12(5).

28. Ciabattari O, Dal Pai A, Dal Pai V. Effect of swimming associated with diet on the anterior tibial muscle of rats: morphological and hystochemical study. Rev Bras Med Esporte. 2005; 11(2).

29. Venero CV, Thompson PD. Managing statin myopathy. Endocrinol Metab Clin N Am. 2009;38:121-136. 
TABLE 1.

Table 1. Clinical observations during treadmill exercise.

\begin{tabular}{|c|c|c|c|c|}
\hline \multirow[b]{2}{*}{ Observations } & \multicolumn{4}{|c|}{ Interventions } \\
\hline & Placebo & Atorvastatin & $\begin{array}{c}\text { Placebo } \\
\text { Discontinuity }\end{array}$ & $\begin{array}{l}\text { Atorvastatin } \\
\text { Discontinuity }\end{array}$ \\
\hline \multicolumn{5}{|c|}{ Exercise Refusal or Escape $^{a}$} \\
\hline \# Observations & 3 & 3 & 4 & 7 \\
\hline \# Animals & $1^{b}$ & $3^{b}$ & $1^{\mathrm{c}}$ & $1^{\mathrm{c}}$ \\
\hline
\end{tabular}


FIGURE 1.

Figure 1. Serum biochemical parameters (U/L) after interventions.

$\mathrm{PS}=$ Placebo Sedentary; $\mathrm{PE}=$ Placebo Exercise $; \mathrm{AS}=$ Atorvastatin Sedentary; $\mathrm{AE}=$ Atorvastatin Exercise; PS_D = Placebo Sedentary Discontinuity; PE_D = Placebo Exercise Discontinuity; AS_D = Atorvastatin Sedentary Discontinuity; AE_D = Atorvastatin Exercise Discontinuity. 


\section{TABLE 2.}

Table 2. Body and muscular weight of the groups after interventions.

\begin{tabular}{ccccc}
\hline Groups & Body Weight (g) & Soleus (g) & GS (g) & EDL (g) \\
\hline 4 weeks of atorvastatin or placebo & & & \\
PS & $467,81 \pm 57,60$ & $0,22 \pm 0,03$ & $3,00 \pm 0,38$ & $0,20 \pm 0,03$ \\
PE & $433,04 \pm 25,01$ & $0,23 \pm 0,03$ & $2,56 \pm 0,16$ & $0,20 \pm 0,02$ \\
AS & $448,00 \pm 54,51$ & $0,23 \pm 0,04$ & $2,82 \pm 0,40$ & $0,21 \pm 0,03$ \\
AE & $478,35 \pm 31,67$ & $0,25 \pm 0,02$ & $2,98 \pm 0,22$ & $0,22 \pm 0,02$ \\
\hline Atorvastatin or placebo discontinuity & & & \\
PS & $486,18 \pm 33,72$ & $0,23 \pm 0,02$ & $2,85 \pm 0,10$ & $0,22 \pm 0,02$ \\
PE & $479,58 \pm 45,94$ & $0,27 \pm 0,03$ & $2,98 \pm 0,30$ & $0,20 \pm 0,05$ \\
AS & $475,90 \pm 39,70$ & $0,22 \pm 0,04$ & $2,72 \pm 0,32$ & $0,20 \pm 0,03$ \\
AE & $430,38 \pm 59,95$ & $0,21 \pm 0,04$ & $2,56 \pm 0,31$ & $0,17 \pm 0,05$
\end{tabular}

PS = Placebo Sedentary; PE = Placebo Exercise; AS = Atorvastatin Sedentary; $\mathrm{AE}=$ Atorvastatin Exercise. 


\section{FIGURE 2}

Figure 2. Cross-sections of soleus (A-D), extensor digitorum longus (EDL - E e F) and gastrocnemius superficial (GS - G e H) muscles. Samples from placebo exercise (A e E) and discontinuity (B); atorvastatin exercise ( $\mathrm{C}$ e $\mathrm{G})$ and discontinuity ( $\mathrm{D}, \mathrm{F}$ e $\mathrm{H}$ ). Hematoxilin \& Eosin $(\mathrm{HE})$. In = Inflammatory Infiltrate; * = Fiber in degeneration; Filled Arrow $=$ Internalized Nuclei; Hollowed Arrow $=$ Splitting. 500X. 


\section{TABLE 3}

Table 3. Incidence and severity of muscle fibers degenerative changes of the studied groups.

\begin{tabular}{|c|c|c|c|c|c|c|c|c|c|}
\hline & $\begin{array}{l}\text { No } \\
\text { An }\end{array}$ & Sol & EDL & GS & & $\begin{array}{l}\text { No } \\
\text { An }\end{array}$ & Sol & EDL & GS \\
\hline \multirow{8}{*}{ 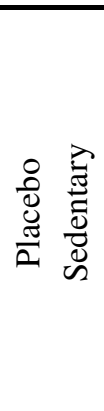 } & 02 & $*$ & \multirow{5}{*}{$*$} & \multirow{5}{*}{$\begin{array}{l}* \\
*\end{array}$} & \multirow{8}{*}{ 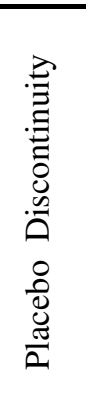 } & & & & \\
\hline & 03 & $*$ & & & & & & & \\
\hline & 05 & * & & & & & & & \\
\hline & 06 & * & & & & 01 & & & \\
\hline & 08 & * & & & & 07 & $*$ & $*$ & \\
\hline & 09 & * & * & * & & 11 & $*$ & * & \\
\hline & 10 & * & & $\bar{x}$ & & & & & \\
\hline & 13 & * & $*$ & $*$ & & & & & \\
\hline \multirow{8}{*}{ 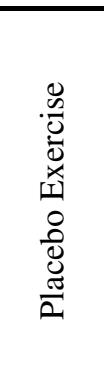 } & 15 & $* * *$ & & * & \multirow{8}{*}{ 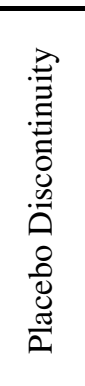 } & & & & \\
\hline & 17 & $*$ & $*$ & 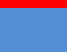 & & 16 & E* & & * \\
\hline & 19 & * & * & * & & 18 & * & & \\
\hline & 20 & & & 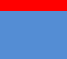 & & 21 & $* *$ & & \\
\hline & 22 & $* *$ & & * & & 27 & $*$ & * & $*$ \\
\hline & 23 & $* *$ & & * & & 28 & $*$ & & $*$ \\
\hline & 24 & $* *$ & & * & & 38 & $*$ & & \\
\hline & 25 & * & & & & & & & \\
\hline \multirow{8}{*}{ 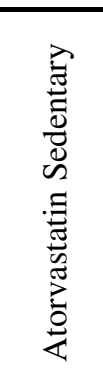 } & 26 & $* *$ & & & \multirow{8}{*}{ 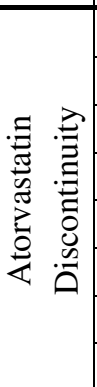 } & & & & \\
\hline & 29 & 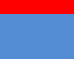 & & * & & 31 & * & & \\
\hline & 30 & * & . & * & & 33 & $*$ & $*$ & \\
\hline & 32 & & & & & 34 & * & & \\
\hline & 35 & $*$ & $*$ & 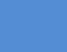 & & 37 & & & \\
\hline & 36 & t & & * & & 40 & $*$ & & \\
\hline & 53 & $*$ & & & & 41 & $*$ & & \\
\hline & 59 & $*$ & & * & & & & & \\
\hline \multirow{8}{*}{ 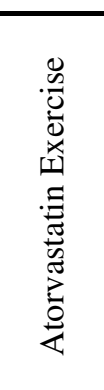 } & 44 & $* * *$ & & * & \multirow{8}{*}{ 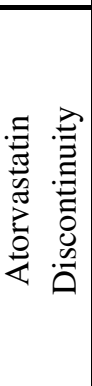 } & & & & \\
\hline & 45 & $*$ & & * & & & & & \\
\hline & 47 & $*$ & & * & & 42 & & & \\
\hline & 48 & $* *$ & & $* *$ & & 55 & $* *$ & & $*$ \\
\hline & 49 & $* * *$ & $*$ & $*$ & & 58 & $* * *$ & $*$ & \\
\hline & 51 & & & * & & 69 & $* * *$ & & $*$ \\
\hline & 52 & $* *$ & $*$ & & & 70 & $*$ & & \\
\hline & 54 & $* *$ & * & & & & & & \\
\hline
\end{tabular}

Sol $=$ Soleus $;$ EDL $=$ Extensor Digitorum Longus; GS = Gastrocnemius Superficial. No An $=$ Animal Number. Red $=$ Necrosis presence. Blue $=$ Necrosis Absence. $*$ Mínimal change; **Mild change; ***Moderate change. 
FIGURE 3.

Figure 3. Cross-sections of soleus (A-F) and extensor digitorum longus (EDL - G e H) muscles. Samples from placebo exercise (A e G) and discontinuity (B); atorvastatin sedentary (C) and discontinuity (D); atorvastatin exercise (E) and discontinuity (F e H). NADH-TR. Arrows $=$ Fibers with loss of reaction. 500X. 
TABELA 4

Tabela 4. Values of lesser diameter fibers $(\mu \mathrm{m})$ of the muscles studied.

\begin{tabular}{|c|c|c|c|c|c|c|c|c|c|c|c|}
\hline & & \multirow{2}{*}{ Sol } & \multicolumn{6}{|c|}{ EDL } & \multicolumn{3}{|c|}{ GS } \\
\hline & & & I & $\% \mathrm{I}$ & IIA & \% IIA & IIB & $\%$ IIB & I & II & $\%$ II \\
\hline \multicolumn{12}{|c|}{4 weeks of atorvastatin or placebo } \\
\hline \multirow{2}{*}{ PS } & $X$ & 54,41 & 31,67 & 21,21 & 39,52 & 38,50 & 56,50 & 40,29 & 43,61 & 59,49 & 97,87 \\
\hline & DP & 3,85 & 2,80 & 4,64 & 3,90 & 10,01 & 5,02 & 10,01 & 5,80 & 5,02 & 1,91 \\
\hline \multirow[b]{2}{*}{ PE } & $X$ & 54,62 & 30,24 & 20,71 & 36,57 & 33,67 & 52,20 & 45,62 & 42,57 & 56,33 & 96,43 \\
\hline & $\mathrm{DP}$ & 4,96 & 1,62 & 6,70 & 3,32 & 12,78 & 3,73 & 16,54 & 8,30 & 5,37 & 4,62 \\
\hline \multirow{2}{*}{$\mathbf{A S}$} & $\mathrm{X}$ & 51,33 & 30,86 & 21,68 & 38,44 & 31,81 & 54,51 & 46,50 & 44,02 & 59,74 & 98,44 \\
\hline & $\mathrm{DP}$ & 5,29 & 2,52 & 3,13 & 4,20 & 7,35 & 3,36 & 8,57 & 7,77 & 3,86 & 3,73 \\
\hline \multirow[b]{2}{*}{$\mathbf{A E}$} & $X$ & 56,94 & 33,54 & 17,06 & 40,05 & 28,40 & 59,88 & 54,54 & 46,20 & 61,13 & 94,35 \\
\hline & DP & 3,89 & 3,17 & 6,12 & 4,91 & 9,23 & 4,44 & 11,45 & 5,26 & 4,41 & 5,70 \\
\hline \multicolumn{12}{|c|}{ Atorvastatin or placebo discontinuity } \\
\hline \multirow{2}{*}{ PS } & $\mathrm{X}$ & 48,60 & 31,36 & 20,24 & 37,35 & 38,89 & 59,86 & 40,87 & 40,52 & 57,09 & 98,05 \\
\hline & $\mathrm{DP}$ & 14,55 & 1,67 & 5,15 & 2,22 & 12,98 & 7,88 & 9,90 & $0^{\mathrm{a}}$ & 2,81 & 3,38 \\
\hline \multirow[b]{2}{*}{ PE } & $X$ & 57,48 & 31,75 & 22,75 & 40,13 & 25,98 & 59,08 & 51,26 & 43,82 & 56,14 & 93,88 \\
\hline & DP & 3,25 & 1,32 & 8,77 & 1,93 & 14,15 & 5,57 & 21,22 & 2,50 & 1,65 & 9,33 \\
\hline \multirow{2}{*}{$\mathbf{A S}$} & $X$ & 54,17 & 33,93 & 17,07 & 40,84 & 31,36 & 60,91 & 51,56 & 44,33 & 59,29 & 98,59 \\
\hline & DP & 4,82 & 2,70 & 2,75 & 2,74 & 8,96 & 4,08 & 9,30 & 8,09 & 3,50 & 1,09 \\
\hline \multirow[b]{2}{*}{$\mathbf{A E}$} & $X$ & 52,00 & 32,39 & 18,54 & 40,87 & 27,19 & 57,76 & 54,27 & 41,73 & 57,56 & 93,52 \\
\hline & DP & 2,92 & 2,59 & 4,94 & 3,22 & 5,76 & 10,17 & 4,91 & 3,61 & 5,19 & 3,60 \\
\hline
\end{tabular}

${ }^{\mathrm{a} O n l y}$ one animal presented type I fibers thus there is not standard deviation. Sol = Soleus; EDL $=$ Extensor Digitorum Longus; GS = Gastrocnemius Superficial. PS = Placebo Sedentary; PE = Placebo Exercise; $\mathrm{AS}=$ Atorvastatin Sedentary; $\mathrm{AE}=$ Atorvastatin Exercise 